
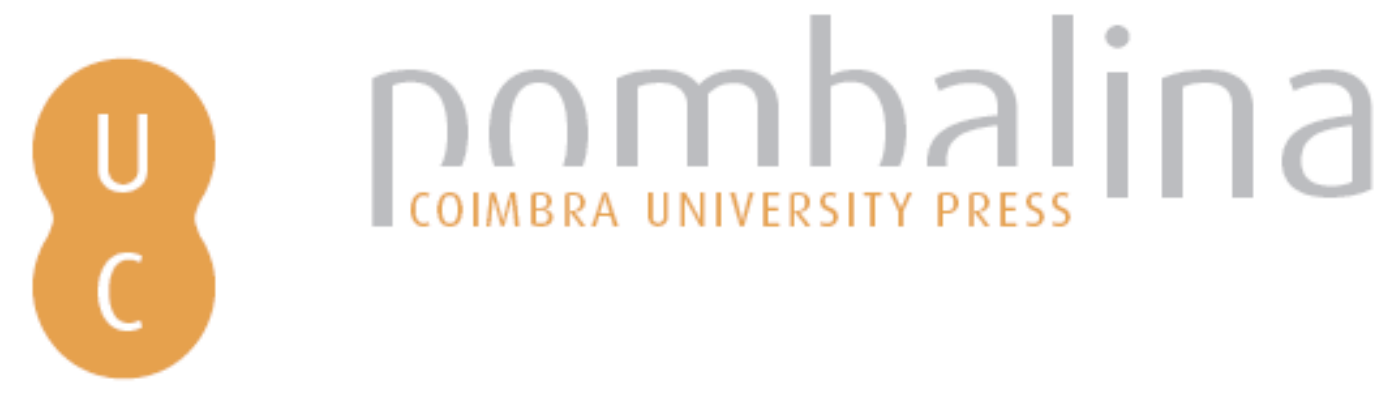

\title{
Desenvolvimento de aplicações farmacêuticas e biomédicas através de métodos de impregnação/deposição com fluidos supercríticos.
}

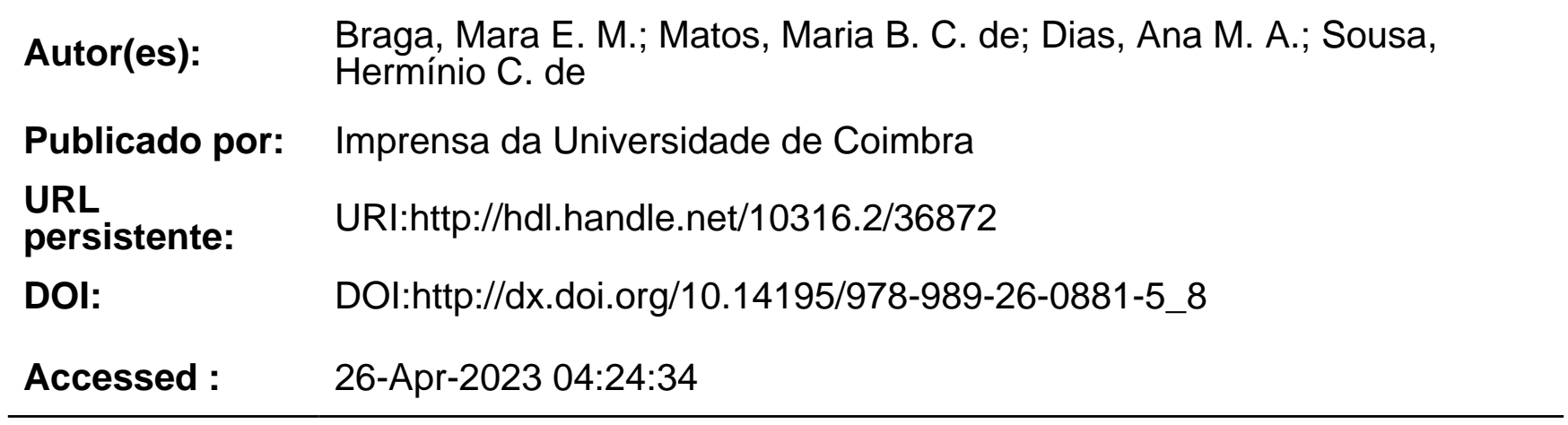

A navegação consulta e descarregamento dos títulos inseridos nas Bibliotecas Digitais UC Digitalis, UC Pombalina e UC Impactum, pressupõem a aceitação plena e sem reservas dos Termos e Condições de Uso destas Bibliotecas Digitais, disponíveis em https://digitalis.uc.pt/pt-pt/termos.

Conforme exposto nos referidos Termos e Condições de Uso, o descarregamento de títulos de acesso restrito requer uma licença válida de autorização devendo o utilizador aceder ao(s) documento(s) a partir de um endereço de IP da instituição detentora da supramencionada licença.

Ao utilizador é apenas permitido o descarregamento para uso pessoal, pelo que o emprego do(s) título(s) descarregado(s) para outro fim, designadamente comercial, carece de autorização do respetivo autor ou editor da obra.

Na medida em que todas as obras da UC Digitalis se encontram protegidas pelo Código do Direito de Autor e Direitos Conexos e demais legislação aplicável, toda a cópia, parcial ou total, deste documento, nos casos em que é legalmente admitida, deverá conter ou fazer-se acompanhar por este aviso.

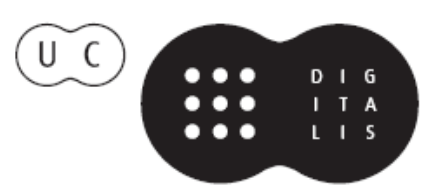


IOMATERIAIS APLICADOS AO DESENVOLVIMENTO DE SISTEMAS TERAPÊUTICOS AVANÇADOS

IOMATERIALES APLICADOS AL DISEÑO DE SISTEMAS TERAPÉUTICOS AVANZADOS

Hermínio C. de Sousa Mara E. M. Braga Alejandro Sosnik (editores) 


\section{CAPÍTULO 8. DESENVOLVIMENTO DEAPLICAÇÕ ES FARMACÊTICAS E BIOMÉDICAS ATRAVÉS DE MÉTODOS DE IMPREGNAÇÃO/DEPOSIÇÃO COM F L U I D O S U P E R C R ÍTICOS}

Mara E. M. Braga, Maria B. C. de Matos, Ana M. A. Dias, Hermínio C. de Sousa CIEPQPF, Departamento de Engenharia Quimica, FCTUC, Universidade de Coimbra, Rua Sílvio Lima, Pólo II - Pinhal de Marrocos, 3030-790 Coimbra, Portugal.

\section{Resumo:}

Neste capítulo, e além de uma discussão breve dos principais métodos convencionais de incorporação (impregnação/deposição) de aditivos em materiais sólidos (e semi-sólidos), são apresentados e discutidos detalhadamente os métodos de impregnação/deposição de aditivos usando solventes supercríticos (SSI/SSD, do inglês "Supercritical Solvent Impregnation/Deposition") e, em particular, os casos onde se usa o dióxido de carbono supercrítico $\left(\mathrm{scCO}_{2}\right)$ como solvente de impregnação/ deposição para o desenvolvimento de aplicações farmacêuticas e biomédicas. São apresentadas as suas principais características e requisitos bem como as suas potenciais aplicabilidades e vantagens/desvantagens. É feita uma revisão bibliográfica exaustiva dos trabalhos e sistemas específicos já estudados e são ainda apresentados e discutidos, de uma forma breve, os principais requisitos e enquadramentos regulamentares necessários ao desenvolvimento de medicamentos, dispositivos médicos e produtos de combinação usando os métodos SSI/SSD. Por tudo o que é apresentado, pode-se então concluir que estas metodologias, e em particular aquelas que usam $\mathrm{scCO}_{2}$ como solvente, têm vindo a ser 
cada vez mais estudadas e aplicadas no desenvolvimento de potenciais e inovadoras aplicações farmacêuticas e biomédicas, esperando-se que, nos próximos anos, algumas destas técnicas e aplicações consigam ser transpostas com sucesso para escalas industriais de produção de produtos farmacêuticos e biomédicos comerciais.

Palavras-chave: incorporação de aditivos; materiais sólidos e semi-sólidos; métodos de impregnação/deposição de aditivos usando solventes supercríticos (SSI/SSD); aplicações farmacêuticas e biomédicas.

\section{Abstract:}

In this chapter, and in addition to a brief discussion on the conventional methods commonly used for the incorporation of additives into solid/ semi-solid materials, the so-called Supercritical Solvent Impregnation/ Deposition (SSI/SSD) methodologies are presented, detailed and discussed, namely those employing supercritical carbon dioxide $\left(\mathrm{scCO}_{2}\right)$ as the impregnation/deposition solvent for the development of pharmaceutical and biomedical applications. The main features and requisites of these methods, as well as their potential applications and advantages/disadvantages, are presented and discussed in detail. The state-of-the-art of the already studied specific works/systems is presented, and the main regulatory framework for the development of medicines, medical devices and combination products using the SSI/ SSD methodologies are also briefly presented and discussed. It can be concluded that, in recent years, the SSI/SSD methodologies and particularly those employing $\mathrm{scCO}_{2}$, have been increasingly studied and applied for the development of several innovative pharmaceutical and biomedical applications which, in the near future, may be successfully transposed to industrial-scale production of commercial pharmaceutical and biomedical products.

Keywords: Additive incorporation; solid/semi-solid materials; supercritical solvent impregnation/deposition methods (SSI/SSD); pharmaceutical and biomedical applications. 


\subsection{Introdução}

A incorporação e dispersão de aditivos em materiais sólidos ou semi-sólidos (do tipo orgânico, inorgânico ou compósito) é um procedimento habitual para conseguir a funcionalização específica de materiais/ produtos, tendo como principal objectivo conferir-lhes determinadas propriedades (químicas, termomecânicas, reológicas, morfológicas e de superfície, biológicas, eléctricas, magnéticas, ópticas, etc.) de forma a se conseguirem atingir as propriedades funcionais necessárias para as aplicações finais pretendidas ou, simplesmente, para facilitar/possibilitar o seu processamento. Estas propriedades irão sempre ser dependentes das propriedades intrínsecas destes mesmos aditivos, das interacções específicas que se podem estabelecer com os materiais sólidos/semi-sólidos (e das interacções entre os aditivos) bem como da composição relativa com que são incorporados nesses materiais/produtos. Por outro lado, estes aditivos podem ser de muitas e diferentes naturezas, e apresentar propriedades químicas, físicas e biológicas muito distintas. Isto irá possibilitar a preparação de uma vasta gama de materiais/produtos funcionalizados para aplicações específicas em diferentes áreas como, por exemplo, em aplicações farmacêuticas e biomédicas, cosméticas, alimentares, electrónicas, têxteis, revestimentos e ambientais. De entre estes aditivos podem-se referir: fármacos, proteínas e factores de crescimento, peptídeos e enzimas, vitaminas, extractos e produtos naturais, antioxidantes, corantes e pigmentos, adoçantes, acidificantes, aromas, biocidas/pesticidas, plastificantes, protectores de UV e de ozono, agentes de enchimento, agentes compatibilizantes, agentes de dissolução, agentes anti-estáticos, lubrificantes, metais, cerâmicos, polímeros, monómeros, iniciadores, oligómeros, etc. A incorporação destes aditivos pode conduzir à obtenção de materiais homogéneos ou heterogéneos, híbridos ou compósitos, e incluindo incorporação/deposição superficial. A incorporação de aditivos pode ser feita de várias maneiras: i) através de processos de mistura/"blending" (exemplos: fusão e mistura no estado líquido, vazamento/evaporação de solvente, mistura física no estado sólido/semi-sólido, etc.); ii) durante os processos reaccionais que levam 
à formação/modificação dos materiais sólidos/semi-sólidos onde irão ser incorporados (exemplos: reacções de polimerização, enxerto, reticulação, métodos sol-gel, etc.); iii) através da absorção/deposição a partir de soluções líquidas/gasosas (ou de suspensões) seguidas da remoção dos solventes utilizados; ou iv) através de deposição superficial (com ou sem posterior difusão para camadas interiores do material através do uso de solventes e/ou calor) [1-26].

No entanto, existem ainda muitas dificuldades e desafios na optimização e implementação (a várias escalas) de algumas das vias sintéticas e de processamento mais usadas para a obtenção destes materiais/ produtos. Estas questões têm essencialmente a ver com o controlo da eficiência e da heterogeneidade de incorporação, com a ocorrência de reacções químicas indesejadas, com o uso de condições que põem em causa a compatibilidade e a estabilidade química das substâncias envolvidas (temperaturas e pressões elevadas, uso de substâncias/solventes que promovem a degradação de determinadas substâncias, etc.), com a eficiência energética e com os custos associados a alguns processos, e com questões de segurança e de toxicidade dos processos e dos materiais/produtos neles envolvidos. A grande maioria destes problemas são ainda mais importantes no caso de materiais e de produtos para aplicações farmacêuticas, biomédicas, cosméticas e alimentares, e onde existem regulamentações muito apertadas em termos de pureza, de homogeneidade, de estabilidade e da presença de resíduos/substâncias que possam afectar a eficiência, a segurança e a toxicidade dos mesmos.

No caso específico dos produtos farmacêuticos e biomédicos, e além das instituições reguladoras existentes em cada país, existem várias entidades reguladoras que são consideradas como as referências a nível mundial e que, desta forma, acabam por desempenhar o papel mais relevante e por estabelecer a grande maioria dos aspectos técnicos e das regulamentações relacionadas com o desenvolvimento, teste, fabrico, autorização de mercado e vigilância pós-comercialização destes tipos de produtos. São elas: a FDA ("Food and Drug Administration", Estados Unidos da América, EUA), a EMA ("European Medicines Agency", União Europeia, UE), o MHLW ("Ministry of Health, Labour and Welfare", Japão) e a ICH ("International Conference 
on Harmonization"). Refira-se que a ICH é uma organização transnacional, envolvendo as entidades reguladoras e a indústria farmacêutica dos EUA, UE e Japão, e que tem como principais objectivos a formulação, harmonização e normalização dos aspectos científicos, técnicos e de toda legislação envolvida no desenvolvimento e fabrico de produtos farmacêuticos para uso humano [27-30].

Assim, e de forma a melhorar a eficiência, custos associados, segurança e a evitar alguns constrangimentos regulamentares, nos últimos anos tem-se procurado activamente desenvolver métodos e processos alternativos para o fabrico de produtos farmacêuticos e biomédicos para uso humano. De entre estes e devido às suas bem conhecidas propriedades e vantagens, os métodos/processos que envolvem o uso de fluidos supercríticos (FSCs), e em particular os que envolvem o uso de dióxido de carbono supercrítico $\left(\mathrm{scCO}_{2}\right)$, têm vindo a ser cada vez mais estudados e/ ou aplicados no desenvolvimento de muitas destas aplicações [23, 31-56].

Neste capítulo começaremos por abordar e descrever brevemente os principais métodos de incorporação/deposição de aditivos em matrizes sólidas e semi-sólidas para o desenvolvimento de aplicações farmacêuticas e biomédicas, para depois abordarmos com maior detalhe o método de impregnação/deposição de aditivos usando solventes supercríticos (SSI/SSD, do inglês "Supercritical Solvent Impregnation/Deposition") e, em particular, os casos em que se usa o $\mathrm{scCO}_{2}$ como solvente de impregnação/deposição para o desenvolvimento de aplicações farmacêuticas e biomédicas. É ainda apresentada uma revisão bibliográfica exaustiva, não só dos principais trabalhos referentes à aplicação de FSCs para diversas aplicações farmacêuticas e biomédicas, mas também, e em particular, dos trabalhos e sistemas já estudados usando as metodologias SSI/SSD para estas mesmas aplicações.

\subsection{Impregnação/deposição de aditivos para aplicações farmacêu- ticas e biomédicas}

A impregnação/deposição ou, simplesmente, a incorporação/mistura de aditivos em matrizes sólidas/semi-sólidas (do tipo orgânico, inorgânico 
ou compósito) para aplicações farmacêuticas e biomédicas tem normalmente como principais objectivos: i) o desenvolvimento de sistemas com a capacidade de entregar e libertar determinadas substâncias bioactivas de uma forma controlada e reprodutível; ii) o desenvolvimento de materiais e produtos com capacidade antimicrobiana; e iii) conferir determinadas propriedades químicas (e.g., estabilidade, degradabilidade), físicas (e.g., propriedades termomecânicas, reológicas, de absorção de água e morfológicas/superfície), biológicas (e.g., biocompatibilidade, adesão e proliferação celular, degradabilidade e libertação de substâncias bioactivas), ou de outro tipo (e.g., cor, aroma, sabor), e que possam melhorar a sua processabilidade e, obviamente, o seu desempenho final para as aplicações específicas pretendidas [2, 4, 8-21, 24, 26].

Para se atingirem a maioria destes objectivos, há que ter em consideração alguns factores extremamente importantes como sejam: a estabilidade (química e térmica), toxicidade e os perfis farmacocinético e farmacodinâmico das substâncias bioactivas envolvidas; o aumento da biodisponibilidade de substâncias bioactivas com baixa solubilidade em sistemas aquosos; o "design" apropriado das formulações em termos de processabilidade, eficiência terapêutica e de segurança (incluindo o uso dos solventes e dos excipientes/aditivos adequados); e a preparação de sistemas que permitam uma boa adesão pelos pacientes aos sistemas terapêuticos (do inglês, "compliance"), e ainda que sejam o menos invasivos possível [10-26, 57, 58].

As aplicações farmacêuticas e biomédicas (de base sólida ou semi-sólida) mais importantes a considerar são as seguintes: i) sistemas terapêuticos e medicamentos (que têm como objectivo primário a entrega/libertação de substâncias bioactivas - fármacos e biofármacos, i.e., fármacos de baixo peso molecular e fármacos à base de proteínas) e as respectivas formas de dosagem sólidas (ou semi-sólidas); ii) produtos biológicos (de base sólida ou semi-sólida); iii) dispositivos médicos implantáveis de base sólida/ semi-sólida, incluindo aqueles com carácter temporário que podem ser usados em aplicações específicas na área da engenharia de tecidos e da medicina regenerativa (normalmente designados por "scaffolds"), e com ou sem a capacidade de libertarem substâncias bioactivas; e iv) outros dispositivos médicos como, por exemplo, lentes de contacto, materiais 
de sutura, ferramentas cirúrgicas, bioadesivos, pensos e "dressings", cateteres, sacos de sangue, etc. (com ou sem a capacidade de libertarem substâncias bioactivas) [11-12, 14-19, 21-22, 24-26].

Convém explicitar quais são as principais diferenças existentes entre os sistemas terapêuticos/medicamentos, os produtos biológicos, os dispositivos médicos e uma outra categoria, designada por produtos de combinação. Assim, e por exemplo, a FDA considera que fármacos (ou sistemas terapêuticos/medicamentos, "drugs") são produtos/artigos que podem ser usados para fins de diagnóstico, cura, mitigação, tratamento ou prevenção de doenças em seres humanos (ou em outros animais), e artigos destinados a afectar a estrutura ou qualquer função do corpo humano (ou de outros animais) [18, 22, 26-27, 59]. Por outro lado, a FDA faz uma distinção clara entre os produtos anteriores e os chamados produtos biológicos ("biological products"), os quais são, por exemplo, vírus, soros terapêuticos, toxinas, anti-toxinas, vacinas, sangue e componentes/derivados de sangue, produtos alergénicos, e proteínas (excepto qualquer polipeptídeo sintetizado quimicamente), e que sejam aplicados na prevenção, tratamento ou cura de uma doença ou condição em seres humanos [18, 22, 26-27, 60]. Além disso, a FDA classifica um dispositivo médico ("device") como sendo um instrumento, "apparatus", utensílio, ferramenta, máquina, dispositivo, implante, reagente "in vivo", ou outro artigo similar ou relacionado (incluindo os seus componentes ou acessórios), que possa ser usado no diagnóstico de doenças ou de outras condições, na cura, mitigação, tratamento ou prevenção de doenças em seres humanos (ou em outros animais), ou para afectar a estrutura ou qualquer função do corpo humano (ou de outros animais), mas que não atinja os seus propósitos principais (primários) através de reacções químicas no corpo humano (ou de outros animais) e que não seja dependente da sua metabolização para atingir os seus propósitos principais [18, 22, 26-27, 59]. Por fim, a FDA considera que um produto de combinação ("combination product") é, e conforme o seu nome indica, a combinação dos diferentes produtos/ entidades singulares acima descritos, ou seja: um fármaco combinado com um dispositivo médico, um fármaco combinado com um produto biológico, um dispositivo médico combinado com um produto biológico, ou 
um dispositivo médico combinado com um fármaco e com um produto biológico. No entanto, não são considerados produtos de combinação: um fármaco com um fármaco, um produto biológico com um produto biológico, um dispositivo médico com um dispositivo médico, um produto alimentar com um fármaco, dispositivo médico ou produto biológico, e um produto cosmético com um fármaco, dispositivo médico ou produto biológico. Estes produtos podem ser "combinados" através de mistura química e/ou física (numa única entidade), por co-embalagem (em "kits") ou embalados/vendidos separadamente mas rotulados especificamente para uso em conjunto [18, 22, 26-27, 59-61]. Alguns exemplos de produtos de combinação (segundo a FDA) são, por exemplo: um "stent" cardiovascular dotado com a capacidade de libertação de um fármaco, um catéter revestido com um agente anti-microbiano, um implante ortopédico carregado com um factor de crescimento, um conjugado anti-corpo/fármaco, um dispositivo de entrega de fármaco (ou de produto biológico) pré-cheio (e.g., seringas ou inaladores que contenham fármacos ou produtos biológicos), um fármaco activável por acção da luz e uma fonte luminosa, etc. Saliente-se que, e para cada aplicação farmacêutica ou biomédica em estudo/desenvolvimento, é necessário definir muito bem qual é o tipo de produto que se deve considerar (se sistema terapêutico/medicamento, se produto biológico, se dispositivo médico ou se produto de combinação), uma vez que os correspondentes processos regulatórios, legislação e comités/centros de avaliação/aprovação competentes (pertencentes às autoridade reguladoras) podem ser bastante diferentes. Esta definição é particularmente importante no caso dos produtos de combinação onde, e no caso da FDA, é necessário estabelecer qual é o chamado "Modo de Acção Primário" (PMOA, do inglês "Primary Mode of Action") e, assim, definir qual será o enquadramento legal e a jurisdição competente para a sua avaliação/aprovação [18, 22, 26-27, 59-62]. Na EMA, que é a entidade competente na UE, as definições, distinções, processos regulatórios, legislação e comités/centros de avaliação/aprovação competentes (para os produtos farmacêuticos/biomédicos e para as situações acima descritas) são ligeiramente diferentes das consideradas pela FDA [22, 26, 28, 63]. No entanto, os pressupostos, os objectivos subjacentes e a legislação 
aplicável são, na sua essência, muito semelhantes aos da FDA pelo que não serão descritos aqui em detalhe.

De entre os aditivos mais usados no desenvolvimento e fabrico dos diferentes tipos de produtos farmacêuticos e biomédicos acima indicados, devem ser consideradas em primeiro lugar as substâncias bioactivas com capacidade terapêutica ou de substituição (e.g., fármacos do tipo pequena-molécula, fármacos de base proteica, enzimas, peptídeos, factores de crescimento, hormonas, etc.). No entanto, devem-se igualmente considerar outros casos, tais como: substâncias bioactivas com capacidade antimicrobiana (i.e., substâncias com actividade biocida específica ou de largo espectro), biomarcadores, agentes de contraste, vitaminas, extractos vegetais e produtos naturais, antioxidantes, conservantes, plastificantes, agentes de enchimento, agentes compatibilizantes, surfactantes, lubrificantes, corantes/pigmentos e protectores de radiação UV, adoçantes, acidificantes e aromas. Além dos requisitos terapêuticos específicos necessários para cada aplicação particular pretendida, os exigentes requisitos regulamentares necessários para o desenvolvimento deste tipo de aplicações e para a sua introdução no mercado impõem ainda que todos estes aditivos tenham uma segurança, biocompatibilidade e toxicidade comprovada (bem como os seus eventuais produtos de degradação) e que apresentem todas as características necessárias em termos de pureza, homogeneidade e estabilidade [10-26].

A incorporação/dispersão de substâncias bioactivas em matrizes sólidas/semi-sólidas bem como a preparação de formas de dosagem sólidas/ semi-sólidas com vista ao desenvolvimento ou ao aperfeiçoamento de sistemas de entrega e libertação controlada representa, sem qualquer dúvida, a maior parte das aplicações nestas áreas. De acordo com várias considerações de índole prática e com a farmacocinética e farmacodinâmica requeridas para os processos terapêuticos envolvidos, estes sistemas devem ser preferencialmente desenhados e preparados de forma a libertar as substâncias bioactivas de um modo muito específico, ou seja, apenas nos locais desejados e com uma taxa/velocidade de libertação adequada. Por exemplo e para substâncias bioactivas com baixa solubilidade em água, a melhoria das taxas de dissolução dos ingredientes bioactivos 
pode ser conseguida através da preparação de formulações cujas matrizes sólidas/semi-sólidas são bastante solúveis em meios aquosos (a valores específicos de $\mathrm{pH}$ e de força iónica). No caso oposto e para substâncias bioactivas muito solúveis em água e/ou com tempos de meia vida curtos, é normalmente necessária a incorporação e a preparação de sistemas sólidos/ semi-sólidos hidrofóbicos e com baixa solubilidade em água. No entanto sabe-se que, para qualquer uma das situações acima descritas e de modo a se obterem os melhores efeitos terapêuticos possíveis, as substâncias bioactivas devem preferencialmente encontrar-se dispersas nas matrizes sólidas/semi-sólidas de suporte a um nível molecular, i.e., homogeneamente misturadas, caso contrário a dissolução e a biodisponibilidade das mesmas podem ser grandemente afectadas [9-17, 19-21, 25-26, 64-69].

A grande maioria dos métodos de produção destas formas sólidas/ semi-sólidas de dosagem envolve o uso de processos clássicos de processamento farmacêutico, i.e., processos baseados na mistura física (seca ou húmida) e na dispersão heterogénea dos ingredientes activos e dos excipientes adequados (a temperaturas relativamente baixas), aos quais se seguem, por exemplo, os processos de granulação, secagem, "pelletização”, compressão e enchimento de cápsulas/saquetas, esterilização, etc. [11-12, 14-17, 19-21, 70-74].

Outra maneira relativamente simples de incorporar aditivos em matrizes sólidas/semi-sólidas consiste na mistura física das várias substâncias envolvidas (normalmente no estado sólido, embora alguns líquidos possam ser usados) e no posterior aquecimento até à fusão (total ou parcial) destas misturas. Alguns aditivos podem/devem ser introduzidos na fase inicial do processo (antes da fusão) ou, preferencialmente e no caso das substâncias bioactivas lábeis, apenas quando as matrizes de suporte já estão fundidas. Estas misturas (homogéneas ou heterogéneas) são depois arrefecidas, daí resultando a incorporação dos aditivos de interesse em variadas formas tridimensionais. Por exemplo, este é o método que serve de base à formação de materiais e dispositivos sólidos de base polimérica (através do uso de diversos processos de extrusão e moldagem - por injecção e/ou por sopro), em diversas formas e geometrias e usando polímeros termoplásticos (ou ligas poliméricas - "blends" - de polímeros termoplásticos) 
[11, 16]. A grande maioria das matrizes sólidas/semi-sólidas envolvidas (normalmente de natureza polimérica) tem de ter a capacidade de fundir (sem degradar) a temperaturas até cerca de $100-150{ }^{\circ} \mathrm{C}$. No entanto e apesar destas matrizes poderem não sofrer degradação térmica até à sua fusão, há que considerar que a grande maioria dos aditivos de interesse para aplicações farmacêuticas e biomédicas são substâncias termicamente lábeis (quer com o aquecimento a temperaturas elevadas, quer com processos de aquecimento/arrefecimento rápidos). Além disso, e com o uso de temperaturas relativamente elevadas, existe ainda a possibilidade de ocorrerem reacções químicas indesejáveis entre as substâncias envolvidas e entre estas e os ingredientes bioactivos [11, 16, 75-76].

Em alternativa e para evitar o uso de altas temperaturas de fusão, a incorporação de aditivos em matrizes sólidas/semi-sólidas para fins farmacêuticos ou biomédicos pode também ser feita recorrendo a métodos em que se usam substâncias líquidas voláteis como solventes ou como agentes de dispersão para os aditivos. As matrizes e os aditivos a incorporar são assim dissolvidos (ou dispersos) nestes líquidos e, posteriormente, os mesmos são removidos de diversas maneiras (e.g., liofilização, evaporação, secagem supercrítica, "spray-drying", electrofiação ("electro-spinning”) etc.), obtendo-se assim as matrizes sólidas/ semi-sólidas (sob diversas formas) com os aditivos nelas incorporados. No entanto e embora não sejam normalmente requeridas temperaturas tão elevadas como nos processos que envolvem a fusão das substâncias envolvidas, será quase sempre necessário o uso de processos térmicos e/ ou sob vácuo para a remoção dos líquidos usados e/ou para a secagem completa dos materiais sólidos obtidos. Se estas substâncias líquidas apresentarem problemas de segurança e toxicidade, então a sua remoção a níveis aceitáveis (e normalmente muito baixos) poderá ser muito difícil de conseguir [11, 13, 16, 20-21, 70-71, 74, 77-81].

A incorporação de aditivos pode também ser feita durante os processos reaccionais que levam à formação (ou à modificação) dos materiais sólidos/semi-sólidos onde irão ser incorporados. Existem inúmeras maneiras de aplicar este tipo de procedimentos, as quais derivam dos muitos tipos de reacções químicas e de modos de reacção que podem ser utilizados 
para estes fins. Como exemplos podemos referir as reacções de polimerização/copolimerização, enxerto e reticulação (para a formação de materiais poliméricos), e os métodos sol-gel (para a obtenção de matrizes sólidas/ semi-sólidas inorgânicas ou híbridas). Assim, os aditivos a incorporar são inicialmente misturados com solventes líquidos, reagentes (monómeros, co-monómeros, pré-polímeros, e outros precursores químicos), e com outras substâncias químicas necessárias ao processo (iniciadores, agentes de transferência de cadeia, surfactantes, catalisadores, ácidos/bases, etc.). À medida que as reacções decorrem, irão formar-se as matrizes desejadas ficando os aditivos retidos fisicamente, por oclusão, no seu interior. Além de processos que envolvem reacções químicas (i.e., formação de ligações covalentes), podem também ser usadas estratégias semelhantes para a oclusão de aditivos em matrizes sólidas/semi-sólidas mas onde está apenas envolvido o estabelecimento de interacções físicas (interacções iónicas, de pontes de hidrogénio e hidrofóbicas) para a formação de estruturas tridimensionais de materiais poliméricos e/ou inorgânicos (e.g., técnicas de auto-organização, do inglês "self-assembly"). No entanto, a maioria destes métodos podem trazer algumas complicações uma vez que normalmente implicam o uso temperaturas relativamente elevadas, de solventes e de outras espécies químicas (muitas vezes tóxicas ou perigosas e que terão de ser removidas), e a possibilidade de ocorrência de reacções indesejáveis (que podem promover a degradação das substâncias de interesse e/ou a formação de compostos perigosos) [7, 11, 13, 81-86].

Por fim, uma outra técnica muito usada consiste no contacto das matrizes sólidas/semi-sólidas previamente preparadas com soluções líquidas (ou mesmo com emulsões ou dispersões finas) contendo os aditivos a incorporar. Isto pode ser feito através da imersão das matrizes nas soluções/emulsões/dispersões líquidas ou por adição de determinadas quantidades das soluções/emulsões/dispersões líquidas às matrizes. Nestas situações, as matrizes usadas (poliméricas, inorgânicas ou compósitas/ híbridas) não se devem dissolver nos solventes líquidos usados, embora possam (e devam) absorver grandes quantidades dos mesmos para, desta forma, incharem e facilitarem o processo de difusão dos aditivos para o seu interior. Após este processo difusional, os aditivos ficam incorpo- 
rados através das interacções específicas estabelecidas com as matrizes sólidas/semi-sólidas. No entanto e na maioria dos casos, estes processos são demorados, conduzem a incorporações pouco homogéneas e não são muito eficientes em termos das quantidades incorporadas. Isto acontece essencialmente devido à baixa difusividade dos aditivos empregues, às baixas capacidades dos solventes líquidos para inchar as matrizes e/ ou às fracas interacções que se conseguem estabelecer entre os aditivos e as matrizes. O aumento da temperatura pode ser usado para melhorar esta eficiência mas também pode provocar a degradação das substâncias envolvidas. Além disso e uma vez mais, poderão estar envolvidas substâncias líquidas tóxicas ou perigosas, e será assim necessário usar procedimentos adicionais de remoção destes líquidos e de secagem dos materiais. No entanto, estes procedimentos também requerem normalmente o uso de temperaturas relativamente elevadas e que podem degradar as substâncias envolvidas [87-90].

Pode-se assim concluir que, e em termos gerais, todos os métodos convencionais de incorporação de aditivos em matrizes sólidas/semi-sólidas para aplicações farmacêuticas e biomédicas podem apresentar alguns problemas e desvantagens importantes, em particular as relacionadas com a baixa heterogeneidade e com os baixos rendimentos de incorporação, com a possível ocorrência de reacções químicas indesejadas, com a necessidade de remoção das substâncias líquidas usadas e com a secagem dos materiais obtidos, com o uso de condições de processamento que podem degradar e diminuir a estabilidade das substâncias envolvidas (em particular, das substâncias bioactivas), com a pureza, segurança e toxicidade dos substâncias químicas e solventes usados (e com a presença de quantidades residuais dos mesmos), bem como com a eficiência energética e custos associados a estes métodos.

Como já referido na Introdução e embora todos os problemas acima referidos sejam também muito relevantes de um ponto de vista tecnológico e/ou económico, as questões relacionadas com a pureza, segurança e toxicidade tornam-se críticas para as aplicações farmacêuticas e biomédicas, onde existem várias entidades reguladoras (a nível nacional e internacional) que definem e fiscalizam a grande maioria dos aspectos 
científicos, técnicos e regulamentares como, por exemplo, quais as substâncias que podem ser usadas e que estabelecem ainda limitações muito restritivas em termos de pureza, de homogeneidade, de reprodutibilidade, de estabilidade e de quantidades residuais de substâncias/aditivos que possam afectar a segurança e toxicidade dos produtos farmacêuticos, dispositivos médicos e produtos de combinação para uso humano. Além das instituições reguladoras existentes em cada país, estas entidades reguladoras de referência a nível mundial para estes propósitos são, como já foi referido, a FDA (EUA), a EMA (UE), o MHLW (Japão) e a ICH (organização transnacional) [9-19, 22-23, 26-30].

Desta forma, torna-se necessário desenvolver e aplicar métodos e processos alternativos que possam permitir a incorporação dos aditivos pretendidos em produtos farmacêuticos, dispositivos médicos e produtos de combinação para uso humano, de uma forma eficiente e economicamente viável e que, simultaneamente, possam evitar as questões de segurança acima referidas e estar de acordo com as regulamentações existentes.

\subsection{O uso de fluidos supercríticos no desenvolvimento de aplicações farmacêuticas e biomédicas}

De entre as alternativas aos métodos convencionais de incorporação de aditivos em matrizes sólidas/semi-sólidas para aplicações farmacêuticas e biomédicas e devido às suas bem conhecidas propriedades e vantagens, os métodos/processos que envolvem o uso de fluidos supercríticos (FSCs), e em particular os que envolvem o uso de dióxido de carbono supercrítico $\left(\mathrm{scCO}_{2}\right)$, têm vindo a ser cada vez mais estudados e/ou aplicados. Este facto acontece essencialmente porque, e na grande maioria dos casos, são técnicas "livres-de-solventes" (do inglês, "solvent-free") e porque permitem processamentos bastante versáteis e que podem ser realizados a temperaturas relativamente próximas da temperatura ambiente. Em termos muito gerais, pode-se dizer que os FSCs possuem algumas propriedades com valores semelhantes às dos líquidos (e.g., densidade) e outras propriedades com valores próximos das dos gases (e.g., propriedades de transporte 
como a viscosidade e a difusividade). Isto pode permitir que, em determinadas condições, um FSC possa penetrar com relativa facilidade para o interior de determinadas matrizes sólidas/semi-sólidas e assim extrair ou depositar determinadas substâncias dessas/nessas mesmas matrizes. Além disso, estas propriedades são facilmente ajustáveis através da variação das condições de pressão e/ou temperatura. Em certos casos, os FSCs apresentam também excelentes propriedades enquanto agentes plastificantes temporários, uma vez que conseguem difundir-se e dissolver-se em muitas matrizes poliméricas, promovendo assim seu intumescimento e a posterior difusão de substâncias no seu interior. Assim e por exemplo, os processos de extracção e de impregnação/deposição que se pretendam realizar irão ser beneficiados com esta situação. Finalmente, uma outra vantagem muito importante é a que resulta da sua fácil eliminação (por passagem ao estado gasoso por despressurização simples), com a consequente recuperação dos produtos finais de uma forma fácil, barata, e sem a presença de quaisquer vestígios residuais [23, 31-56].

$\mathrm{O}$ dióxido de carbono supercrítico $\left(\mathrm{scCO}_{2}\right)$ é, sem qualquer dúvida, o FSC mais utilizado. Para esta substância química, o estado supercrítico pode ser facilmente atingido e o processamento nestas condições pode assim ser efectuado a temperaturas imediatamente acima dos $32{ }^{\circ} \mathrm{C}$ e a pressões acima dos $7.4 \mathrm{MPa}$ (uma vez que a sua temperatura crítica e pressão crítica são $31.1{ }^{\circ} \mathrm{C}$ e $7.4 \mathrm{MPa}$, respectivamente). Além disso, o $\mathrm{CO}_{2}$ é uma substância considerada segura no desenvolvimento de aplicações alimentares (é considerado como uma substância GRAS - do inglês "Generally Recognized As Safe" - pela FDA, EUA) [91], é ambientalmente aceitável (podendo ser recuperado e reutilizado, não contribuindo assim para o efeito de estufa), tem baixa ou inexistente toxicidade, e não é inflamável. É barato e abundante, possui uma reactividade relativamente baixa (nas condições em que é normalmente usado), é inerte à oxidação e, mais recentemente, tem também sido usado como agente esterilizante terminal para várias aplicações, incluindo para materiais biológicos e aplicações biomédicas [23, 31-56, 73, 92-94].

Assim, e em termos de aplicações farmacêuticas e biomédicas, os FSCs podem ser usados como solventes, antisolventes, solutos e, embora seja 
muito raro, podem até ser utilizados como reagentes. De entre as vastas aplicações possíveis nestas áreas, podem salientar-se: reacções em FSCs com vista à produção de ingredientes farmacêuticos activos (APIs, do inglês "Active Pharmaceutical Ingredients"), de compostos intermediários e de excipientes; secagem de APIs, excipientes e de formulações farmacêuticas; controlo de morfologia e obtenção de polimorfos de alta pureza; separação de misturas racémicas de substâncias bioactivas; fraccionamento de substâncias bioactivas (proteínas, polímeros, lípidos, compostos polifenólicos) e de excipientes; "refolding" de proteínas; produção de lipossomas e de complexos de inclusão; revestimento de formas finais de dosagem e de implantes e dispositivos médicos; agentes esterilizantes; cromatografia supercrítica; extracção de substâncias bioactivas e de impurezas/solventes residuais; auxiliares de processamento (redutores de viscosidade e plastificantes temporários); agentes morfológicos, porogénicos e espumantes; produção de micro- e nanopartículas (e de micro- e nanocápsulas); e ainda impregnação/deposição de substâncias bioactivas em matrizes sólidas ou semi-sólidas. Todas estas potenciais e efectivas aplicações foram já apresentadas e revistas em muitos trabalhos que podem ser encontrados na literatura científica e técnica [23, 31-56, 74, 80, 92-94, 95-133].

Nas secções seguintes, iremos abordar em detalhe estas últimas metodologias, ou seja, iremos apresentar e descrever a técnica de impregnação/ deposição de aditivos em matrizes/materiais sólidos (ou semi-sólidos) usando solventes supercríticos (SSI/SSD, do inglês "Supercritical Solvent Impregnation/Deposition") e, em particular, a situação mais comum que é a que envolve o uso de $\mathrm{scCO}_{2}$ como solvente de impregnação/deposição para o desenvolvimento de aplicações farmacêuticas e biomédicas para uso humano.

\subsection{Impregnação/deposição com solventes supercríticos para apli- cações farmacêuticas e biomédicas}

Os métodos de impregnação/deposição com solventes supercríticos (SSI/ SSD) foram inicialmente sugeridos e/ou aplicados para o desenvolvimento 
de aplicações farmacêuticas há cerca de 30 anos, por Berens, Sand, Paulaitis, Perman e colaboradores [128, 134-139]. Desde aí, e como veremos adiante, têm sido cada vez mais estudados, explorados e aplicados no desenvolvimento de algumas destas aplicações. Em termos muito gerais, estas técnicas consistem na aplicação sequencial de 3 passos principais [23, 38, 40-41, 45, 52, 128-129, 134, 136, 138-139, 140-147].

(i) Dissolução do(s) aditivo(s) num fluido comprimido muito volátil (normalmente um gás à pressão atmosférica), ou numa mistura de fluidos comprimidos, em gamas adequadas de composição, temperatura e pressão (muito próximas ou acima da temperatura e pressão crítica do fluido - ou da mistura de fluidos comprimidos). Para aumentar a solubilidade dos aditivos nas condições usadas, podem-se adicionar pequenas quantidades de co-solventes (ou de surfactantes);

ii) Colocação da mistura fluida comprimida (resultante do passo anterior) em contacto com a matriz sólida (ou semi-sólida) a ser processada, durante um período de tempo conveniente, e em gamas adequadas de pressão e de temperatura (que podem ser diferentes das usadas para a dissolução dos aditivos). Durante este passo do processo, a mistura fluida comprimida, que contém o(s) aditivo(s) dissolvido(s), ir-se-á difundir para o interior da matriz sólida/semi-sólida e, nalguns casos, podendo/ devendo também dissolver-se na matriz e assim actuar como um agente plastificante temporário e/ou como um agente de intumescimento dessa mesma matriz;

iii) Após o tempo de contacto considerado conveniente, é feita a remoção da mistura fluida comprimida, através de uma despressurização e expansão controlada (a qual pode ser feita de uma forma lenta ou rápida). No final, recupera-se a matriz sólida (ou semi-sólida) com o(s) aditivo(s) nela impregnado(s) ou depositado(s) (com determinados níveis de incorporação e de homogeneidade) e num estado "livre-de-solvente" (caso não se usem quaisquer outras substâncias líquidas no processo).

Estas técnicas podem assim permitir a impregnação/deposição de aditivos (que sejam solúveis nos FSCs usados em várias matrizes sólidas/ semi-sólidas: poliméricas, inorgânicas e híbridas/compósitas) e, quando 
desejado e adequadamente usadas (i.e., usando o FSC adequado e as condições operacionais apropriadas), sem alterar as propriedades químicas e físicas (incluindo as propriedades termomecânicas e morfológicas) dos materiais usados e sem degradar termicamente e/ou quimicamente as substâncias envolvidas no processo. Além disso, e como veremos adiante, a eficiência e a homogeneidade de impregnação/deposição podem ser facilmente controladas através da manipulação de várias condições experimentais (pressões, temperaturas, tempos de processamento, velocidades de despressurização, uso de co-solventes e de surfactantes, etc.). No final, e caso não se usem quaisquer substâncias líquidas em condições de temperatura e pressão ambientais, os materiais serão sempre recuperados numa forma seca e sem a presença de quaisquer solventes residuais. Finalmente e não menos importante: estas técnicas permitem também a incorporação de vários aditivos de interesse em materiais e outros dispositivos sólidos/semi-sólidos (e.g., produtos acabados) que já foram previamente preparados por outras técnicas, com diferentes formas e geometrias, sem com isso interferir com os processos de produção e de processamento destes mesmos materiais/dispositivos [38, 40, 129, 140-141, 143-147].

O rendimento final dos processos de SSI/SSD e as propriedades dos sistemas obtidos serão sempre função das interacções específicas que existem e/ou que se podem estabelecer entre todas as substâncias envolvidas (FSCs, aditivos, matrizes sólidas/semi-sólidas, co-solventes, etc.), bem como das suas magnitudes/intensidades relativas, e das condições de processamento utilizadas, como se verá mais adiante e com mais detalhe. No entanto e como já brevemente referido, existem alguns requisitos prévios fundamentais que se devem ter em consideração quando se pretende desenvolver e aplicar o processo SSI/SSD. Assim e em primeiro lugar, os aditivos a incorporar devem ter uma solubilidade elevada ou, pelo menos, apreciável no FSC, i.e., as interacções aditivo/ FSC devem/têm de ser bastante favoráveis. Como já referido, esta solubilidade pode ser melhorada através da adição de pequenas quantidades de co-solventes específicos (ou de surfactantes), os quais são escolhidos de forma a melhorar estas interacções aditivo/FSC. No caso do FSC mais 
utilizado, i.e., no caso do uso de $\mathrm{scCO}_{2}$, deve-se referir que se trata de uma substância apolar (i.e., sem momento dipolar permanente), apesar de apresentar um forte quadrupólo. Tem uma baixa polarizabilidade (semelhante à do metano) e comporta-se geralmente como um ácido de Lewis fraco (embora também tenha também algumas características de base de Lewis fraca devido ao seu quadrupólo permanente). Como tal e também devido ao seu baixo peso molecular, geralmente o $\mathrm{scCO}_{2}$ só consegue dissolver substâncias apolares (ou de baixa polaridade) e de peso molecular relativamente baixo. No entanto, e devido ao seu quadrupólo e à adição de co-solventes polares e/ou de surfactantes adequados, poderá conseguir dissolver substâncias com alguma polaridade (embora numa extensão limitada) [38, 40, 129, 140-164].

Por outro lado e para que a técnica seja aplicável, as matrizes sólidas/semi-sólidas não devem ser solúveis nos FSCs usados, i.e., as interacções matriz/FSC não devem ser tão favoráveis que possibilitem esta mesma dissolução. No entanto e para que o processo SSI/SSD seja eficiente, é desejável que existam algumas interacções relativamente favoráveis entre os FSCs e as matrizes sólidas/semi-sólidas em uso, para que estes se consigam difundir facilmente no seu interior, promover o seu intumescimento, e assim facilitar o processo de incorporação dos aditivos. Mas e mais uma vez, esta afinidade entre os FSCs e as matrizes não pode ser muito grande uma vez que pode levar a uma outra situação relativamente comum para alguns sistemas sólidos de base orgânica e polimérica: a quantidade de FSC que se solubiliza nos materiais sólidos é tão elevada que irá promover um nível de plastificação temporária extremamente alto, o qual acabará por levar à "fusão" do material sólido. Este fenómeno é a base de três tipos de outros processos envolvendo FSCs e que podem também ser utilizados no desenvolvimento de aplicações farmacêuticas e biomédicas: os processos PGSS (do inglês, "Particles from Gas-Saturated Solutions") $[23,31,35,45,52,97,99-101,103,106-108,165-166]$, e os processos SFM (do inglês "Supercrical-assisted Foaming and Mixing"), e de extrusão/injecção com "foaming" por FSCs (do inglês "Supercrical fluid extrusion/injection foaming") [33-41, 98, 111-121, 167-168]. No entanto, 
estes processos não serão aqui desenvolvidos uma vez que saem fora do âmbito deste trabalho.

Refira-se uma vez mais que, e no caso do uso de $\mathrm{scCO}_{2}$ e quando se usam de matrizes sólidas/semi-sólidas de base orgânica e polimérica, só as substâncias de baixo peso molecular (e.g., ceras, oligómeros) ou os polímeros pertencentes às famílias dos poli(siloxanos) (devido às ligações -Si-O-Si- muito flexíveis da cadeia polimérica) e dos poli(perfluoroalcanos) (devido às interacções favoráveis entre ${\mathrm{o} \mathrm{CO}_{2}}$ e as ligações C-F), conseguem ser solúveis numa quantidade apreciável em $\mathrm{scCO}_{2}$ [38-41, 45, $48-50,52,98,119,142,154-155,169-172]$. Por oposição e devido aos seus pesos moleculares normalmente muito elevados e à ausência de interacções favoráveis com o $\mathrm{scCO}_{2}$, os polissacarídeos e as proteínas são praticamente insolúveis em $\mathrm{scCO}_{2}$ (mesmo com a adição de co-solventes e/ou surfactantes específicos). No entanto e do ponto de vista da solubilidade do $\mathrm{scCO}_{2}$ nas matrizes sólidas/semi-sólidas de base orgânica e polimérica, são essencialmente as estruturas químicas e físicas destes materiais (e não tanto os seus pesos moleculares) que irão condicionar e ter maior influência no processo de sorpção e de solubilização do $\mathrm{CO}_{2}$ nestas matrizes. Por fim, deve também referir-se que outras propriedades físicas destes materiais (como a cristalinidade, índice de polidispersão, tacticidade e grau de ramificação) irão também condicionar a solubilidade recíproca entre $\mathrm{o} \mathrm{scO}_{2}$ e estes materiais [38-41, 45, 48-50, 52, 98, 119, 129, 140-164, 169-172].

Na Figura 8.1 são indicadas as três situações que podem ocorrer no processo SSI/SSD. No caso da Figura 8.1 A), o FSC é muito pouco solúvel ou insolúvel na matriz sólida a processar e são apresentadas 2 situações: i) em cima, é apresentado o caso em que uma matriz sólida, quando em contacto com um FSC contendo um aditivo dissolvido, não consegue absorver e dissolver esta mistura em quantidades apreciáveis. Esta matriz sólida e os poros existentes nela podem, no entanto, sofrer pequenas deformações e aumentar ligeiramente de volume (devido a uma pequena absorção da mistura, às altas pressões usadas e ao aumento da quantidade da mistura FSC+aditivo no interior dos poros do material) mas o sistema é incapaz de inchar verdadeiramente (por absorção). Isto 
pode também promover a ruptura de partes do material levando à criação de novos poros e assim a um aumento da porosidade do material. Por exemplo, este é o caso de polímeros onde o $\mathrm{scCO}_{2}$ é muito pouco solúvel mas que têm propriedades mecânicas que permitem a ocorrência de deformações por acção mecânica da pressão de operação (exemplos: polissacarídeos como a quitina e o quitosano e alguns dos seus derivados). Após a despressurização controlada do sistema (lenta ou rápida), o FSC é removido e a matriz sólida retorna às suas dimensões iniciais (se a pequena deformação ocorrida for completamente elástica) ou, como é mais frequente, fica com dimensões muito próximas das originais. A diminuição da pressão vai provocar a diminuição da solubilidade do aditivo na fase fluida móvel, fazendo com que este precipite (por um processo de nucleação e crescimento), e ficando assim depositado na forma sólida na superfície dos poros do material ou em regiões muito próximas da superfície do material; ii) em baixo, é mostrada uma situação em que a matriz sólida não consegue absorver e dissolver o FSC no seu interior. Nem consegue ser deformada por acção do FSC e das altas pressões usadas. Por exemplo, este é o caso de materiais porosos do tipo cerâmico/ inorgânico ou de alguns polímeros porosos termoendurecíveis (exemplo: sílicas mesoporosas). Assim e após a despressurização, o material retém as dimensões iniciais e, de novo, o aditivo é precipitado e depositado na superfície dos poros do material. 


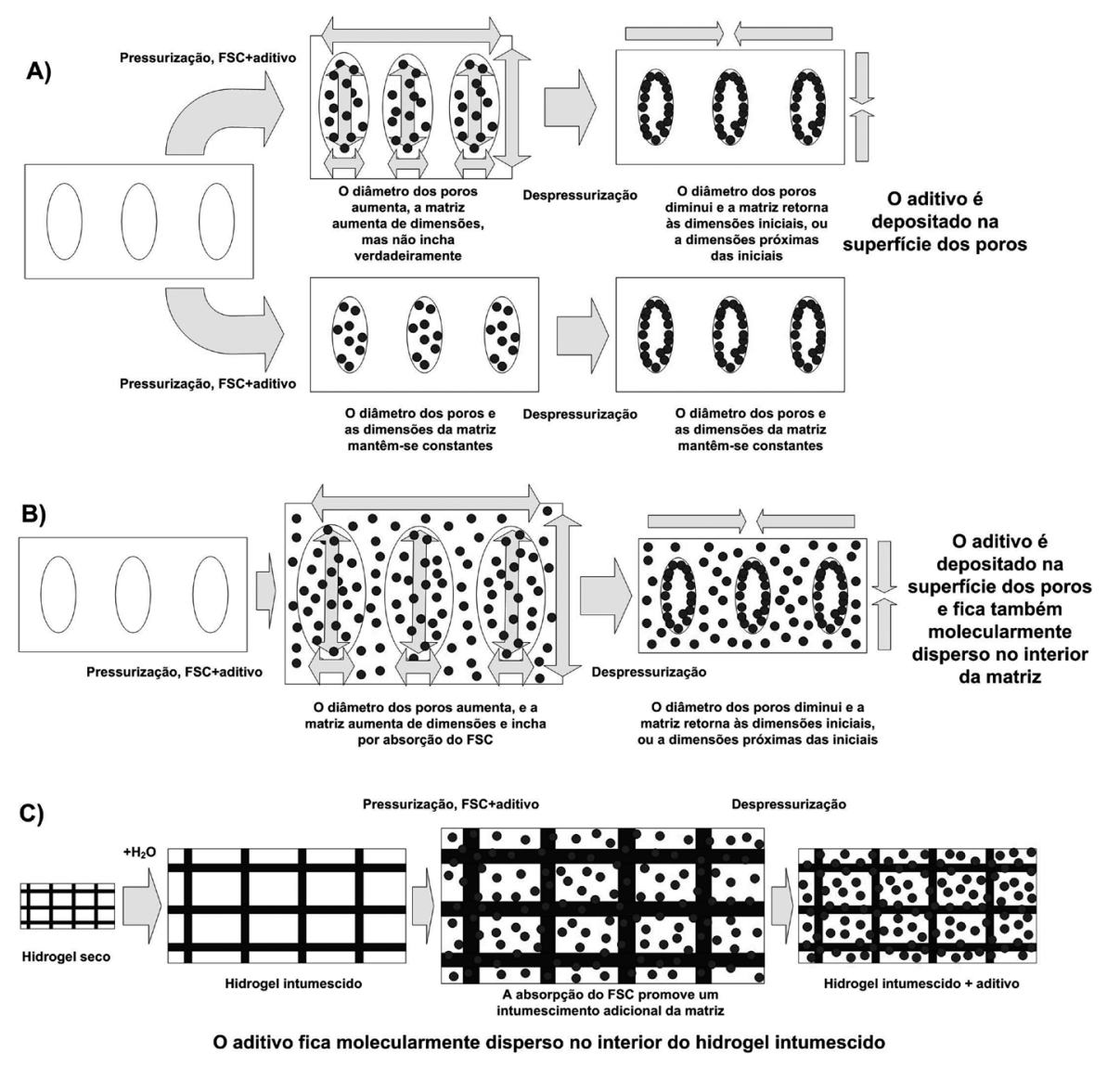

Figura 8.1. Possíveis situações que podem ocorrer durante o processo SSI/SSD. A) Matrizes sólidas onde os FSCs não são solúveis (ou são muito pouco solúveis); B) Matrizes sólidas onde os FSCs são solúveis em quantidades apreciáveis; C) Matrizes semi-sólidas previamente inchadas por outros solventes líquidos (e.g., hidrogel intumescido em água) e em que os FSCs são relativamente solúveis.

A Figura 8.1 B) representa a situação típica e desejável do método SSI/SSD e que corresponde à situação em que o FSC tem uma solubilidade apreciável na matriz sólida a processar. Por exemplo, este é o caso da maioria dos polímeros termoplásticos (reticulados ou não) como o poli(metacrilato de metilo) ou outros poli(acrilatos), o polietileno e o polipropileno, etc. A difusão da mistura FSC+aditivo para o interior da matriz sólida e a sua dissolução nela em quantidades apreciáveis, vai fazer com que esta inche e altere as suas dimensões. O efeito mecânico 
do aumento de volume e da pressão de operação também vai promover a deformação temporária dos poros do material sólido. Após a despressurização lenta ou rápida do sistema, o FSC é removido e a matriz sólida retorna às suas dimensões iniciais (ou a dimensões próximas da original) ficando, neste caso, o aditivo molecularmente disperso no interior da matriz sólida e ainda depositado (sob a forma sólida) na superfície dos poros do material.

Por fim e na Figura 8.1 C) é apresentada uma situação particular e onde a matriz a processar (normalmente constituída por materiais química- ou fisicamente reticulados) pode ser considerada como sendo uma matriz semi-sólida, uma vez que já foi previamente inchada com um outro solvente líquido. Por exemplo, esta situação traduz o caso de hidrogéis de base polimérica (i.e., contendo água) ou de materiais inorgânicos produzidos por uma via húmida (e.g., através de um método sol-gel em etanol/metanol e/ou água).

Neste caso, a difusão da mistura FSC+aditivo para o interior da matriz semi-sólida e a sua dissolução no líquido já aí presente, irá promover um inchaço adicional desta matriz, com a consequente alteração das suas dimensões, e fazendo com que a matriz se comporte, em termos gerais, como um líquido expandido por um gás (do inglês, "gas-expanded liquid") [173-177]. Após a despressurização (lenta ou rápida) do sistema, o FSC é removido do sistema (podendo arrastar igualmente algum do solvente líquido) e a matriz semi-sólida retorna às suas dimensões iniciais (ou a dimensões muito próximas da original). Neste caso, o aditivo fica apenas molecularmente disperso no interior da matriz semi-sólida.

Em termos experimentais, existem diferentes variações da técnica SSI/ SSD, embora todas elas envolvam sempre um passo descontínuo (devido à necessidade de carga dos aditivos sólidos e de carga/recuperação das matrizes sólidas ou semi-sólidas a processar). Obviamente, não se pretende descrever aqui, e em grande detalhe, os modos de funcionamento e os procedimentos específicos de qualquer uma das maneiras de aplicar a técnica SSI/SSD. Há no entanto uma condição essencial e prévia a ter em consideração: devido às condições experimentais normalmente usadas, é indispensável que todos os equipamentos e acessórios usados para 
estes métodos sejam adequados e seguros para o uso de altas pressões. Normalmente e quando se usa $\mathrm{scCO}_{2}$, esta gama de pressões pode variar normalmente desde os 60-70 bar até aos 350-400 bar. No entanto, e embora seja muito raro, por vezes podem até ser utilizadas pressões de operação superiores a 1000 bar. De entre os equipamentos e acessórios preparados para altas pressões que podem ser usados devem-se salientar: compressores, bombas de líquidos, misturadores, manómetros, tubagens, válvulas (de vários tipos), acessórios de ligação, medidores de caudal, discos de ruptura, filtros de linha e, obviamente, os vasos/células de alta pressão onde irá ser feita a dissolução dos aditivos e o contacto das misturas contendo os aditivos com as matrizes sólidas/semi-sólidas.

A gama de temperaturas a utilizar terá obviamente de ter em conta a temperatura crítica do FSC em uso e a estabilidade térmica das substâncias envolvidas. Quando se usa $\mathrm{scCO}_{2}$, a gama de temperaturas de operação pode variar normalmente entre $31^{\circ} \mathrm{C}$ e uma temperatura que não possa promover a degradação das substâncias presentes (normalmente e no máximo até $60-100{ }^{\circ} \mathrm{C}$ ). No entanto, outras condições de temperatura podem ser limitantes como, por exemplo, aquelas que podem levar à transição vítrea e/ou "fusão" de matrizes sólidas poliméricas a certas pressões de operação (por absorção e solubilização do $s c \mathrm{CO}_{2}$ ). Além disso, a conjugação das condições de temperatura com as de pressão de operação irá permitir "ajustar" a densidade e as propriedades de transporte da fase fluida para a aplicação pretendida. Desta forma, consegue-se assim também controlar a solubilidade dos aditivos na fase fluida, bem como a viscosidade e difusividade da fase fluida e a sua solubilidade nas matrizes sólidas (ou semi-sólidas) a processar.

Na Figura 8.2 estão representadas, de uma forma muito genérica, os esquemas das variações experimentais mais habituais na técnica SSI/SSD. Nas Figuras 8.2 A) e B) são apresentados dois esquemas de instalações experimentais puramente descontínuas e onde a principal diferença entre elas consiste na forma em como é feita a dissolução dos aditivos nos fluidos comprimidos (ou nos FSCs): no mesmo recipiente onde é feito o contacto com as matrizes sólidas/semi-sólidas (A) ou em recipientes separados (B). 
A)

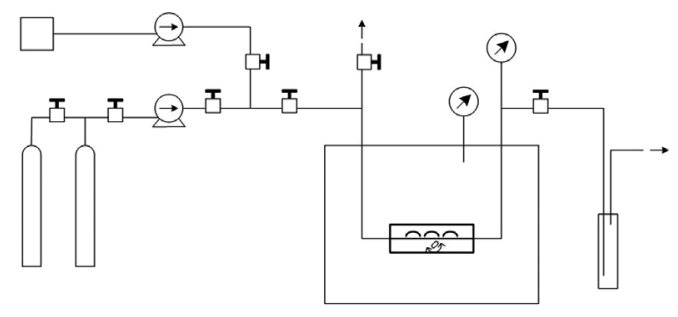

B)

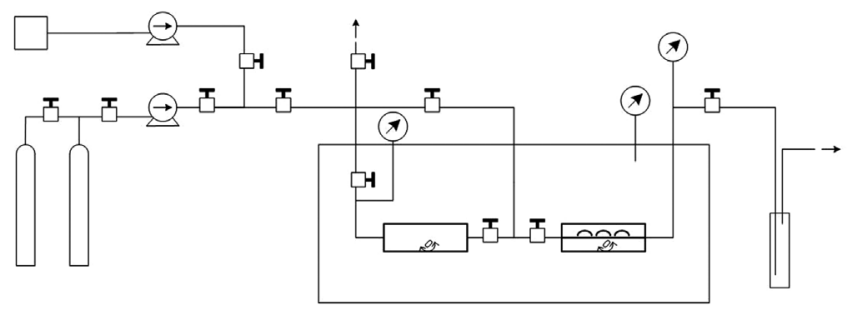

C)

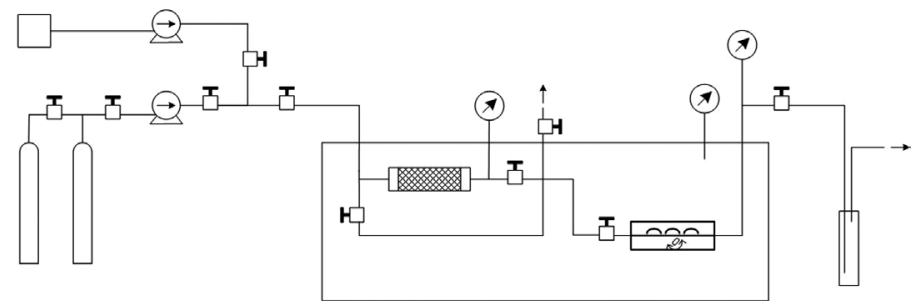

Figura 8.2. Representação esquemática de diferentes equipamentos laboratoriais para realizar ensaios experimentais de SSI/SSD. A) Sistema descontínuo, onde os aditivos são dissolvidos nos fluidos comprimidos (ou nos FSCs) no mesmo recipiente de alta-pressão onde é feito o contacto com as matrizes sólidas/semi-sólidas a processar; B) Sistema descontínuo, onde os aditivos são previamente dissolvidos nos fluidos comprimidos (ou nos FSCs) num recipiente de alta-pressão e, posteriormente, são colocados em contacto com as matrizes sólidas/semi-sólidas a processar num outro recipiente a alta pressão; C) Sistema semi-descontínuo, onde um fluxo contínuo dos fluidos comprimidos (ou dos FSCs) vai dissolver os aditivos (imobilizados num recipiente de alta-pressão) e, posteriormente, vai entrar em contacto (também em modo contínuo) com as matrizes sólidas/semi-sólidas a processar (num outro recipiente a alta pressão) (adaptado das referências 140-141).

Já na Figura 8.2 C) é apresentado um esquema experimental onde os aditivos são dissolvidos através da passagem de uma corrente contínua de FSCs (ou de fluidos comprimidos) através de um recipiente contendo os aditivos imobilizados, a qual é depois feita passar pelo recipiente onde se encontram as matrizes sólidas/semi-sólidas a processar (num outro recipiente). 
Como se pode observar, todos estes esquemas experimentais são constituídos por 4 partes fundamentais: i) sistema de pressurização de FSC ou de misturas de fluidos comprimidos (incluindo a adição de co-solventes ou de soluções de surfactantes); ii) sistema de dissolução de aditivos nas misturas comprimidas ou nos FSCs; iii) sistema de contacto entre as matrizes sólidas/sólidas a processar e as misturas de fluidos comprimidos+aditivos ou de FSCs+aditivos; e iv) sistema de despressurização.

Cada um destes sistemas experimentais genéricos pode depois, por questões práticas e/ou considerando as especificidades de cada sistema aditivo/FSC/matriz sólida (ou semisólida) a estudar, sofrer algumas alterações/modificações, nomeadamente em termos de: sistema de compressão e mistura de fluidos comprimidos/FSCs e de co-solventes; sistemas de refrigeração e aquecimento; sistemas de medida e de controlo de temperatura e de pressão; sistemas de controlo de pressurização/ despressurização; sistemas de medida e controlo de caudais; sistemas de segurança; e, os mais importantes, os sistemas de dissolução de aditivos e os sistema de contacto entre as matrizes sólidas/semi-sólidas e as misturas de fluidos comprimidos+aditivos ou de FSCs+aditivos (incluindo diferentes maneiras de adição/imobilização de aditivos, presença/ausência de agitação magnética (ou de ultrassons), modos de imobilização/ acondicionamento das matrizes a processar; estratégias de protecção das matrizes durante a despressurização, uso de filtros e “traps", etc.).

Em termos de aplicações industriais e apesar da existência de muitos estudos académicos já publicados na literatura e de muitos pedidos de patentes registados (em vários países), não temos conhecimento da existência de nenhuma aplicação industrial/comercial (em larga escala) que esteja actualmente implementada e que use a técnica de SSI/SSD para o desenvolvimento de aplicações e produtos nas áreas farmacêutica e biomédica. No entanto, já existem vários equipamentos comercialmente disponíveis (a várias escalas e com varias capacidades de processamento) e processos industriais em funcionamento que usam a metodologia SSI/SSD para a incorporação de corantes e pigmentos em fibras têxteis (sintéticas e naturais) [38, 40, 46, 178-185] bem como para o tratamento e curtimenta de peles de animais e impregnação de biocidas em madeiras e em compósitos de 
madeira [46, 186-192]. Nestes casos e apesar de terem sido introduzidas algumas modificações necessárias para cada uma destas aplicações específicas, os equipamentos desenvolvidos e usados têm todos como base os já acima referidos métodos descontínuo e semi-descontínuo. Quer isto dizer que, havendo já fabricantes de equipamentos à escala industrial para este tipo de metodologias e processos, não será certamente muito difícil modificá-los e adaptá-los para futuras aplicações farmacêuticas e biomédicas comerciais. No entanto, o fabrico e a instalação dos equipamentos, bem como os procedimentos, condições de operação, controlo biológico, limpeza e validação destes equipamentos (entre outras condições), terão de ter sempre em conta e de respeitar os indispensáveis requisitos cGMP (do inglês, "Current Good Manufacturing Practices") para a área dos medicamentos para uso humano (ou dos dispositivos médicos e dos produtos de combinação) [13-14, 16, 18, 22-23, 27-30, 32, 41, 43, 193-195].

Como já foi referido e devido às suas bem conhecidas propriedades, particularmente aquelas relacionadas com a sua segurança e não-toxicidade, o $\mathrm{scCO}_{2}$ é o FSC mais usado na técnica SSI/SSD. No entanto, e embora isso implique a adopção de medidas de segurança mais restritivas bem como o uso de gamas operacionais de temperatura e de pressão relativamente diferentes das usadas para o $\mathrm{scCO}_{2}$, outros FSCs podem também ser usados, em princípio, na técnica SSI/SSD (puros ou na forma de misturas), nomeadamente: etano, etileno, propano, propileno, n-propano, trifluorometano, hexafluoreto de enxofre, etc. [50-52]. Outras substâncias poderiam igualmente ser consideradas mas, e para as aplicações farmacêuticas e biomédicas, é fundamental ter em conta as gamas de temperaturas/pressões desejadas, e que a substância que se use como FSC seja um gás à temperatura ambiente e à pressão atmosférica (de forma a que, e após o processamento, as matrizes fiquem secas e praticamente livres de quaisquer resíduos perigosos).

Há assim que ter em conta as questões de segurança (e.g, inflamabilidade) e de toxicidade no uso destes solventes (no estado supercrítico ou noutro - líquido subcrítico ou gasoso). Como se sabe, existem fortes limitações em relação ao uso e à presença residual de solventes nos produtos farmacêuticos e biomédicos para uso humano (ou animal). Estas 
limitações para o uso de solventes estão bem estabelecidas pelas autoridades regulatórias competentes como, por exemplo, pela FDA (nos EUA), EMA (na UE) e pela ICH. Desta forma, estes solventes são classificados como: i) solventes a serem evitados (Classe 1, solventes com elevado e comprovado potencial tóxico e/ou apresentando riscos elevados para o meio ambiente). Estes solventes não devem ser usados no fabrico de APIs, de excipientes e de medicamentos, e só em situações muito específicas e bem justificadas é que podem ser usados (i.e., quando não existam quaisquer alternativas e que permitam o desenvolvimento de medicamentos de grande e inovadora relevância terapêutica); ii) solventes fortemente limitados no seu uso (Classe 2, solventes apresentando toxicidade inerente conhecida) e que têm limites residuais de concentração (em ppm) muito restritivos; e iii) solventes de baixo potencial tóxico (Classe 3, solventes que não apresentam riscos comprovados para a saúde humana) mas cujo uso, e por precaução, deve ser sempre regulado e limitado por considerações cGMP (ou por outros requisitos de Qualidade). Existem muitos solventes já listados nestas três categorias (bem como as concentrações residuais máximas permitidas em produtos farmacêuticos e dispositivos médicos para uso humano). No caso de solventes que não sejam já considerados nas três classes acima referidas, ou tratando-se de solventes sem dados e resultados de toxicidade devidamente comprovados, se o seu uso for do interesse para o fabrico de APIs, de excipientes, e de medicamentos, dispositivos médicos e produtos de combinação para uso humano, então os fabricantes terão sempre de justificar convenientemente o seu uso, as quantidades residuais presentes bem como determinar os seus limites de exposição diária permitidos (PDE, do inglês "Permitted Daily Exposure") e as concentrações máximas permitidas (em ppm) [16-19, 22, 193-200].

Da mesma forma e para este tipo de aplicações, os co-solventes que podem ser usados para aumentar a solubilidade dos aditivos nos FSCs (ou na mistura de fluidos comprimidos) devem igualmente ser escolhidos criteriosamente. Assim, isto deve ser feito não só tendo em conta os efeitos pretendidos na polaridade dos FSCs e na solubilidade dos aditivos a processar, mas também considerando as questões relacionadas com a segurança e toxicidade dos mesmos e com a sua facilidade de remoção 
(tanto das matrizes sólidas/semi-sólidas processadas como do FSC ou da mistura de fluidos comprimidos - e se a recuperação e reutilização destes fluidos for pretendida). Assim e para além da água, os co-solventes mais usados para estas aplicações são: etanol, isopropanol, acetona e acetato de etilo. Apesar de existirem limites para a sua presença residual em produtos farmacêuticos, dispositivos médicos e produtos de combinação (que são definidos pelas cGMP ou por outros requisitos de Qualidade), estes solventes são classificados como sendo solventes de baixo potencial tóxico (Classe 3). Outros co-solventes como metanol, hexano e tolueno (considerados como solventes de uso limitado - Classe 2) podem também ser utilizados mas têm de se ter cuidados especiais e acrescidos com o controlo da presença dos seus resíduos nas matrizes sólidas/semi-sólidas processadas. Tal como no caso dos solventes, os co-solventes classificados na Classe 1 devem ser evitados [16-19, 22, 193-200].

Em relação aos surfactantes que podem ser usados, estes podem ser considerados como sendo agentes ou "impurezas" de processamento, ou como sendo um dos "excipientes" nas formulações, embora esta última situação seja (e deva ser) a mais comum e a mais correcta. Por exemplo, nos EUA os polisorbatos (como o Polisorbato 20, Polisorbato 60 ou Polisorbato

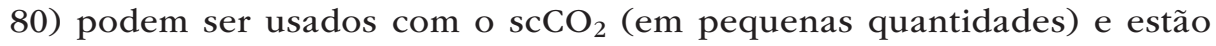
autorizados pela FDA para uso como excipientes (substâncias não-activas - ou inactivas). No entanto e para outros agentes tensioactivos, deve-se sempre verificar junto das autoridades reguladoras quais são as substâncias que já estão aprovados para o fabrico de medicamentos, de dispositivos médicos e de produtos de combinação para uso humano, quais são os limites/quantidades que podem ser usados para cada aplicação específica pretendida e quais os métodos/normas de teste para quantificar a sua presença e para avaliar as suas biocompatibilidades. Os surfactantes que foram já especificamente desenvolvidos para o uso com $\mathrm{scCO}_{2}$, i.e., surfactantes que apresentam domínios $\mathrm{CO}_{2}$-fílicos e que permitem o aumento de solubilidade e mesmo a emulsificação de substâncias numa fase fluida a alta pressão contendo $\mathrm{CO}_{2}$ (como sejam os surfactantes de base poli(fluoroéter), de base poli(siloxano) ou de base poli(fluoroacrilato), podem também ser usados embora não estejam ainda aprovados pelas 
entidades reguladoras, nem existam ainda dados de segurança e toxicidade devidamente avaliados e comprovados [11-19, 21-23, 26, 32, 38, 40, 43-49, 52, 98, 142, 154, 169-172, 201-206].

Quanto aos aditivos que podem ser usados na técnica SSI/SSD no desenvolvimento de aplicações farmacêuticas e biomédicas para uso humano, e tendo em consideração as questões já referidas em relação à solubilidade dos aditivos nos FSCs e nas misturas de fluidos comprimidos (i.e., a técnica está limitada a aditivos apolares - ou pouco polares - e de peso molecular relativamente baixo), estes poderão ser sólidos (o que acontece na maioria dos casos) ou líquidos, e das seguintes famílias de compostos de interesse: substâncias bioactivas com capacidade terapêtica ou de substituição (e.g., fármacos do tipo pequena-molécula, hormonas, etc.), biomarcadores e agentes de contraste, substâncias bioactivas com capacidade antimicrobiana, extractos e produtos naturais bioactivos, vitaminas, antioxidantes, conservantes, plastificantes, agentes compatibilizantes, surfactantes, lubrificantes, corantes/pigmentos e protectores de radiação UV, adoçantes, acidificantes e aromas. Para aplicações mais específicas e onde se pressupõe a realização de uma reacção química no interior/superfície das matrizes sólidas (ou semi-sólidas) a serem processadas, podem-se ainda considerar outros tipos de substâncias como monómeros, iniciadores, precursores metálicos e de óxidos metálicos, etc. $[1-2,6,10-19,21-26,31-31,34-35,37,40,44-46$, 49-50, 52-56, 97-99, 103, 105, 114, 122-123, 184-185, 203].

Na Tabela 8.1 apresentam-se alguns dos aditivos específicos já estudados e que foram usados em técnicas SSI/SSD para o desenvolvimento de materiais e dispositivos sólidos/semi-sólidos para fins farmacêuticos e biomédicos. Os resultados apresentados permitem concluir que a maior parte dos aditivos incorporados em matrizes sólidas/semi-sólidas (as quais são quase sempre de natureza polimérica) corresponde, sem qualquer dúvida, aos fármacos de baixo peso molecular (Tabela 8.1 a). No entanto, outros tipos de substâncias bioactivas sintéticas de baixo peso molecular e potenciais biomarcadores foram já também impregnadas/depositadas através destas técnicas (Tabela 8.1 b). Mais recentemente, tem sido também estudada a impregnação/deposição de produtos naturais (ou mesmo de 
extractos contendo produtos naturais) com actividade biológica. A maior parte destes aditivos de origem natural são metabolitos secundários de origem vegetal (como lípidos, terpenoides e flavonoides) (Tabela $8.1 \mathrm{c}$ ), ou outras substâncias de origem natural (ou modificadas) (Tabela $8.1 \mathrm{~d}$ ). Apresentam-se também alguns monómeros e precursores químicos que já foram impregnados pelas técnicas SSI/SSD, os quais podem depois ser polimerizados ou participarem noutras reacções químicas, e de forma a se obterem materiais quimicamente modificados e/ou compósitos.

Apesar de a tabela apresentar apenas os aditivos/extractos já usados na técnica SSI/SSD e descritos na literatura, muitos outros aditivos/extractos foram também já estudados para outros tipos de técnicas/aplicações que usam FSCs como um solvente (condição necessária para a técnica). Sendo assim, estes aditivos/extractos poderão também ser futuramente usados nas técnicas SSI/SSD (desde que satisfaçam os já referidos requisitos de solubilidade nos FSCs - e no $\mathrm{scCO}_{2}$ em particular).

Como a maioria dos aditivos apresentados na Tabela 8.1 correspondem a ingredientes farmacêuticos activos (APIs) que já são utilizados em medicamentos de uso humano (ou seja, já aprovados pelas autoridades competentes para serem comercializados sob diversas formas de dosagem - podendo mesmo serem usados em medicamentos genéricos), o processo regulatório associado ao desenvolvimento de formulações usando a técnica SSI/SSD e contendo estes mesmos aditivos poderá estar bastante facilitado. No entanto, a avaliação da toxicidade, da biodisponibilidade e a definição das doses para estas novas formulações deverá ser sempre avaliada, tendo em conta a formulação específica desenvolvida e a forma final de dosagem pretendida e, em particular, prestando especial atenção aos excipientes usados.

No caso de quaisquer outras substâncias bioactivas sintéticas de baixo peso molecular que não estejam ainda aprovadas pelas autoridades competentes enquanto APIs, as mesmas (e as suas formulações e formas finais de dosagem) terão de passar pelos morosos, exigentes e dispendiosos processos de autorização de introdução no mercado enquanto medicamentos, dispositivos médicos e produtos de combinação para uso humano (incluindo a realização de testes não-clínicos e de todas as fases de ensaios 
clínicos em humanos). O mesmo será exigido no caso de substâncias puras de origem natural (ou modificadas a partir de produtos naturais) e das suas formulações, quando as mesmas se pretendam comercializar sob a forma de medicamentos, dispositivos médicos e produtos de combinação para uso humano. Convém não esquecer que muitas substâncias de origem natural apresentam toxicidades e riscos relativamente elevados (incluindo alguns riscos de contaminação biológica) e, como tal, não se deve aceitar a ideia tanta vez difundida de que todos os produtos de origem natural são seguros e não apresentam quaisquer riscos para a saúde humana (ou mesmo para o meio ambiente). Finalmente e no caso de extractos bioactivos contendo produtos naturais, é ainda necessário considerar que um extracto bioactivo é quase sempre uma mistura complexa de várias substâncias bioactivas e, como tal e considerando os quadros regulatórios actuais, nunca poderá ser aprovado como sendo um API (no estrito sentido dado a esta designação pelas entidades regulatórias).

No entanto, algumas substâncias bioactivas não aprovadas enquanto APIs (de origem natural ou mesmo sintética), ou os extractos contendo produtos naturais, poderão encontrar outro tipo de aplicações terapêuticas reconhecidas pelas autoridades competentes como, por exemplo, enquanto medicamentos homeopáticos ou como medicamentos à base de plantas. Um medicamento homeopático é definido como sendo um medicamento obtido a partir de determinadas substâncias bioactivas (denominadas como "stocks" ou como matérias-primas homeopáticas), e de acordo com um processo de fabrico descrito numa farmacopeia reconhecida (como a Farmacopeia Europeia). Por outro lado e por definição, um medicamento à base de plantas, é um medicamento que contém exclusivamente como substâncias bioactivas uma ou mais substâncias químicas derivadas de plantas, uma ou mais formulações à base de plantas ou uma ou mais substâncias derivadas de plantas em associação com uma ou mais formulações à base de plantas. Estes dois tipos específicos de medicamentos têm processos de autorização de introdução do mercado diferentes e mais simplificados do que os processos correspondentes e referentes aos medicamentos para uso humano [18, 22, 27-30]. Apesar de não estarem no âmbito deste trabalho, podem-se ainda referir outros tipos de 
aplicações onde a bioactividade dos aditivos a incorporar nos materiais sólidos/semi-sólidos é uma característica distintiva e fundamental para as aplicações pretendidas, como sejam as aplicações veterinárias, cosméticas, alimentares e nutracêuticas. No entanto, existem também várias autoridades regulatórias e disposições regulamentares específicas para a sua aprovação e autorização para estes fins.

Tabela 8.1. Aditivos usados em técnicas SSI/SSD para o desenvolvimento de materiais e dispositivos sólidos/semi-sólidos para potenciais aplicações farmacêuticas e biomédicas.

a) Fármacos sintéticos de baixo peso molecular

\begin{tabular}{|c|c|c|}
\hline $\begin{array}{l}\text { Flurbiprofeno [143-145, 175, } \\
207] \\
\text { Ibuprofeno [163, 208-214] } \\
\text { Ketoprofeno [215-219] } \\
\text { Naproxeno [220-221] } \\
\text { Triflusal [37, 222-225] } \\
\text { Ácido Flufenâmico [226] } \\
\text { Ácido Salicílico [211, 227- } \\
\text {-229] } \\
\text { Ácido Acetilsalicílico [211] } \\
\text { Ácido o-Hidroxibenzóico [230] }\end{array}$ & $\begin{array}{l}\text { Piroxicam [231] } \\
\text { Nimesulide }[218,232] \\
\text { Dexametasona }[167,233] \\
\text { Indometacina }[234-238] \\
\text { Norfloxacina [177] } \\
\text { Roxitromicina [239] } \\
\text { Natamicina [240] } \\
\text { Diacetato de Clorohexidina [241] } \\
\text { Cefuroxime Sal de Sódio [176] }\end{array}$ & $\begin{array}{l}\text { Acetazolamida [146, 174] } \\
\text { Maleato de Timolol [143, } \\
\text { 145- 147] } \\
\text { Carbamazepina [242] } \\
\text { Paclitaxel [243] } \\
\text { 5-Fluorouracilo [244-246] } \\
\text { Molsidomina [247] } \\
\text { Tranilast [248] } \\
\text { Acetato de Megestrol [218] } \\
\text { Fenofibrato [249] }\end{array}$ \\
\hline
\end{tabular}

b) Outras substâncias bioactivas sintéticas e potenciais biomarcadores (de baixo peso molecular)

\begin{tabular}{|c|c|c|}
\hline $\begin{array}{l}\text { Colesterol }[250-251] \\
\beta \text {-Estradiol }[246,252]\end{array}$ & $\begin{array}{l}\alpha \text {-Tocoferol, vitamina E [253-254] } \\
\text { Rodamina B [255-257] }\end{array}$ & $\begin{array}{l}\text { Fluoresceina [257] } \\
\text { 7-Hidroxicumarina [257] }\end{array}$ \\
\hline \multicolumn{3}{|c|}{ c) Produtos naturais e extractos contendo produtos naturais } \\
\hline $\begin{array}{l}\text { Artemisinina [258] } \\
\text { Vanilina [259] } \\
\text { Curcumina [260] } \\
\text { Quercetina [261] } \\
\text { Timol [261-263] } \\
\text { 1-Mentol [259] } \\
\text { Juglona [264] } \\
\text { 1,4-Naftoquinona [264] }\end{array}$ & $\begin{array}{l}\text { Plumbagina [264] } \\
\text { Cinamaldeído [265] } \\
\text { Ácido Oleico [266] } \\
\text { Jucá (Libidibia ferrea) [267] } \\
\text { Líquens de Usnea [268] } \\
\text { Lavanda (Lavandula bybrida) } \\
{[269]} \\
\beta-C a r o t e n o ~[270] \\
\text { Linho (Linum usitatissimum) } \\
{[266,271]}\end{array}$ & $\begin{array}{l}\alpha \text {-Pineno [272] } \\
\text { D-Limoneno [273-274] } \\
\text { Hinokitiol [273-274] } \\
\text { trans-2-Hexenal [274] } \\
\text { Thujopsis dolabrata } \text { var. } \\
\text { bondae [275] } \\
\text { Oregão (Origanum vulgare) } \\
\text { [276] }\end{array}$ \\
\hline
\end{tabular}

d) Outras substâncias de origem natural (ou modificadas)

\begin{tabular}{|c|c|c|}
\hline $\begin{array}{l}\text { Lactulose [277] } \\
\text { Lecitina de Soja [278] }\end{array}$ & $\begin{array}{l}\text { Eritorbato de Sódio [278] } \\
\text { Lisina [216] }\end{array}$ & $\begin{array}{l}\text { Sericina de seda [279] } \\
\text { Lisozima [280] }\end{array}$ \\
\hline \multicolumn{3}{|c|}{ e) Monómeros e outros precursores químicos } \\
\hline $\begin{array}{l}\text { N-Isopropilacrilamida [281- } \\
\text {-282] } \\
\text { Ácido Acrílico [150, 283] } \\
\text { Ácido Metacrílico [284] }\end{array}$ & $\begin{array}{l}\text { Acrilatos vinílicos [284-286] } \\
\text { Estireno [216, 284, 287-288] } \\
\text { Acetato de vinilo [289] }\end{array}$ & $\begin{array}{l}\text { Anidrido maleico [290] } \\
\text { Silano-precursores [291-294] } \\
\text { Divinilbenzeno [295] }\end{array}$ \\
\hline
\end{tabular}

Por fim, refira-se que é também possível encontrar na literatura científica muitos outros trabalhos que visam a preparação de materiais sólidos/ 
semi-sólidos (híbridos ou compósitos), de base polimérica e/ou inorgânica, através da impregnação/deposição (usando a técnica SSI/SSD) de espécies químicas reactivas (como, por exemplo, monómeros, agentes de reticulação, precursores metálicos ou de óxidos metálicos, iniciadores, catalisadores, etc.) e da subsequente reacção que leva à formação de novos materiais (na superfície e/ou no interior das matrizes sólidas/semi-sólidas iniciais). Apesar de muitos destes trabalhos não visarem as aplicações biomédicas e farmacêuticas em particular, os princípios e alguns dos objectivos subjacentes a estas técnicas são, na sua essência, muito semelhantes. Por isso, apresentam-se igualmente alguns exemplos destas situações (Tabela $8.1 \mathrm{e}$ ).

Como já referido e como esperado, a grande maioria das matrizes sólidas/semi-sólidas que foram já processadas através da técnica SSI/ SSD para aplicações farmacêuticas e biomédicas são essencialmente matrizes de base polimérica, biodegradáveis ou não-biodegradáveis, quer de origem sintética quer de origem natural e/ou modificada. No entanto, existem já bastantes trabalhos publicados na literatura que descrevem a impregnação/deposição de aditivos pela técnica SSI/SSD em materiais cerâmicos/inorgânicos e em materiais compósitos (do tipo inorgânico/ polimérico, polimérico/polimérico e inorgânico/ inorgânico). Existem também já alguns trabalhos que aplicam as metodologias SSI/SSD no processamento de produtos acabados, i.e., de potenciais dispositivos médicos e produtos de combinação de base sólida/semi-sólida. Estes materiais sólidos/semi-sólidos já usados/estudados nas metodologias SSI/ SSD estão compilados na Tabela 8.2.

As matrizes sólidas a processar pela técnica SSI/SSD podem estar num estado perfeitamente seco, molhado/húmido ou pré-inchado num solvente (i.e., num estado semi-sólido), e apresentarem-se na forma de pós, micro- e nanopartículas, granulados, "pellets", filmes, espumas, fibras/fios, dispersões, géis, ou mesmo num qualquer outro formato tridimensional (já pré-formado). Assim, e como também já foi referido, as matrizes a processar podem também ser potenciais dispositivos médicos e produtos de combinação já pré-formados (de base polimérica, inorgânica ou compósita, como fios de sutura, lentes de contacto e intraoculares, pensos/"dressings" para feridas, implantes, etc. (Tabela 8.2 c). Além das 
outras vantagens já anteriormente referidas, existe ainda uma vantagem adicional no uso da técnica SSI/SSD para processar materiais/produtos já pré-formados: a incorporação dos aditivos pretendidos pode ser feita sem interferir com os métodos de síntese e processamento que levam à formação destes materiais e produtos.

Além disso, apesar de não existirem na literatura quaisquer referências específicas para este tipo de aplicações mas devido a natureza dos materiais envolvidos, a técnica de SSI/SSD poderá também apresentar um grande potencial para a incorporação homogénea ou heterogénea de aditivos (substâncias bioactivas ou de outra natureza e carácter funcional) noutros materiais e dispositivos médicos ainda não estudados como fitas cirúrgicas, agrafos, tubos e cateteres, "grafts" e "stents" cardiovasculares, peças/componentes de "pacemakers" e válvulas cardíacas, pregos, parafusos e placas ósseas, cimentos ósseos/dentários, peças/ componentes de implantes de anca, joelho e ombro, peças/componentes de implantes dentários, etc.

Tal como no caso dos FSCs, co-solventes e surfactantes, é preciso ter particular cuidado com a biocompatibilidade e segurança dos materiais que constituem as matrizes sólidas/semi-sólidas a usar e com a presença de quantidades residuais de quaisquer outras substâncias que sejam usadas na sua síntese/processamento (e.g., solventes, plastificantes e outras espécies químicas). Além disso, é preciso ter também em consideração os riscos e a toxicidade dos eventuais produtos de degradação, erosão e dissolução resultantes destas mesmas matrizes.

Além do conhecimento profundo de toda a legislação existente e de todos os procedimentos regulamentares específicos que se devem considerar, será também necessário averiguar junto das autoridades reguladoras competentes quais são as substâncias (poliméricas, inorgânicas e compósitas) que estão já aprovadas (ou proibidas) para uso em medicamentos, dispositivos médicos e produtos de combinação (e em que condições particulares é que podem ser utilizadas). Caso não existam ainda dados de segurança e de toxicidade/biocompatibilidade devidamente avaliados e comprovados, será então igualmente necessário que os fabricantes justifiquem adequadamente o seu uso, bem como avaliem aprofundadamente os riscos e segurança 
a ele associados, e tendo sempre em consideração o uso final pretendido e o tipo e tempo previsto de exposição/contacto biológico.

Assim e no caso das matrizes sólidas/semi-sólidas para aplicações farmacêuticas e biomédicas, há que distinguir três situações distintas: i) quando são usadas como excipientes, i.e., como ingredientes não-activos de um medicamento ou de um produto biológico; ii) quando constituem um dispositivo médico (ou fazem parte dele); e iii) quando constituem (ou fazem parte) de um produto de combinação.

No primeiro caso, i.e., no caso de serem ingredientes não-activos de um medicamento ou produto biológico, e de um ponto de vista regulatório, as matrizes sólidas/semi-sólidas devem obviamente ser tratadas como excipientes e deve-se assim verificar se estes materiais e o seu uso estão autorizados para as aplicações terapêuticas e formas finais de dosagem pretendidas $[2,4,8,10-14,16-19,22,25-28,62-63,85,193-194,196-$ -203]. Por exemplo e no caso dos EUA, isto pode também ser verificado junto da autoridade regulatória competente (FDA) e da IPEC-Americas ("International Pharmaceutical Excipients Council of the Americas"), que já estabeleceram também quais são os estudos não-clínicos necessários e que devem ser realizados de forma a obter a autorização para o uso e teste de novos excipientes. Situações e procedimentos relativamente semelhantes ocorrem e são necessários na UE (neste caso, com a EMA e a IPEC-Europe) e noutros países [370-374]. 
Tabela 8.2. Matrizes sólidas/semi-sólidas já usadas/estudadas em técnicas SSI/SSD e que podem ser usadas para potenciais aplicações farmacêuticas/ biomédicas.

a) Matrizes de base polimérica (de origem sintética, natural e/ou modificada)

\begin{tabular}{|c|c|}
\hline $\begin{array}{l}\text { o) (PP) } \\
\text { (PE) } \\
\text { le vinilo) (PVC) } \\
\text { (PS) e copolímeros de PS } \\
\text { o) (PC) } \\
\text { to de etileno) (PET) }\end{array}$ & $\begin{array}{l}{[37,211,235,238-239,243-244,246,} \\
248,275] \\
{[217,235,238,244,246-247,280]} \\
{[235,248,272-275]} \\
{[147,167,210,250,255-256,268,270,} \\
272-275,296] \\
{[272]} \\
{[260]} \\
{[147,212,235]} \\
{[164,206,257,291,297-299]} \\
{[37,140-141,144-146,159,174-177,20} \\
213] \\
{[221-223,230,241,250-251,300-302]} \\
{[163,212-213,215,218-219,231,242,} \\
252] \\
{[303]} \\
{[284-285,304-309]} \\
{[290,294,310-315]} \\
{[254,262,285,287,289,297-298,316-} \\
-323] \\
{[284,306,324]} \\
{[288,325-329]} \\
{[210,284,324,330-332]} \\
{[260,303,333-335]} \\
{[147,221,289,336]} \\
{[150,177,322,337-339]} \\
{[340-342]} \\
{[257,343-346]}\end{array}$ \\
\hline
\end{tabular}

b) Matrizes de base inorgânica

\begin{tabular}{|c|c|}
\hline $\begin{array}{l}\text { Materiais porosos à base de sílica (incluindo nano- } \\
\text { argilas) } \\
\text { Nanotubos de carbono } \\
\text { Outros materiais porosos inorgânicos }\end{array}$ & $\begin{array}{l}{[167,253,292,294,325,355-363]} \\
{[364-367]} \\
{[228,368-369]}\end{array}$ \\
\hline \multicolumn{2}{|l|}{ c) Produtos acabados comerciais } \\
\hline $\begin{array}{l}\text { Fios de sutura } \\
\text { Lentes intraoculares } \\
\text { Lentes de contacto } \\
\text { Implantes de anca e joelho } \\
\text { Pensos para feridas } \\
\text { Gazes de algodão } \\
\text { Dispositivos médicos de base silicone e uretano }\end{array}$ & $\begin{array}{l}{[156]} \\
{[176]} \\
{[145-146,174-175]} \\
{[254]} \\
{[267]} \\
{[263]} \\
{[299]}\end{array}$ \\
\hline
\end{tabular}


No caso de materiais sólidos/semi-sólidos para uso em dispositivos médicos, e devido à grande variedade de dispositivos médicos que podem ser considerados bem como os seus múltiplos fins, as situações e os procedimentos específicos a considerar podem aumentar bastante de complexidade. Na grande maioria dos casos, os materiais para estes fins são do tipo polimérico (que normalmente são designados como "plásticos") e, mesmo antes da realização de quaisquer ensaios clínicos posteriores, será sempre necessário que estes materiais sejam testados para a biocompatibilidade e para vários tipos de toxicidade, tanto para os materiais poliméricos individuais usados, como para os dispositivos acabados e para os aditivos neles incorporados. Por exemplo e no caso dos EUA, estes procedimentos/métodos foram claramente definidos pela FDA, a qual adoptou as Normas ISO-10993, Partes 1-20, em particular no que dizem respeito aos critérios de selecção dos testes de biocompatibilidade a serem realizados (e.g., citoxicidade, hemocompatibilidade, sensibilidade, toxicidade aguda/crónica, carcinogenicidade e genotoxicidade, degradabilidade, etc.) [375-376]. No entanto, muitos fabricantes destes tipos de dispositivos exigem aos seus fornecedores e/ou usam ainda os testes de biocompatibilidade estabelecidos pela USP ("United States Pharmacopeial Convention") para testarem estes dispositivos ou materiais (através da USP 26 NF1). Na realidade, a maioria destes testes são muito similares (senão iguais) aos requeridos pelas Normas ISO-10993, em particular no que diz respeito ao Capítulo 87 (referente a testes "in vitro") e ao Capítulo 88 (referente a testes "in vivo") [377]. Por exemplo e mais uma vez no caso de materiais poliméricos ("plásticos"), deve ser feita a certificação/classificação dos mesmos numa das classes definidas pela USP (i.e., como "plásticos" das Classes I-VI, e sendo a Classe VI a classe mais restritiva - e por conseguinte exigindo níveis de segurança maiores) e tendo em conta o uso final pretendido, o tipo e tempo de exposição/contacto biológico (limitado, prolongado ou permanente.

Já na Europa, o uso de materiais sólidos/semi-sólidos para uso em dispositivos médicos deve ser enquadrado nas várias "guidelines" MEDDEV e Directivas Europeias que regulam o seu uso e desenvolvimento, incluindo 
a Certificação de acordo com as regras de marcação CE [9, 10, 13, 18, 22, 24-26, 63, 378-379].

Tal como no caso do ICH (para medicamentos), foram e estão a ser desenvolvidos esforços internacionais no sentido de se conseguir uma harmonização regulatória para a área dos dispositivos médicos, primeiro com a "Global Harmonization Task Force on Medical Devices" (GHTF), e mais recentemente com a "International Medical Device Regulators Forum" (IMDRF) [380].

Existem também algumas bases de dados que podem ser consultadas e que compilam informação relevante e descrevem muitos materiais que podem ser usados no desenvolvimento de dispositivos biomédicos (já aprovados ou com potencial para o serem). De entre estas, podemos referir a base de dados "online" de materiais médicos da ASM International [381], que inclui dados e outra informação relevante acerca de potenciais aplicações biomédicas para determinados materiais, das suas propriedades químicas, físicas e biológicas (incluindo as de biocompatibilidade), de critérios de selecção de materiais para fins biomédicos, de métodos de teste e avaliação, de estratégias de “design" de produtos, de submissão de propostas para autorização de mercado, etc.).

Por fim, e para os materiais de suporte sólidos que podem usados no desenvolvimento de produtos de combinação através dos métodos SSI/SSD, há que ter em conta as já anteriormente referidas especificidades associadas aos produtos de combinação, isto é e em termos muitos gerais, será primeiramente necessário ter em consideração qual é o Modo de Acção Primário" (PMOA, do inglês "Primary Mode of Action") do produto de combinação em análise (se será um sistema terapêutico/medicamento, se será um produto biológico, ou se será um dispositivo médico). Só depois de se fazer esta avaliação e classificação é que será possível definir qual a jurisdição competente e o procedimento regulatório adequado que os materiais sólidos/ semi-sólidos devem seguir para a sua avaliação/aprovação junto da FDA (e/ou da EMA, e de acordo com o já antes referido para cada um destes casos) [382]. 


\subsection{Optimização das técnicas de impregnação/deposição usando solventes supercríticos (SSI/SSD).}

Como já foi brevemente referido, as interacções físico-químicas que se estabelecem entre todas as substâncias presentes num determinado sistema acabam por ser as principais responsáveis, de forma directa ou indirecta, pelo sucesso (ou pelo insucesso) relativo dos processos SSI/ SSD que se pretendam desenvolver. Isto acontece porque, e em termos muitos gerais, o rendimento final de incorporação dos aditivos pretendidos nas matrizes sólidas ou semi-sólidas em processamento, bem como algumas das propriedades físicas finais destes sistemas, são fortemente dependentes destas interacções físico-químicas específicas que existem e/ou que se podem estabelecer entre FSCs, aditivos, matrizes sólidas/ semi-sólidas, co-solventes ou outras substâncias, e, principalmente, das suas magnitudes/intensidades relativas.

Estas interacções físico-químicas (muitas vezes também chamadas de forças intermoleculares) dependem obviamente das funcionalidades químicas específicas existentes nas moléculas das substâncias presentes no sistema, e podem ser de vários tipos: i) interacções electroestáticas de van der Waals: dipolo-permanente/dipolo-permanente (ou forças de Keesom), dipolo-permanente/dipolo induzido (ou forças de Debye), e dipolo-induzido/dipolo-induzido (ou forças de dispersão de London); ii) interacções electroestáticas envolvendo iões: ião-dipolo, ião-dipolo induzido; e ii) ligações de hidrogénio (ou "pontes" de hidrogénio). De uma forma genérica e uma vez que a magnitude relativa destas interacções vai depender muito das moléculas particulares que estão envolvidas e da sua estereoquímica, pode-se dizer que, dos tipos de interacções acima descritos, as interacções mais fortes são normalmente as ligações de hidrogénio e as interacções ião-dipolo e ião-dipolo induzido, seguidas pelas ligações dipolo-permanente/dipolo-permanente e, finalmente, pelas interacções dipolo-permanente/dipolo induzido e dipolo-induzido/dipolo-induzido.

O estabelecimento destas interacções (favoráveis ou desfavoráveis, i.e., de atracção ou de repulsão) irá, em primeiro lugar, determinar a 
compatibilidade e as solubilidades mútuas das espécies presentes (i.e., equilíbrio de solubilidade de aditivos no FSC ou na mistura de fluidos comprimidos, equilíbrio de absorção do FSC ou da mistura de fluidos comprimidos nas matrizes sólidas/semi-sólidas, e equilíbrio de adsorpção dos aditivos nas matrizes sólidas/semi-sólidas), os coeficientes de partição finais dos aditivos entre a fase sólida/semi-sólida e a fase fluida, e algumas propriedades termofísicas e de transporte da fase fluida. Além da natureza e magnitude das interacções físico-químicas específicas, têm ainda que se considerar outros factores relevantes (como a já referida estereoquímica) e outras propriedades físicas como as propriedades morfológicas e de superfície (e.g., a composição química superficial e a área de superfície, a porosidade, os diâmetros de poros das matrizes sólidas, etc.) dos compostos e materiais sólidos envolvidos, e que podem ter igualmente papel muito importante na eficiência global do processo SSI/SSD. Algumas propriedades termofísicas e de transporte das fases fluidas presentes no sistema (FSCs ou líquidos/gases comprimidos) como sejam, por exemplo, a densidade, polaridade (i.e., momento dipolar), polarizabilidade, tensão superficial, difusividade e viscosidade, poderão ser também cruciais para o sucesso/insucesso dos métodos SSI/SSD na incorporação de aditivos em matrizes sólidas/semi-sólidas para aplicações farmacêuticas e biomédicas.

No entanto, muitas destas propriedades podem ser manipuladas e ajustadas através do controlo de algumas condições operacionais, como sejam a temperatura, a pressão e a adição de co-solventes, surfactantes ou de outros aditivos/substâncias (e a respectiva composição relativa). Desta forma e em primeiro lugar, pode-se actuar sobre a densidade da fase fluida e sobre o grau de solvatação dos solutos (e logo sobre a solubilidade dos aditivos no FSC ou na mistura de fluidos comprimidos), sobre a polaridade da fase fluida e sobre algumas das interacções físico-químicas existentes entre as espécies presentes no sistema (e logo sobre a solubilidade de aditivos no FSC ou na mistura de fluidos comprimidos, sobre a solubilidade do FSC (ou mistura de fluidos comprimidos) nas matrizes sólidas/semi-sólidas, e sobre os processos de adsorpção/desorpção, i.e., sobre a "solubilidade" dos aditivos nas matrizes). Em segundo lugar, 
a manipulação das acima referidas condições operacionais permite ainda actuar sobre algumas das propriedades de transporte da fase fluida, as quais podem afectar a difusão da fase móvel para o interior das matrizes sólidas/semi-sólidas (ou, pelo contrário, do interior das matrizes para o exterior) e, desta forma, condicionar a velocidade global do processo de impregnação/deposição e até o grau de plastificação e de intumescimento/contracção ("swelling/deswelling") dessas mesmas matrizes (nos casos em que estes fenómenos possam acontecer). Isto permite, por exemplo, controlar os graus de profundidade e de homogeneidade pretendidos para a incorporação do aditivo.

Por fim, convém referir que existem ainda outras condições do processo, como o tempo de operação e a velocidade de despressurização, que podem ser também muito relevantes para a eficiência global do processo SSI/SSD, uma vez que o seu adequado controlo poderá facilitar/impedir que se atinjam determinadas condições de equilíbrio específicas (e.g. solubilidades de aditivos no FSC, do FSC nas matrizes e equilíbrio de adsorpção/desorpção aditivos/matrizes), bem como alterar a morfologia dos aditivos sólidos depositados (precipitados) e da própria matriz sólida/ semi-sólida, incluindo a sua integridade dimensional.

Todos estes aspectos e situações têm sido abundantemente descritos, discutidos e compilados na literatura, em termos teóricos e experimentais, e tanto para os métodos SSI/SSD em geral, como para os sistemas particulares que foram sendo estudados ao longo dos últimos anos. [38, 40, 128-129, 134-137, 140-164, 170-171, 174-175, 177, 211-218, 222-224, 228-232, 251, 253, 259, 261, 264, 267, 284, 288, 296-297, 300, 302, 312, $317,327,330,332-334,357,383-404]$.

De seguida, ir-se-ão abordar com mais detalhe os diferentes tipos de interacções físico-químicas que estão normalmente envolvidos nos processos SSI/SSD (Figura 8.3) e, e em particular e pelos motivos já antes referidos, para os sistemas que usam o $\mathrm{scCO}_{2}$ como FSC. Serão também referidos alguns métodos experimentais que podem ser usados para medir e correlacionar algumas das propriedades mais relevantes para o processo bem como para medir/inferir algumas das interacções físico-químicas (e respectivas intensidades relativas) que se estabelecem no processo. 

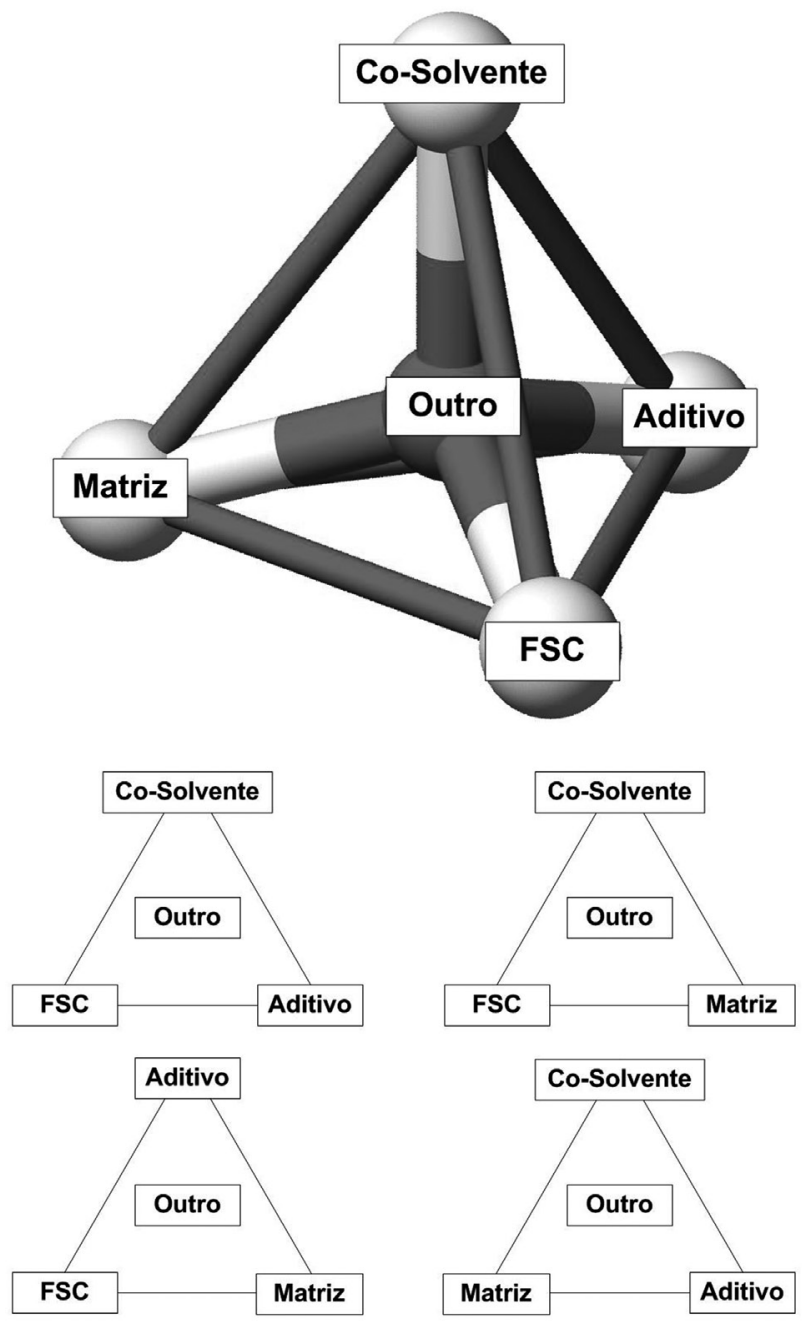

Figura 8.3. Diferentes interacções que se podem estabelecer entre todas as substâncias presentes nos métodos SSI/SSD.

\subsubsection{Interacções FSC/aditivo/co-solvente/outro composto}

Como já foi referido e para garantir elevados rendimentos no processo SSI/SSD, os aditivos a incorporar nas matrizes sólidas/semi-sólidas devem ter uma solubilidade relativamente elevada no FSC a ser usado no processo 
(ou numa mistura de fluidos comprimidos). Sendo assim e para que isto seja possível, as interacções físico-químicas que se devem estabelecer entre o FSC (ou a mistura de fluidos comprimidos), o(s) co-solvente(s), os aditivos e outras substâncias presentes no sistema devem ser bastante favoráveis, e uma vez que serão elas que, de alguma forma, irão controlar a solubilidade dos aditivos na fase fluida móvel a alta pressão.

No caso da fase fluida móvel ser constituída essencialmente por $\mathrm{scCO}_{2}$, é preciso ter em consideração que se trata de uma substância de baixo peso molecular, apolar (i.e., sem momento dipolar permanente, apesar de poder apresentar um momento quadrupolar permanente apreciável), com uma baixa constante dieléctrica e de baixa polarizabilidade (semelhante à do metano). $\mathrm{O} \mathrm{scCO}_{2}$ é geralmente considerado como um ácido de Lewis fraco (i.e., um receptor de par de electrões, ou electrófilo). Esta é, sem dúvida, a sua característica dominante e que faz com que o $\mathrm{scCO}_{2}$ interaja preferencialmente com moléculas contendo grupos do tipo base de Lewis fraca (i.e., dadores de par de electrões, ou nucleófilos): No entanto, o seu quadrupólo permanente pode fazer com que, em certas situações, o $\mathrm{scCO}_{2}$ se possa comportar também como uma base de Lewis fraca. Isto acontece devido à deslocalização de electrões para os átomos de oxigénio exteriores da molécula e à consequente separação de cargas parciais entre o átomo de carbono central (que se comportará como um ácido de Lewis fraco, com carga parcial positiva) e os dois átomos externos de oxigénio, que se comportarão como bases de Lewis fracas (com cargas parciais negativas) [38, 40, 98, 128-129, 134, 137, 142, 148, 150-164, 383-404].

Por tudo isto, $\mathrm{o} \mathrm{scC}_{2}$ conseguirá estabelecer interacções favoráveis (e terá a capacidade para as dissolver) com aditivos de peso molecular relativamente baixo (tipicamente menores que 500-600 g/mol), que sejam genericamente apolares (ou de baixa polaridade), e que contenham preferencialmente também grupos pouco polares e/ou do tipo base de Lewis fraca. Estes grupos funcionais são normalmente do tipo fenilo, metilo, etilo, carbonilo, éster ou fluoro. $\mathrm{O}_{\mathrm{scCO}}$ pode também estabelecer algumas interacções físico-químicas favoráveis (embora não tão intensas) com grupos do tipo ácido carboxílico e amina (com grupos primários, secundários ou terciários). No entanto, existe um grande risco de ocorrência 
de reacções químicas (reversíveis ou irreversíveis) com as alquilaminas (ou com outras aminas) e que podem levar à formação de carbamatos ou de ácidos carbâmicos (em particular com moléculas contendo grupos amina primários e/ou secundários) [38, 349, 405-407].

Como já várias vezes referido e para aplicações farmacêuticas e biomédicas, estas interacções (e consequentemente a solubilidade dos aditivos no $\mathrm{scCO}_{2}$ ) podem ser incrementadas através da adição quantidades relativamente pequenas de co-solventes que apresentem baixos riscos de toxicidade e que sejam mais polares que o $\mathrm{scCO}_{2}$, que tenham volatilidades apreciáveis e pesos moleculares relativamente baixos como, por exemplo: água, etanol, isopropanol, acetona, ácido acético e acetato de etilo. Devido ao facto de serem usados em quantidades relativamente baixas, estes co-solventes deverão ser ainda completamente miscíveis na fase fluida (de $\mathrm{scCO}_{2}$ ) e irão assim provocar um ligeiro aumento da polaridade desta fase, bem como promover o estabelecimento de novas interacções favoráveis (ou aumentar as já existentes) com aditivos contendo grupos hidroxilo, carbonilo, ácido carboxílico, amina, éster e fluoro. Convém salientar que, por exemplo, as estruturas típicas da maioria dos fármacos de baixo peso molecular contêm estes tipos de grupos funcionais, pelo que as suas solubilidades em fases móveis contendo $\mathrm{scCO}_{2}$ podem assim ser facilmente aumentadas usando estas estratégias e este tipo de co-solventes.

Por outro lado, o uso de pequenas quantidades de surfactantes (normalmente de peso molecular relativamente baixo e de baixo risco de toxicidade) também pode ser considerado para os mesmos fins ou, em alternativa, para promover a formação de emulsões (ou de microemulsões) de aditivos insolúveis ou com baixa solubilidade em scCO2. Como possíveis exemplos de surfactantes comuns, de biocompatibilidade comprovada, e com potencial para serem usados em aplicações biomédicas e farmacêuticas, podem-se referir os polisorbatos (e.g, Tween 60 e Tween 80), os poloxâmeros (e.g, Pluronics e Kollophor) e as fosfatidilcolinas (como a lecitina de ovo ou de soja).

Os possíveis efeitos das outras variáveis de processo nestas interacções (como sejam a temperatura, pressão, tempo de operação e velocidade de despressurização) e na eficiência global do processo SSI/SSD foram 
já brevemente discutidos anteriormente (na introdução da Secção 8.5.), enquanto a influência da presença de outros compostos no sistema será discutida mais adiante, na Secção 8.5.3.

Devido à grande complexidade destes sistemas e ao tipo de medidas que se pretendem realizar, é extremamente difícil determinar e quantificar todas as interacções mútuas que se estabelecem entre aditivos, FSC (ou mistura de fluidos comprimidos), co-solvente e outras substâncias que se pretendam usar num processo SSI/SSD, bem como a sua dependência das variáveis de processo (em particular da pressão, temperatura e composição). No entanto, e como alternativa o como complemento a esta determinação experimental, podem-se efectuar cálculos teóricos (usando vários modelos e teorias) e/ou usar métodos de simulação molecular e métodos computacionais ab initio, de Quantum Monte Carlo, etc. [408-416].

Assim, este tipo de interacções físico-químicas são normalmente inferidas indirectamente através de outros tipos de medidas experimentais, i.e., através das medidas de outras propriedades termofísicas, nomeadamente aquelas cujo conhecimento é indispensável para definir as condições operacionais dos processos SSI/SSD: medidas de solubilidade e de equilíbrio de fases a altas pressões entre aditivos, FSC (ou mistura de fluidos comprimidos), co-solventes ou outras substâncias presentes no sistema. Apesar destas medidas também poderem ser relativamente difíceis de realizar (além de poderem ser dispendiosas e morosas), elas são na realidade extremamente importantes para o sucesso dos processos SSI/SSD (bem como para outras metodologias envolvendo FSCs e misturas fluidas a alta pressão) e devem ser efectuadas em gamas adequadas de pressão, temperatura e composição (as chamadas medidas de equilíbrio $P, T, x$, $y$ ). Conforme o tipo de fases presentes (ou que se possam formar), estas medidas podem ser do tipo: equilíbrio líquido-vapor (ELV); equilíbrio líquido-líquido (ELL); equilíbrio líquido-líquido-vapor (ELLV); equilíbrio sólido-líquido (ESL); e equilíbrio sólido-vapor (ESV). Isto pode ser feito usando vários métodos e técnicas experimentais, de base sintética ou analítica, e através de métodos estáticos/descontínuos ou dinâmicos/ contínuos. Além da necessidade de obtenção de dados de equilíbrio de fases, na maioria dos casos existe ainda a necessidade de correlacionar 
os dados experimentais obtidos (e normalmente para que se possa evitar a realização de muitos ensaios experimentais de equilíbrio). Esta correlação pode ser feita através: i) de modelos empíricos (ou semi-empíricos) baseados na densidade da fase fluida, como sejam os modelos de Chrastil, de Bartle, de Méndez-Santiago-Teja, etc.; ii) de modelos baseados em equações de estado cúbicas, como sejam as equações de Peng-Robinson (PR), Soave-Redlich-Kwong (SRK), Patel-Teja-Valderrama (PTV), etc., e usando diferentes regras de mistura (van der Waals, Panagiatopoulos-Reid, Mukhopadhyay-Rao, Wong-Sandler, etc.) e de combinação; iii) e de outros modelos teóricos como sejam equações de estado não-cúbicas, modelos baseados nas teorias de associação de fluidos, em coeficientes de actividade, na teoria das soluções regulares e no modelo de Flory-Huggins, etc.) $[38,40-41,45-46,49-53,56,417-432]$.

A grande maioria dos modelos empíricos/teóricos e os dados experimentais de solubilidade e de equilíbrio de fases de aditivos (e co-solventes) em sistemas a alta pressão (FSCs e misturas de fluidos comprimidos), bem como a sua respectiva correlação através dos vários modelos acima referidos, são normalmente publicados em revistas científicas das áreas da termodinâmica, química-física, propriedades termofísicas, equilíbrio de fases, engenharia química e fluidos supercríticos, como por exemplo: Journal of Chemical \& Engineering Data, Journal of Physical and Chemical Reference Data, Fluid Phase Equilibria, Journal of Chemical Thermodynamics, Termochimica Acta, Industrial \& Engineering Chemistry Research, Chemical Engineering Science, Journal of Supercritical Fluids, etc. Existem ainda excelentes livros, compilações de dados de equilíbrio de fases e artigos de revisão sobre todos estes assuntos, incluindo os métodos experimentais de determinação de equilíbrio de fases a altas pressões [56, 417, 421-423, 435-445].

\subsubsection{Interacções FSC/matriz/co-solvente/outro composto}

Tal como no caso anterior (para as interacções FSC/aditivo/co-solvente/ outro composto), as interacções FSC/matriz/co-solvente/outro composto 
vão ser também muito importantes para o sucesso ou insucesso relativo dos processos SSI/SSD no desenvolvimento de aplicações farmacêuticas e biomédicas. Se nos casos descritos na Figura 8.1 A), e onde as matrizes sólidas não conseguem absorver grandes quantidades de FSCs (ou de misturas de fluidos comprimidos), estas interacções não sejam muito importantes, elas irão ser fundamentais para todos os outros casos onde isso seja possível de acontecer.

Como seria de esperar, estas interacções físico-químicas (e as suas intensidades relativas) vão essencialmente depender dos grupos constituintes e da estereoquímica de todas as moléculas presentes. A estereoquímica pode ainda desempenhar um papel adicional muito relevante nas matrizes sólidas/semi-sólidas (de base polimérica) uma vez que poderá alterar algumas das propriedades físicas destas matrizes, as quais podem, por sua vez, condicionar o processo SSI/SSD. No entanto, outros factores poderão ser igualmente relevantes para estas interacções e para a eficiência global do processo, como sejam: algumas das propriedades termofísicas específicas (tanto da matriz sólida/semi-sólida como da fase fluida); determinadas propriedades morfológicas e de superfície (especialmente relevantes para as matrizes sólidas/semi-sólidas); as condições de operação (temperatura, a pressão e a adição de co-solventes, surfactantes ou de outros aditivos/ substâncias - e respectiva composição relativa - tempo de operação e velocidade de despressurização).

Assim, todos os factores acima referidos irão determinar, em conjunto, vários aspectos e situações que podem ocorrer num processo SSI/SSD (bem como o seu grau relativo de extensão), como sejam: i) a solubilidade do FSC (ou da mistura de fluidos comprimidos) e do co-solvente na matriz sólida/semi-sólida (e o grau de absorção/solubilização); ii) a solubilidade da matriz sólida no FSC (ou na mistura de fluidos comprimidos), i.e., se a matriz sólida se consegue dissolver na fase fluida e em que extensão é que isto pode acontecer; iii) se a matriz sólida consegue sofrer um intumescimento ou se, pelo contrário, sofre antes uma contracção de volume (e em que grau é que estes processos podem ocorrer); iv) se a matriz sólida/semi-sólida pode "fundir" e ficar num estado de "líquido viscoso" por acção da absorção e solubilização da fase fluida móvel; e v); se uma 
matriz semi-sólida (já pré-inchada por outro soluto) pode sofrer um intumescimento adicional (ou se, pelo contrário, pode sofrer uma contracção de volume), por absorção difusão e solubilização da fase fluida móvel. Todas estas situações, propriedades e fenómenos envolvidos, bem como as justificações para os resultados até aqui obtidos, têm sido apresentadas, discutidas e compiladas na literatura ao longo dos últimos anos, tanto para o método SSI/SSD em geral, como para os casos particulares que foram estudados $[33-38,40-41,45,48-50,52,98,113-120,128-129,134$, 137, 140-172, 174-177, 204-206, 209-215, 221-224, 230-234, 236-251, 255-257, 284-290, 296, 303, 330, 332, 334, 383-404, 410-413, 438-441, 444-450].

Em resumo e para as condições normalmente exigidas num processo SSI/SSD, as interacções FSC/matriz/co-solvente/outro composto devem ser bastante favoráveis uma vez que, desta forma, podem permitir e/ou facilitar que ocorram os fenómenos de absorção, difusão e solubilização da fase fluida móvel (contendo o aditivo) no interior das matrizes sólidas/ semi-sólidas a processar. Para as matrizes sólidas onde estes processos sejam possíveis (como é o caso de muitos materiais poliméricos), estas interacções (e algumas variáveis operacionais) vão assim também afectar o grau de intumescimento/contracção e o nível de plastificação das matrizes, bem como os processos/velocidades de difusão da fase fluida móvel para o interior das mesmas (facilitando assim o transporte e incorporação dos aditivos nela dissolvidos) ou do interior das matrizes para o exterior (durante a despressurização). No entanto, as interacções que se estabelecem não devem ser tão favoráveis e intensas que possam levar à dissolução (total ou parcial) das matrizes sólidas/semi-sólidas nos FSCs (ou nas misturas de fluidos comprimidos), nem que possam promover graus de absorção e de plastificação tão elevados que façam com que ocorra a "fusão" do material sólido às condições de temperatura e pressão do processo. Uma maneira relativamente simples de evitar ou limitar estas situações, e também usada para outros solventes e/ou outras aplicações, consiste em usar polímeros de peso molecular muito elevado, e em modificar quimicamente (alterando o tipo e a intensidade das interacções que se podem estabelecer) e/ou em reticular estes materiais (através de ligações covalentes ou de fortes interacções físicas). 
No caso da fase fluida móvel ser constituída essencialmente por $\mathrm{scCO}_{2}$ é preciso ter em consideração o que já foi antes referido na Secção 8.5.1, nomeadamente em relação à sua polaridade, polarizabilidade e baixo peso molecular, bem como no que isto poderá influenciar em termos das interacções que $\mathrm{O} \mathrm{scCO}_{2}$ pode estabelecer com todas as outras substâncias presentes. Neste caso, essas substâncias serão as matrizes sólidas/ semi-sólidas em processamento (normalmente de base polimérica), bem como eventuais co-solventes, ou outros compostos presentes no sistema. Assim, e sendo essencialmente uma substância apolar e um ácido de Lewis fraco, o $\mathrm{scCO}_{2}$ irá interagir mais favoravelmente com polímeros de peso molecular relativamente baixo, que contenham grupos tipicamente apolares (e.g., fenilo, metilo, etilo), grupos com características de bases de Lewis fracas (e.g., carbonilo, éster), ou grupos organofluorados (i.e., com ligações C-F). Estes factos justificam, por exemplo, os diferentes polímeros já estudados na técnica SSI/SSD e que vêm indicados na Tabela 2. Uma situação ligeiramente diferente envolve os polímeros pertencentes à família dos poli(siloxanos) que, para além das interacções favoráveis que podem ser estabelecidas com o $\mathrm{scCO}_{2}$ (e.g., grupos metilo, etilo), têm ainda cadeias poliméricas("backbones") -Si-O-Si- muito mais "flexíveis" e com maior "mobilidade" que as cadeias -C-C-C- da maioria dos polímeros. Assim, ao interagirem muito favoravelmente com o $\mathrm{scCO}_{2}$ e ao absorverem grandes quantidades da fase fluida móvel, conseguem mesmo ser solúveis em $\mathrm{scCO}_{2}$ em quantidades apreciáveis. Como isto é indesejável para o processo SSI/SSD, esta potencial dissolução em $\mathrm{scCO}_{2}$ pode ser normalmente evitada através, por exemplo, da modificação química destes polímeros (e.g., reticulação covalente).

Finalmente, e por oposição ao que foi acima referido, isto é, devido aos seus pesos moleculares normalmente muito elevados, devido à presença de muitos grupos polares e com fraca interacção com o scCO $\mathrm{CO}_{2}$ (normalmente grupos funcionais do tipo hidroxilo, ácido carboxílico, amina ou amida) e à ausência de outras interacções mais favoráveis com o $\mathrm{scCO}_{2}$, os polissacarídeos e as proteínas são praticamente insolúveis em $\mathrm{scCO}_{2}$ e não possuem a capacidade para absorverem grandes quantidades de $\mathrm{scCO}_{2} \mathrm{e}$, desta maneira, de adquirirem elevados níveis 
de intumescimento e de plastificação. Apesar disto, é possível melhorar este comportamento dos polissacarídeos e das proteínas em contacto com $\mathrm{scCO}_{2}$ usando as mesmas estratégias que se usam para aumentar a solubilidade de aditivos numa fase móvel constituída por $\mathrm{scCO}_{2}$, i.e., com a adição de pequenas quantidades de co-solventes mais polares e com a capacidade de interagirem favoravelmente com os biopolímeros em processamento, usando biopolímeros de peso molecular mais baixo ou, alternativamente, modificando quimicamente estes biopolímeros através da introdução de grupos funcionais que interajam mais favoravelmente com o scCO2 [143, 258, 261].

Além da já referida forte influência que a estrutura química e o peso molecular dos polímeros usados podem ter no processo SSI/SSD, deve ainda referir-se que outras propriedades destes materiais podem igualmente ter um grande efeito no processo, como por exemplo: morfologia e microestrutura, grau de cristalinidade, índice de polidispersão, estrutura (linear, ramificada, tipo-estrela, tipo e tamanho de grupos pendentes, etc.), estereoquímica e tacticidade, grau de ramificação e de reticulação, etc. [154].

Em termos gerais, os efeitos da adição de pequenas quantidades de co-solventes nas interacções FSC/matriz/co-solvente/outro composto na eficiência global do processo SSI/SSD são muito semelhantes aos efeitos já descritos para as interacções FSC/aditivo/co-solvente/outro composto (Secção 8.5.1) e devem ser tomados em atenção considerando agora também as funcionalidades químicas específicas existentes nas matrizes sólidas/semi-sólidas em processamento. Por outro lado, os efeitos das variáveis de processo nestas interacções e no processo global SSI/SSD também já foram brevemente discutidos anteriormente na introdução desta secção (Secção 8.5). Quer isto dizer que estratégias operacionais semelhantes às aí referidas podem ser igualmente adoptadas com o objectivo de melhorar as interacções FSC/matriz. Por fim, a presença de outros compostos no sistema será discutida na próxima secção (Secção 8.5.3).

Tal como no caso da determinação e quantificação das interacções mútuas que se estabelecem entre aditivos, FSCs (ou mistura de fluidos comprimidos), co-solventes e outras substâncias que se pretendam usar num processo SSI/SSD, também é bastante difícil medir e quantificar as 
interacções que se estabelecem entre os FSCs, as matrizes, os co-solventes e outras substâncias presentes no sistema. Mas existem várias técnicas (a alta pressão) que permitem obter esta informação de uma forma quase directa ou, alternativamente, que permitem inferi-las a partir da medida de outras propriedades, tais como sejam: métodos de queda de pressão e de aumento de volume por absorção de gases (dilatometria), métodos gravimétricos simples de desorpção; outros métodos gravimétricos de sorpção/desorpção (microbalanças de suspensão magnética, microbalanças de cristal de quartzo, etc.), métodos de ressonância magnética nuclear (RMN), métodos cromatográficos, métodos de espectroscopia (UV/vis ou de infravermelhos: de Raman, NIR ou de transformada de Fourier - FTIR), métodos de microscopia confocal, calorimetria, etc. [40, 127-129, 137, 142, 151-153, 156, 159-160, 162-169, 211-212, 218, 222-224, 296, 300, 312, 317, 319, 330, 332, 334, 389-391, 393-394, 396-398, 400-404, 412-413, 449-450].

Também nestes casos será possível efectuar cálculos teóricos e/ou usar métodos de simulação molecular dinâmica para determinar e aferir estas propriedades e interacções, bem como para correlacionar os dados experimentais obtidos. De entre os modelos teóricos que podem ser usados para estes fins, devem-se referir: i) modelos empíricos de sorpção ("dual mode"); ii) modelos baseados em equações de estado cúbicas; iii) equações de estado baseadas em teorias de estrutura de rede ("lattice-fluid"), como seja as equação de Sanchez-Lacombe, bem como as suas posteriores modificações (modelos NRHB, QCHB, NELF); iv) equações de estado baseadas em modelos "off-lattice" (e.g., PHSC, SAFT, PC-SAFT); e v) modelos de plastificação de polímeros (como os modelos de Condo ou de "lattice-fluid", e as suas combinações com as teorias de Gibbs-DiMarzio). A grande maioria dos dados/modelos teóricos, experimentais e de correlação que podem ser obtidos para este tipo de interacções são normalmente publicados nas mesmas revistas científicas já referidas na Secção 8.5.1., ou em outros livros de referência, compilações de dados de equilíbrio de fases e artigos de revisão sobre todos estes assuntos. Deve-se salientar que uma dificuldade associada ao uso destes modelos é a necessidade de estimar algumas propriedades termofísicas das substâncias envolvidas no sistema, e uma vez que estes valores não foram 
medidos experimentalmente [38, 40-41, 45, 50, 52, 129, 137, 142, 154-155, 162, 170, 386-388, 396-402, 417-420, 451-469].

\subsubsection{Interacções aditivo/matriz/FSC/outro composto e interacções aditivo/matriz/co-solvente/outro composto}

Em termos gerais, as interacções aditivo/matriz/FSC/outro composto e aditivo/matriz/co-solvente/outro composto, bem como as suas intensidades relativas, vão essencialmente afectar a "solubilidade" do aditivo na matriz sólida/semi-sólida em estudo e o seu coeficiente de partição entre a matriz e a fase fluida móvel (geralmente constituída por um FSC - ou por uma mistura de fluidos comprimidos - contendo o aditivo - ou o aditivo e um co-solvente - nela dissolvidos). Como nos casos já anteriormente discutidos, estas interacções físico-químicas (e as suas intensidades relativas) vão depender essencialmente do tipo e número de grupos funcionais constituintes (e da estereoquímica) de todas as moléculas presentes. Mas e nestas situações específicas, as propriedades morfológicas e de superfície das matrizes sólidas/semi-sólidas, i.e., as propriedades químicas e físicas das suas superfícies vão desempenhar um papel muito mais importante do que anteriormente. E, como também já discutido antes, as condições de processo (temperatura, pressão, adição de co-solventes, presença de outros aditivos/substâncias, tempo de operação e velocidade de despressurização) podem também ter muita influência no rendimento final do processo.

Em primeiro lugar, e nas condições específicas de processamento, se as interacções específicas entre o aditivo e a matriz forem muito mais favoráveis e intensas que as interacções aditivo/FSC (Secção 8.5.1), então o aditivo terá uma maior tendência a ficar incorporado no seio (ou na superfície) da matriz sólida/semi-sólida, i.e., o seu coeficiente de partição entre a matriz e a fase fluida móvel será relativamente elevado. Por exemplo, isto explica porque é que determinados aditivos, que apresentam solubilidades relativamente baixas em $\mathrm{scCO}_{2}$ (ou em misturas $\mathrm{scCO}_{2} / \mathrm{co}$ -solvente), conseguem ser impregnados/depositados em matrizes sólidas/ 
semi-sólidas através do método SSI/SSD: simplesmente porque os aditivos interagem muito favoravelmente com a matriz [40, 126, 142-147, 174-177].

Se, por outro lado, as interacções entre o aditivo e o FSC (ou a mistura de fluidos comprimidos) forem muito mais favoráveis e intensas que as interacções entre o aditivo e a matriz então, e o aditivo terá uma maior tendência para não ser impregnado/depositado e em permanecer dissolvido na fase fluida móvel, i.e., terá um baixo coeficiente de partição entre a matriz e a fase fluida móvel. Além disso e durante a despressurização, o aditivo tenderá preferencialmente a manter-se na fase fluida, sendo removido conjuntamente com o FSC ou sendo precipitado noutros pontos do sistema que não as matrizes sólidas/semi-sólidas em processamento. Esta é a situação típica que acontece quando os aditivos têm uma muito elevada solubilidade no FSC (ou na mistura de fluidos comprimidos) e uma baixa compatibilidade com as matrizes a serem processadas: assim, e apesar de se esperarem elevados rendimentos de impregnação/ deposição, tal não irá acontecer porque os aditivos optam sempre por permanecer na fase fluida móvel [40, 126, 142-147, 174-177].

No entanto, e tal como nos casos já anteriormente vistos, estas duas situações podem ser substancialmente alteradas devido às interacções adicionais que podem ser estabelecidas através da adição de um-solvente (ou até de um anti-solvente). Por exemplo, o co-solvente (ou o anti-solvente) usado pode alterar as interacções aditivo/FSC inicialmente existentes (e assim alterar a solubilidade do aditivo na fase fluida móvel) e/ou as interacções aditivo/matriz (no caso de estabelecerem interacções favoráveis e de serem também solúveis na matriz sólida/semi-sólida). Além disso, a presença de outras substâncias no sistema como sejam, por exemplo, outros solventes usados para pré-inchar matrizes semi-sólidas a serem processadas, podem também desempenhar um papel relevante no processo uma vez que poderão alterar substancialmente as interacções aditivo/matriz (e assim alterar a "solubilidade" do aditivo na matriz) ou, no caso de serem também solúveis no FSC, as interacções aditivo/FSC (e assim alterar a solubilidade do aditivo no FSC). Por fim e também no caso de matrizes semi-sólidas em contacto com uma fase fluida móvel de $\mathrm{scCO}_{2}$, mas estando estas pré-inchadas com água (como, por exemplo, 
no caso hidrogéis de base polimérica ou de base inorgânica), um outro fenómeno importante pode acontecer e que poderá ter muita influência na impregnação/deposição dos aditivos nessa mesma matriz: o scCO ${ }_{2}$ ir-se-á dissolver nesta matriz semi-sólida e também na água que a constitui (devido à elevada solubilidade do $\mathrm{scCO}_{2}$ em água). Desta forma, o $\mathrm{scCO}_{2}$ irá alterar a polaridade e as interacções no seio da matriz, além de poder alterar, por vezes drasticamente, o valor do $\mathrm{pH}$ local do sistema (baixando-o, através da formação de ácido carbónico). Ora, esta alteração de $\mathrm{pH}$ local poderá assim mudar o estado de protonação de várias das substâncias presentes no sistema, como sejam polímeros e copolímeros do tipo polielectrólito e/ou de aditivos também protonáveis (como por exemplos vários fármacos de baixo peso molecular e proteínas/factores de crescimento). Isto irá provocar mudanças drásticas nas interacções específicas aditivo/matriz (devido ao possível estabelecimento de interacções fortes, do tipo iónico) e, consequentemente, no rendimento final do processo SSI/SSD. No entanto, é preciso também considerar que este abaixamento de $\mathrm{pH}$, provocado pela dissolução do $\mathrm{scCO}_{2}$ em água, pode também provocar a degradação de algumas substâncias que sejam sensíveis ao $\mathrm{pH}$ [143-147, 174-177].

A "solubilidade" de aditivos em matrizes sólidas/semi-sólidas e o coeficiente de partição entre a matriz e a fase fluida móvel podem ser determinados experimentalmente de uma forma directa e combinada, ou através de vários métodos complementares entre si, i.e., através de métodos que são usados para determinar a solubilidade de aditivos em FSCs e a solubilidade de FSCs em matrizes sólidas e semi-sólidas (e já anteriormente indicados) e da realização de balanços mássicos apropriados (para se obter aos valores experimentais pretendidos). Embora passíveis da introdução de alguns erros experimentais nos valores obtidos (se não forem apropriadamente usados), podem ainda ser usados métodos gravimétricos simples para a quantificação da massa total impregnada/depositada em matrizes sólidas/semi-sólidas (após o processamento), métodos de lexiviação/remoção total dos aditivos incorporados seguidos pela respectiva quantificação (e.g., por técnicas de análise elemental, de espectroscopia de UV-visível, de cromatografia 
líquida de alta "performance" (ou HPLC) ou de cromatografia gasosa (GC), ou, quando possível (e.g., com matrizes inorgânicas) por termogravimetria. Algumas das técnicas referidas na Secção 8.5.2. podem também ser usadas para obter este tipo de resultados: métodos gravimétricos "online" (microbalanças de suspensão magnética, microbalanças de cristal de quartz, etc.), métodos de ressonância magnética nuclear (RMN) a alta pressão, métodos modificados de espectroscopia (UV/vis ou de infravermelhos: de Raman, NIR ou de transformada de Fourier - FTIR) etc. A correlação destes resultados pode ser feita através de alguns dos métodos já indicados nas Secções 8.5.1 e 8.5.2, bem como através de alguns modelos de adsorpção/desorpção de solutos em sólidos e em interfaces líquido-sólido.

\subsection{Conclusões}

Neste capítulo, e além da discussão breve dos principais métodos convencionais de incorporação (impregnação/deposição) de aditivos em matrizes/materiais sólidos (e semi-sólidos), foram abordados em detalhe aqueles métodos que envolvem o uso de solventes supercríticos (ou de misturas comprimidas a alta pressão), os quais são normalmente designados por métodos (ou técnicas) SSI/SSD. Em particular, foi dada ênfase aos métodos que envolvem o uso de dióxido de carbono supercrítico $\left(\mathrm{scCO}_{2}\right)$ como solvente de impregnação/deposição para o desenvolvimento de aplicações farmacêuticas e biomédicas. Foram apresentadas e revistas as suas principais características, bem como as suas aplicabilidades e as suas potenciais vantagens/desvantagens para as aplicações em vista. Foram ainda apresentados e discutidos os princípios, fenómenos e requisitos subjacentes às metodologias SSI/SSD, os principais modos de operação e as variáveis operacionais relevantes para os processos, os principais tipos de substâncias (aditivos, matrizes sólidas/semi-sólidas, co-solventes, surfactantes, etc.) normalmente envolvidas no método (bem como uma revisão bibliográfica exaustiva dos sistemas já estudados e publicados na literatura), e a relevância de algumas das propriedades físico-químicas (e 
até biológicas e de toxicidade) destas mesmas substâncias para os métodos SSI/SSD. Foram também apresentados e discutidos brevemente alguns aspectos indispensáveis a ter conta no desenvolvimento de aplicações farmacêuticas e biomédicas, nomeadamente em termos das entidades reguladoras e dos requisitos regulamentares para o desenvolvimento de medicamentos, dispositivos médicos e produtos de combinação. Por fim, e em muito maior detalhe, foram apresentados os aspectos mais importantes a ter em consideração para a optimização dos métodos SSI/SSD, nomeadamente as interacções físico-químicas, mútuas e específicas, que se devem (ou não) estabelecer entre as substâncias presentes, o efeito das variáveis operacionais (nestas interacções e noutras propriedades relevantes que possam levar a rendimentos elevados no processo SSI/ SSD), bem como alguns métodos teóricos e experimentais que permitem obter e/ou inferir estas interacções e propriedades.

Em termos muito gerais e em jeito de conclusão, podemos dizer que as técnicas SSI/SSD podem ser usadas com evidentes vantagens para impregnar/depositar aditivos em matrizes sólidas/semi-sólidas de base polimérica, inorgânica ou híbrida/compósita), e de forma a se poderem obter materiais/produtos com actividade terapêutica ou para outros fins e aplicações na área biomédica. São técnicas muito versáteis e quando são adequadamente usadas, i.e., quando se usam os FSCs adequados (ou as misturas de fluidos comprimidos adequadas) e as condições operacionais apropriadas, a incorporação dos aditivos pretendidos pode ser feita sem alterar a grande maioria das propriedades químicas e físicas dos materiais sólidos/semi-sólidos em processamento e sem degradar as substâncias mais sensíveis envolvidas no processo. O rendimento final dos processos de SSI/SSD e algumas propriedades finais dos sistemas processados serão sempre função das interacções mútuas e específicas que existem e/ou que se podem estabelecer entre todas as substâncias envolvidas (FSCs, aditivos, matrizes sólidas/semi-sólidas, co-solventes, etc.), bem como das suas magnitudes/intensidades relativas, e ainda das condições de processamento utilizadas (e/ou alteradas) durante o processo. Isto quer dizer que se podem controlar, de uma forma relativamente fácil, a eficiência e a homogeneidade da impregnação/deposição dos aditivos 
pretendidos através da adequada manipulação de várias condições operacionais (pressão, temperatura, tempo de processamento, velocidade de despressurização, uso de co-solventes e de surfactantes, etc.).

Se não forem utilizadas quaisquer outras substâncias líquidas (em condições ambientais), os materiais/produtos processados poderão ser sempre recuperados num estado seco, i.e., sem a presença de quaisquer solventes residuais. Estas metodologias permitem também a incorporação dos vários aditivos de interesse em materiais e outros produtos sólidos/semi-sólidos (e.g., diferentes tipos de dispositivos biomédicos) que já foram previamente preparados por outras técnicas (e com diferentes formas e geometrias), e sem com isso interferir nos processos de síntese e de processamento/produção destes mesmos materiais/dispositivos.

Devido a tudo o que foi apresentado e discutido, as metodologias SSI/SSD, e em particular as que usam $\mathrm{scCO}_{2}$, têm revelado o seu elevado potencial e vindo a ser cada vez mais estudadas e aplicadas no desenvolvimento de aplicações farmacêuticas e biomédicas, esperando-se assim que, e nos próximos anos, consigam ser transpostas com sucesso para escalas industriais de produção nestas áreas.

\subsection{Agradecimentos}

Os autores agradecem o apoio de: FCT-MCTES/MEC, FUP, FEDER, COMPETE, Programa Ciência 2008 (Portugal), CAPES (Brasil), e Rede CYTED, através dos contratos: PEst-C/EQB/UI0102/2011, PEst-C/EME/ UI0285/2013, POCTI/FCB/38213/2001, PTDC/SAU-BEB/71395/2006, PTDC/ SAU-FCF/71399/2006, Acções Integradas Luso-Espanholas 2010 Ref. E-7/10, Cooperação Científica e Tecnológica FCT/CAPES 2011/2012 Ref. 4.4.1.00, e Rede "RIMADEL - Rede Iberoamericana de Nuevos Materiales para el Diseño de Sistemas Avanzados de Liberación de Fármacos en Enfermidades de Alto Impacto Socioeconómico". Mara E.M. Braga e Ana M.A. Dias agradecem ainda à FCT.MCTES/MEC as bolsas de pós-doutoramento SFRH/ BPD/21076/2004 e SFRH/BPD/40409/2007. 


\subsection{Referências}

[1] E.L. Paul, V.A. Atiemo-Obeng, S.M. Kresta, (Eds.), Handbook of industrial mixing: science and practice, Wiley-Interscience, 2004.

[2] H. Zweifel, R. Maier, M. Schiller, (Eds.), Plastics additives handbook, $6^{\text {th }}$ Ed., Hanser, 2009.

[3] J. Bieleman, (Ed.), Additives for coatings, Wiley-VCH, 2000.

[4] G. Wypych, (Ed.), Handbook of plasticizers, $2^{\text {nd }}$ Ed., William Andrew, 2012.

[5] M. Chanda, S.K. Roy, (Eds.), Plastics technology handbook, $4^{\text {th }}$ Ed., CRC Press, 2006.

[6] E.W. Flick, Cosmetics additives: an industrial guide, Noyes Publications, 1991.

[7] G. Kickelbick, (Ed.), Hybrid materials: synthesis, characterization, and applications, Wiley-VCH, 2007.

[8] S.M. Kenny, M. Buggy, J. Mater. Sci. Mater. Med. 2003, 14(11), 923-38.

[9] B.D. Ratner, A.S. Hoffman, F.J. Schoen, J.E. Lemons, (Eds.), Biomaterials science: an introduction to materials in medicine, $3^{\text {rd }}$ Ed., Academic Press, 2012.

[10] T.S. Hin, (Ed.), Engineering materials for biomedical applications, World Scientific Pub Co, 2004 .

[11] S.K. Niazi, (Ed.), Handbook of pharmaceutical manufacturing formulations, $2^{\text {nd }}$ Ed., CRC Press, 2009.

[12] R.C. Rowe, P.J. Sheskey, W.G. Cook, M.E. Fenton, (Eds.), Handbook of pharmaceutical excipients, $7^{\text {th }}$ Ed., Pharmaceutical Press, 2009.

[13] P.K. Chu, X. Liu, (Eds.), Biomaterials Fabrication and Processing Handbook, CRC Press, 2008.

[14] J.A. Wesselingh, S. Kiil, M.E. Vigild, Design \& development of biological, chemical, food and pharmaceutical products, Wiley, 2007.

[15] Y. Qiu, Y. Chen, G.G.Z. Zhang, L. Liu, W.Porter, (Eds.), Developing solid oral dosage forms: pharmaceutical theory \& practice, Academic press, 2009.

[16] J. Swarbrick, (Ed.), Encyclopedia of pharmaceutical technology, $3^{\text {rd }}$ Ed., CRC Press, 2006.

[17] A. Katdare, M. Chaubal, (Eds.), Excipient development of pharmaceutical, biotechnology, and drug delivery systems, CRC Press, 2006.

[18] D.J. Pisano, D.S. Mantus, (Eds.), FDA regulatory affairs: a guide for prescription drugs, medical devices, and biologics, $2^{\text {nd }}$ Ed., CRC Press, 2008.

[19] E-M. Hoepfner, S. Lang, A. Reng, P.C. Schmidt, (Eds.), Fiedler encyclopedia of excipients: for pharmaceuticals, cosmetics and related areas, Buch + CD-ROM, Editio Cantor, 2007.

[20] S.K. Niazi, (Ed.), Handbook of Pre-Formulation: Chemical, Biological, and Botanical Drugs, CRC Press, 2006.

[21] D.M. Parikh, (Ed.), Handbook of pharmaceutical granulation technology, $3^{\text {rd }}$ Ed., CRC Press, 2009.

[22] J.J. Tobin, G. Walsh, Medical product regulatory affairs: pharmaceuticals, diagnostics, medical devices, Wiley-VCH, 2008.

[23] P. York, U.B. Kompella, B. Y. Shekunov, (Eds.), Supercritical fluid technology for drug product development, CRC Press, 2004.

[24] R.C. Fries, Reliable design of medical devices, $3^{\text {rd }}$ Ed., CRC Press, 2012.

[25] J.D. Bronzino, (Ed.), The biomedical engineering handbook, $3^{\text {rd }}$ Ed., CRC Press, 2006 
[26] S.S. Mehta, Commercializing successful biomedical technologies: basic principles for the development of drugs, diagnostics and devices, Cambridge University Press, 2008.

[27] Website: FDA, U.S. Food and Drug Administration, USA, http://www.fda.gov/, (accessed April 15, 2014).

[28] Website: EMA, European Medicines Agency, EU, http://www.ema.europa.eu/ema/, (accessed April 15, 2014).

[29] Website: MHLW, Ministry of Health, Labour, and Welfare, Japan, http://www.mhlw. go.jp/english/, (accessed April 15, 2014).

[30] Website: ICH, International Conference on Harmonisation of Technical Requirements for Registration of Pharmaceuticals for Human Use, Switzerland, http://www.ich.org/, (accessed April 15, 2014).

[31] U.B. Kompella, K. Koushik, Crit. Rev. Ther. Drug Carr. Syst. 2001, 18, 173-199.

[32] B. Subramaniam, R.A. Rajewski, W.K. Snavely, J. Pharm. Sci. 1997, 86, 885-890.

[33] O.R. Davies, A.L. Lewis, M.J. Whitaker, H. Tai, K.M. Shakesheff, S.M. Howdle, Adv. Drug Deliv. Rev. 2008, 60, 373-387.

[34] H. Tai, V.K. Popov, K.M. Shakesheff, S.M. Howdle, Biochem. Soc. T. 2007, 35 516-521.

[35] E. Reverchon, R. Adami, S. Cardea, G. Della Porta, J. Supercrit. Fluids 2009, 47(3), 484-492.

[36] R.A. Quirk, R.M. France, K.M. Shakesheff, S.M. Howdle, Curr. Opin. Solid State Mater. Sci. 2004, 8, 313-321.

[37] A.M. López-Periago A. Vega, P. Subra, A. Argemí, J. Saurina, C.A. García-González, C. Domingo, J. Mater. Sci. 2008, 43(6), 1939-1947.

[38] E. Beckman, J. Supercrit. Fluids 2004, 28, 121-191.

[39] A.I. Cooper, Adv. Mater. 2003, 15(13), 1049-1059.

[40] S.G. Kazarian, Polym. Sci. Ser. C 2000, 42, 78-101.

[41] M.F. Kemmere, T. Meyer, (Eds.), Supercritical carbon dioxide in polymer reaction engineering, Wiley-VCH, 2006

[42] M.O. Balaban, G. Ferrentino, (Eds.), Dense phase carbon dioxide: food and pharmaceutical applications, Wiley-Blackwell, 2012.

[43] M. Perrut, J-Y. Clavier, Ind. Eng. Chem. Res. 2003, 42(25), 6375-6383.

[44] I. Pasquali, R. Bettini, Int. J. Pharm. 2008, 364(2), 176-187.

[45] A. Bertucco, G. Vetter, (Eds.), High pressure process technology: fundamentals and applications, Elsevier Science, 2001.

[46] G. Brunner, Annu. Rev. Chem. Biomol. Eng. 2010, 1, 321-342.

[47] F. Cansell, C. Aymonier, J. Supercrit. Fluids 2009, 47(3), 508-516.

[48] J.L. Kendall, D.A. Canelas, J.L. Young, J.M. DeSimone, Chem. Rev. 1999, 99, 543-563.

[49] Y-P. Sun, Supercritical fluids in materials science and engineering: syntheses: properties, and applications, CRC Press, 2002.

[50] M.A. McHugh, V.J. Krukonis, Supercritical fluid extraction: principles and practice, $2^{\text {nd }}$ Ed., Butterworth-Heinemann, 1994.

[51] G. Brunner, Gas extraction: a introduction to fundamentals of supercritical fluids and the application to separation processes, Dr Verlag Steinkipff Dietrich, 1994.

[52] E. Kiran, P.G. Debenedetti, C.J. Peters, (Eds.), Supercritical fluids: fundamentals and applications, Kluwer Academic Publishers, 2000. 
[53] M. Mukhopadhyay, Natural extracts using supercritical carbon dioxide, CRC Press, 2000.

[54] P.B. Webb, P.C. Marr, A.J. Parsons, H.S. Gidda, S.M. Howdle, Pure Appl. Chem. 2000, 72(7), 1347-1355.

[55] M. Herrero, J.A. Mendiola, A. Cifuentes, E. Ibanez, J. Chromatogr. A. 2010, 1217(16), 2495-511.

[56] R.B. Gupta, J-J. Shim, Solubility in supercritical carbon dioxide, CRC Press, 2012.

[57] K. Mishima, Adv. Drug Deliv. Rev. 2008, 60(3), 411-32.

[58] G. Pilcer, K. Amighi, Int. J. Pharm. 2010, 392(1-2), 1-19.

[59] Website: FDA, Federal Food, Drug, and Cosmetic Act (FD\&C Act, Sec. 201(g) and Sec. 201(h)), USA, http://www.fda.gov/regulatoryinformation/legislation/federalfooddrugandcosmeticactfdcact/ fdcactchaptersiandiishorttitleanddefinitions/ucm086297.htm, (accessed April 15, 2014).

[60] Website: FDA, Public Health Service Act (PHSA, Sec. 262(i)), USA, http://www.fda.gov/ regulatoryinformation/legislation/ucm149278.htm, (accessed April 15, 2014).

[61] Website: FDA, Code of Federal Regulations Title 21 (21CFR Sec. 3.2(e)), USA, http:// www.accessdata.fda.gov/scripts/cdrh/cfdocs/cfcfr/CFRSearch.cfm?CFRPart=3\&showFR=1, (accessed April 15, 2014).

[62] Website: FDA, Code of Federal Regulations Title 21 (21CFR Sec. 3.2(m)), USA, http:// www.accessdata.fda.gov/scripts/cdrh/cfdocs/cfcfr/CFRSearch.cfm?CFRPart=3\&showFR=1, (accessed April 15, 2014).

[63] Websites: European Commission; Eudralex/Medical Devices, EU, http://ec.europa.eu/ health/documents/eudralex/index_en.htm; http://ec.europa.eu/health/medical-devices/ index_en.htm; (accessed April 15, 2014).

[64] V.V. Ranade, M.A. Hollinger, J.B. Cannon, Drug delivery systems, $2^{\text {nd }}$ Ed., CRC Press, 2003.

[65] W. Mark Saltzman, Drug delivery: engineering principles for drug therapy, Oxford University Press, 2001.

[66] X. Li, Design of controlled release drug delivery systems, McGraw-Hill, 2005.

[67] R.O. Williams III, D.R. Taft, J.T. McConville, Advanced drug formulation design to optimize therapeutic outcomes, CRC Press, 2007.

[68] R. Liu, Water-insoluble drug formulation, $2^{\text {nd }}$ Ed., CRC Press, 2008.

[69] M. Grassi, G. Grassi, R. Lapasin, I. Colombo, Understanding drug release and absorption mechanisms. A physical and mathematical approach, CRC Press, 2006.

[70] B. Bennett, G. Cole, Pharmaceutical production: an engineering guide, $2^{\text {nd }}$ Ed., Institution of Chemical Engineers, 2007.

[71] A.J. Hickey, D. Ganderton, Pharmaceutical process engineering, $2^{\text {nd }}$ Ed., CRC Press, 2009.

[72] E.J. McNally, J.E. Hastedt, Protein formulation and delivery, $2^{\text {nd }}$ Ed., CRC Press, 2007.

[73] W. Rogers, Sterilisation of polymer healthcare products, Smithers Rapra Press, 2008.

[74] M.J. Maltesen, M. van de Weert, Drug Discov. Today Technol. 2008, 5(2-3), e81-e-88.

[75] M. Maniruzzaman, J.S. Boateng, M.J. Snowden, D. Douroumis, ISRN Pharmaceutics, 2012, Article ID 436763.

[76] D. Douromis, (Ed.), Hot-melt extrusion: pharmaceutical applications, John Wiley \& Sons, 2012.

[77] J.H. Wendorff, S. Agarwal, A. Greiner, Electrospinning: materials, processing and applications, Wiley-VCH, 2012.

[78] R. Vehring, Pharm. Res. 2008, 25(5), 999-1022. 
[79] X. Tang, M.J. Pikal, Pharm. Res. 2004, 21(2), 191-200.

[80] C.A. García-González, M. Alnaief, I. Smirnova, Carbohydrate Polym. 2011, 86(4), 1425-1438.

[81] S. Yoshioka, V.J. Stella, Stability of drugs and dosage forms, Kluwer Academic Publishers, 2002

[82] M.E. Byrne, K. Park, N.A. Peppas, Adv. Drug Deliv. Rev. 2002, 54(1), 149-161.

[83] V. Ojijoa, S.S. Raya, Prog. Polym. Sci. 2013, 38(10-11), 1543-1589.

[84] G.T. Kulkarni, Pharmaceutical and biotechnological applications of natural hydrogels: hydrogel technology for drug delivery systems and enzyme immobilization, VDM Verlag Dr. Müller, 2010.

[85] Y. Zhang, H.F. Chan, K.W. Leong, Adv. Drug Deliv. Rev. 2013, 65(1), 104-120.

[86] A.S. Hoffman, Adv. Drug Deliv. Rev. 2012, 64, 18-23.

[87] C.C. Peng, A. Ben-Shlomo, E.O. Mackay, C.E. Plummer, A. Chauhan, Curr. Eye Res. 2012, 37(3), 204-11.

[88] C-C. Li, A. Chauhan, Ind. Eng. Chem. Res. 2006, 45(10), 3718-3734.

[89] D.S. Zimnitsky, T.L Yurkshtovich, P.M. Bychkovsky, J. Colloid Interface Sci. 2006, 295(1), 33-40.

[90] C. Charnay, S. Bégu, C. Tourné-Péteilh, L. Nicole, D.A. Lerner, J.M. Devoisselle, Eur. J. Pharm. Biopharm. 2004, 57(3), 533-40.

[91] Website: FDA, Code of Federal Regulations Title 21 (Part 184), USA, http://www. accessdata.fda.gov/scripts/cdrh/cfdocs/cfcfr/CFRSearch.cfm?CFRPart=184\&showFR=1, (accessed April 15, 2014).

[92] J. Zhang, T.A. Davis, M.A. Matthews, M.J. Drews, M. LaBerge, Y.H. An, J. Supercrit. Fluids 2006, 38(3), 354-372.

[93] A. White, D. Burns, T.W. Christensen, J Biotechnol. 2006, 123(4), 504-515.

[94] M. Perrut, Sterilization and virus inactivation by supercritical fluids (a review). J. Supercrit. Fluids 2012, 66, 359-371.

[95] K. Moribe, Y. Tozuka, K. Yamamoto, Adv. Drug Deliv. Rev. 2008, 60(3), 328-338.

[96] L.S. Daintree, A. Kordikowski, P. York, Adv. Drug Deliv. Rev. 2008, 60(3), 351-372.

[97] N. Foster, R. Mammucari, F. Dehghani, A. Barrett, K. Bezanehtak, E. Coen, G. Combes, L. Meure, A. Ng, H.L. Regtop, A. Tandya, Ind. Eng. Chem. Res. 2003, 42(25),6476-6493.

[98] H.M. Woods, M.M.C.G. Silva, C. Nouvel, K.M. Shakesheff, S.M. Howdle, J. Mater. Chem. 2004, 14, 1663-1678.

[99] M.J Cocero, A. Martín, F. Mattea, S. Varona, J. Supercrit. Fluids 2009, 47(3), 546-555.

[100] M. Bahrami S. Ranjbarian, J. Supercrit. Fluids 2007, 40(2), 263-283.

[101] A. Martín, M.J. Cocero, Adv. Drug Deliv. Rev. 2008, 60(3), 339-350.

[102] E. Reverchon, R. Adami, G. Caputo, I. De Marco, J. Supercrit. Fluids 2008, 47(1), 70-84.

[103] J. Jung, M. Perrut, J. Supercrit. Fluids 2001, 20(3), 179-219.

[104] E. Reverchon, I. De Marco, E. Torino, J. Supercrit. Fluids 2007, 43(1), 126-138.

[105] I. Pasquali, R. Bettini, F. Giordano, Adv. Drug Deliv. Rev. 2008, 60(3), 399-410.

[106] A. Tabernero, E.M. Martín del Valle, M.A. Galán, Chem. Eng. Process. Process Intensif. 2012, 60, 9-25

[107] K. Byrappa, S. Ohara, T. Adschiri, Adv. Drug Deliv. Rev. 2008, 60(3), 299-327. 
[108] S-D. Yeo, E. Kiran, J. Supercrit. Fluids 2005, 34(3), 287-308.

[109] C. Aymonier, A. Loppinet-Serani, H. Reverón, Y. Garrabos, F. Cansell, J. Supercrit. Fluids 2006, 38(2), 242-251.

[110] Y. Zhang, C. Erkey, J. Supercrit. Fluids 2006, 38(2), 252-267.

[111] E. Reverchon, R. Adami, J. Supercrit. Fluids 2006, 37(1), 1-22.

[112] A. Tandya, R. Mammucari, F. Dehghani, N.R. Foster, Int. J. Pharm. 2007, 328(1), 1-11.

[113] Y. Haldorai, J-J. Shim, K.T. Lim, J. Supercrit. Fluids 2012, 71, 45-63.

[114] E. Reverchon, S. Cardea, J. Supercrit. Fluids 2012, 69, 97-107.

[115] S.P. Nalawade, F. Picchioni, L.P.B.M. Janssen, Prog. Polym. Sci. 2006, 31(1), 19-43.

[116] Martial Sauceau, J. Fages, A. Common, C. Nikitine, E. Rodier, Prog. Polym. Sci. 2011, 36(6), 749-766.

[117] A.I. Cooper, Adv. Mater. 2001, 13(14), 1111-1114.

[118] D.L. Tomasko, A. Burley, L. Feng, S-K. Yeh, K. Miyazono, S. Nirmal-Kumar, I. Kusaka, K. Koelling, J. Supercrit. Fluids 2009, 47(3), 493-499.

[119] D.L. Tomasko, H. Li, D. Liu, X. Han, M.J. Wingert, L. James Lee, K.W. Koelling, Ind. Eng. Chem. Res. 2003, 42(25), 6431-6456.

[120] L.J.M. Jacobs, M.F. Kemmere, J.T.F. Keurentjes, Green Chem. 2008, 10, 731-738.

[121] R.B. Yoganathan, R. Mammucari, N.R. Foster, Polym. Rev. 2010, 50(2), 144-177.

[122] E. Reverchon, I. De Marco, J. Supercrit. Fluids 2006, 38(2), 146-166.

[123] M.E.M. Braga, I.J. Seabra, A.M.A. Dias, H.C. de Sousa, in: Natural product extraction: principles and applications, M.A. Rostagno, J.M. Prado (Eds.), RSC Green Chemistry Series, Vol. 21, RSC Press - Royal Society of Chemistry, UK, 231-284, 2013.

[124] S. Keskin, D. Kayrak-Talay, U. Akman, O. Hortaçsu, J. Supercrit. Fluids 2007, 43(1), 150-180.

[125] K. Kalíková, T. Šlechtová, J. Vozka, E. Tesařová, Anal. Chim. Acta 2014, 821, 1-33.

[126] J.M. Płotka, M. Biziuka, C. Morrison, J. Namieśnika, Trends Anal. Chem. 2014, 56, 74-89.

[127] C.R. Yonker, J.C. Linehan, Prog. Nucl. Magn. Reson. Spectrosc. 2005, 47(1), 95-109.

[128] A.R. Berens, G.S. Huvard, R.W. Korsmeyer, F.W. Kunig, J. Appl. Polym. Sci. 1992, 46, 231-242.

[129] I. Kikic, F. Vecchione, Curr. Opin. Solid State Mater. Sci. 2003, 7(4-5), 399-405.

[130] T. Matsuda, J. Biosci. Bioeng. 2013, 115(3), 233-241.

[131] Z. Knez, J. Supercrit. Fluids 2009, 47(3), 357-372.

[132] R.J. St John, J.F. Carpenter, C. Balny, T.W. Randolph, J. Bio. Chem. 2001, 276(50), 46856-46863.

[133] R.J. St John, J.F. Carpenter, T.W. Randolph, Proc. Natl. Acad. Sci. USA 1999, 96(23), 13029-13033.

[134] A.R. Berens, G.S. Huvard, in: Supercritical Fluid Science and Technology, ACS Symposium Series 406, K.P. Johnston, J.M.L. Penninger, Eds., American Chemical Society, Chapter 14, 207-223, 1989.

[135] A.R. Berens, Makromol. Chem. Macromol. Symp. 1989, 29, 95-108.

[136] A.R. Berens, G.S. Huvard, R.W. Korsmeyer, U.S. Pat. 4820752, 1989.

[137] R.G. Wissinger, M.E. Paulaitis, J. Polym. Sci. Part B: Polym. Phys. 1987, 25(12), 2497-2510. 
[138] M.L. Sand, U.S. Pat. 4598006, 1986.

[139] C.A. Perman, M.E. Riechert, U.S. Pat. 5340614, 1994.

[140] H.C. de Sousa, M.H.M. Gil, E.O.B. Leite, C.M.M. Duarte, A.R.C. Duarte, E.P. 1611877, 2006.

[141] H.C. de Sousa, M.H.M. Gil, E.O.B. Leite, C.M.M. Duarte, A.R.C. Duarte, U.S. Pat. 20060008506, 2006.

[142] I. Kikic, J. Supercrit. Fluids 2009, 47(3), 458-465.

[143] M.E.M. Braga, M.T. Vaz Pato, H.S.R.C. Silva, E.I. Ferreira, M.H. Gil, C.M.M. Duarte, H.C. de Sousa, J. Supercrit. Fluids 2008, 44(2), 245-257.

[144] A.R.C. Duarte, A.L. Simplício, A. Vega-Gonzalez, P. Subra-Paternault, P. Coimbra, M.H. Gil, H.C. de Sousa, C.M.M. Duarte, J. Supercrit. Fluids 2007, 42(3), 373-377.

[145] V.P. Costa, M.E.M. Braga, J.P. Guerra, A.R.C. Duarte, C.M.M. Duarte, E.O.B. Leite, M.H. Gil, H.C. de Sousa, J. Supercrit. Fluids 2010, 52(3), 306-316.

[146] V.P. Costa, M.E.M. Braga, C.M.M. Duarte, C. Alvarez-Lorenzo, A. Concheiro, M.H. Gil, H.C. de Sousa, J. Supercrit. Fluids 2010, 53(1-3), 165-173.

[147] M.V. Natu, M.H. Gil, H.C. de Sousa, J. Supercrit. Fluids 2008, 47(1), 93-102.

[148] P. Raveendran, Y. Ikushima, S.L. Wallen, Acc. Chem. Res. 2005, 38(6), 478-485.

[149] H. Zhou, J. Fang, J. Yang, X. Xie, J. Supercrit. Fluids 2003, 26, 137-145.

[150] Q. Xu, Y. Chang, J. Appl. Polym. Sci. 2004, 93(2), 742-748.

[151] P.D. Condo, S.R. Sumpter, M.L. Lee, K.P. Johnston, Ind. Eng. Chem. Res. 1996, 35(4), 1115-1123.

[152] S.G. Kazarian, M.F. Vincent, F.V. Bright, C.L. Liotta, C.A. Eckert, J. Am. Chem. Soc. 1996, 118(7), 1729-1736.

[153] J.C. Meredith, K.P. Johnston, J.M. Seminario, S.G. Kazarian, C.A. Eckert, J. Phys. Chem. 1996, 100(26), 10837-10848.

[154] E. Kiran, J. Supercrit. Fluids 2009, 47(3), 466-483.

[155] C.F. Kirby, M.A. McHugh, Chem. Rev. 1999, 99, 565-602.

[156] M. Champeau, J-M. Thomassin, C. Jérôme, T. Tassaing, J. Supercrit. Fluids 2014, 90, 44-52.

[157] K.H. Kim, Y. Kim, Bull. Korean Chem. Soc. 2007, 28(12), 2454-2458.

[158] O. Kajimoto, Chem. Rev. 1999, 99, 355-389.

[159] S.G. Kazarian, N.H. Brantley, B.L. West, M.F. Vincent, C.A. Eckert, Appl. Spectrosc. 1997, 51(4), 491-494.

[160] Y.P. Handa, P. Kruus, M. O’Neill, J. Polym. Sci. Part B: Polym. Phys. 1996, 34(15), 2635-2639.

[161] V.M. Shah, B.J. Hardy, S.A. Stern, J. Polym. Sci. Part B: Polym. Phys. 1993, 31(3), 313-317.

[162] I. Kikic, M. Lora, A. Cortesi, P. Sist, Fluid Phase Equilib. 1999, 158-160, 913-921.

[163] S.G. Kazarian, G.G. Martirosyan, Int. J. Pharm. 2002, 232(1-2), 81-90.

[164] S.G. Kazarian, M.F. Vincent, B.L. West, C.A. Eckert, J. Supercrit. Fluids 1998, 13(1-3), 107-112.

[165] Z. Knez, E. Weidner, Curr. Opin. Solid State Mater. Sci. 2003, 7(4-5), 353-361.

[166] A.R.S. de Sousa, A.L. Simplício, H.C. de Sousa, C.M.M. Duarte, J. Supercrit. Fluids 2007, (43(1), 120-125. 
[167] M.B.C de Matos, A.P. Piedade, C. Alvarez-Lorenzo, A. Concheiro, M.E.M. Braga, H.C. de Sousa, Int. J. Pharm. 2013, 456(2), 269-281.

[168] M.D. Wilding, Melt processing thermally unstable and high molecular weight polymers with supercritical carbon dioxide. PhD Thesis, Virginia Polytechnic Institute and State University, USA, 2007.

[169] J. Eastoe, A. Dupont, D.C. Steytler, Curr. Opin. Colloid Interface Sci. 2003, 8(3), 267-273.

[170] B. Bonavoglia, Phase equilibria in polymer-supercritical CO2 systems, PhD Thesis, Swiss Federal institute of Technology Zurich (EHTZ), Switzerland, 2005.

[171] M.A. Jacobs, Measuring and modeling of thermodynamic properties for the processing if polymers in supercritical fluids, PhD Thesis, Technische Universiteit Eindhoven, The Netherlands, 2004.

[172] J. Eastoe, C. Yan, A. Mohamed, Curr. Opin. Colloid Interface Sci. 2012, 17(5), 266-273

[173] P.G. Jessop, B. Subramaniam, Chem Rev. 2007, 107(6), 2666-2694.

[174] M.E.M. Braga, V.P. Costa, M.J. Pereira, P.T. Fiadeiro, A.P. Gomes, C.M.M. Duarte, H.C. de Sousa, Int. J. Pharm. 2011, 420(2), 231-243.

[175] F. Yañez, L. Martikainen, M.E.M. Braga, C. Alvarez-Lorenzo, A. Concheiro, C.M.M. Duarte, M.H. Gil, H.C. de Sousa, Acta Biomater. 2011, 7(3), 1019-1030.

[176] Y. Masmoudi, L. Ben Azzouk, O. Forzano, J-M. Andre, E. Badens, J. Supercrit. Fluids 2011, 60, 98-105.

[177] C. González-Chomón, M.E.M. Braga, H.C. de Sousa, A. Concheiro, C. Alvarez-Lorenzo, Eur. J. Pharm. Biopharm. 2012, 82(2), 383-391.

[178] Website: Uhde High Pressure Technologies, Germany, http://www.uhde-hpt.com (accessed April 15, 2014).

[179] Website: DyeCoo, The Netherlands, http://www.dyecoo.com (accessed April 15, 2014 ).

[180] Website: Feyecon, The Netherlands, http://www.feyecon.com (accessed April 15, 2014).

[181] Website: Applied Separations, USA, http://www.appliedseparations.com (accessed April 15, 2014).

[182] Website: Nantong Supercritical Extraction, China, http://www.supercritical.co (accessed April 15, 2014).

[183] Website: Hisaka Works Ltd., Japan, http://www.hisaka.co.jp (accessed April 15, 2014 ).

[184] G.A. Montero, C.B. Smith, W.A. Hendrix, D.L. Butcher, Ind. Eng. Chem. Res. 2000, 39(12), 4806-4812.

[185] M. Banchero, Color. Technol. 2013, 129(1), 2-17.

[186] Website: Superwood AS, Denmark, http://www.superwood.dk (accessed April 15, 2014).

[187] A.W. Kjellow, O. Henriksen, J. Supercrit. Fluids 2009, 50(3), 297-304.

[188] A.W. Kjellow, Supercritical wood impregnation. PhD Thesis, University of Copenhagen, Denmark, 2010.

[189] J. Fernandes, A.W. Kjellow, O. Henriksen, J. Supercrit. Fluids 2012, 66, 307-314.

[190] M. Renner, E. Weidner, B. Jochems, H. Geishler, J. Supercrit. Fluids 2012, 66, 291-296.

[191] M. Renner, H. Geishler, E. Weidner, Pat. DE 102009018232, 2009.

[192] M. Renner, E. Weidner, G. Brandin, Chem. Eng. Res. Des. 2009, 87(7), 987-996.

[193] J.D. Nally, (Ed.), Good manufacturing practices for pharmaceuticals, 6 ${ }^{\text {th }}$ Ed., CRC Press, 2006. 
[194] I.R. Berry, R.P. Martin, (Eds.), The pharmaceutical regulatory process, $2^{\text {nd }}$ Ed., CRC Press, 2008.

[195] M. Levin, (Ed.), Pharmaceutical process scale-up, 2nd Ed., CRC Press, 2007.

[196] Website: FDA, Guidances (Drugs), USA, http://www.fda.gov/Drugs/ GuidanceComplianceRegulatoryInformation/Guidances/default.htm, (accessed April 15, 2014).

[197] Website: FDA, Guidance for industry, Q3C impurities: residual solvents, USA, http:// www.fda.gov/downloads/Drugs/GuidanceComplianceRegulatoryInformation/Guidances/ UCM073394.pdf, (accessed April 15, 2014).

[198] Website: FDA, Guidance for industry, Q3C - tables and list, USA, http://www.fda.gov/ downloads/Drugs/GuidanceComplianceRegulatoryInformation/Guidances/UCM073395. pdf, (accessed April 15, 2014).

[199] Website: EMA, Impurities: guideline for residual solvents, EU, http://www.ema.europa. eu/docs/en_GB/document_library/Scientific_guideline/2011/03/WC500104258.pdf, (accessed April 15, 2014).

[200] Website: ICH, Impurities: guideline for residual solvents, Q3C(R5), http://www.ich. org/fileadmin/Public_Web_Site/ICH_Products/Guidelines/Quality/Q3C/Step4/Q3C_R5_ Step4.pdf, (accessed April 15, 2014).

[201] Website: FDA, Inactive ingredient search for approved drug products, USA, http:// www.accessdata.fda.gov/scripts/cder/iig/, (accessed April 15, 2014).

[202] Website: FDA, Inactive ingredients database download, USA, http://www.fda.gov/ Drugs/InformationOnDrugs/ucm113978.htm, (accessed April 15, 2014).

[203] M. Malmsten, Surfactants and polymers in drug delivery. CRC Press, 2002.

[204] K.P. Johnston, S.R.P. da Rocha, J. Supercrit. Fluids 2009, 47(3), 523-530.

[205] K.P. Johnston, Curr. Opin. Colloid Interface Sci. 2003, 5(5-6), 350-355.

[206] P. Alessi, I. Kikic, A. Cortesi, A. Fogar, M. Moneghini, J. Supercrit. Fluids 2003, 27(3), 309-315.

[207] A.R.C. Duarte, A.L. Simplício, A. Vega-Gonzalez, P. Subra-Paternault, P. Coimbra, M.H. Gil, H.C. de Sousa, C.M.M. Duarte, Curr. Drug Deliv. 2008, 5(2) 102-107.

[208] A. Cosijns, D. Nizet, I. Nikolakakis, C. Vervaet, T. De Beer, F. Siepmann, J. Siepmann, B. Evrard, J.P. Remon, Drug Develop. Ind. Pharm. 2009, 35(6), 655-662.

[209] R. Yoganathan, R. Mammucari, N.R. Foster, J. Phys. Conf. Ser. 2010, 215(1) 012087.

[210] R. Yoganathan, R. Mammucari, N.R. Foster, Materials 2010, 3(5), 3188-3203.

[211] S-L. Ma, Z-W. Lu, Y-T. Wu, Z-B. Zhang, J. Supercrit. Fluids 2010, 54(2), 129-136.

[212] P.W. Labuschagne, S.G. Kazarian, R.E. Sadiku, J. Supercrit. Fluids 2011, 57(2), 190-197.

[213] Y.A. Hussain, C.S. Grant, J. Supercrit. Fluids 2012, 71, 127-135.

[214] M. Nia, Q-Q. Xua, J-Z. Yin, J. Mater. Res. 2012, 27(2), 2902-2910.

[215] L. Manna, M. Banchero, D. Sola, A. Ferri, S. Ronchetti, S. Sicardi, J. Supercrit. Fluids 2007, 42(3), 378-384.

[216] M. Banchero, L. Manna, J. Supercrit. Fluids 2012, 67, 76-83.

[217] J. Kluge, M. Mazzotti, Int. J. Pharm. 2012, 436(1-2), 394-402.

[218] A. Cortesi, P. Alessi, I. Kikic, S. Kirchmayer, F. Vecchione, J. Supercrit. Fluids 2000, 19(1), 61-68.

[219] P. Marizza, S.S. Keller, A. Müllertz, A. Boisen, J. Control. Release 2014, 173, 1-9. 
[220] A.R.C. Duarte, M. Sousa Costa, A.L. Simplício, M.M. Cardoso, C.M.M. Duarte, Int. J. Pharm. 2006, 308(1-2), 168-174.

[221] A. Argemí, J.L. Ellis, J. Saurina, D.L. Tomasko, J. Pharm. Sci. 2010, 100(3), 992-1000.

[222] A. López-Periago, A. Argemí, J.M. Andanson, V. Fernández, C.A. García-González, S.G. Kazarian, J. Saurina, C. Domingo, J. Supercrit. Fluids 2009, 48(1), 56-63.

[223] A. Argemí, A. López-Periago, C. Domingo, J. Saurina, J. Pharm. Biomed. Anal. 2008, 46(3), 456-462.

[224] J.M. Andanson, A. López-Periago, C.A. García-González, C. Domingo, S.G. Kazarian, Vibrat. Spectrosc. 2009, 49(2), 183-189.

[225] N. Murillo-Cremaes, A. López-Periago, J. Saurina, A. Roig, C. Domingo, J. Supercrit. Fluids 2013, 73, 34-42.

[226] M. Soares da Silva, F.L. Nobrega, A. Aguiar-Ricardo, E.J. Cabrita, T. Casimiro, J. Supercrit. Fluids 2011, 58(1), 150-157.

[227] C. Domingo, J. García-Carmona, M.A. Fanovicha, J. Saurina, Analyst 2001, 126, 1792$-1796$.

[228] C. Domingo, J. García-Carmona, M.A. Fanovich, J. Llibre, R. Rodríguez-Clemente, J. Supercrit. Fluids 2001, 21(2), 147-157.

[229] C. Domingo, J. García-Carmona, M.A. Fanovich, J. Saurina, Anal. Chim. Acta 2002, 452(2), 311-319.

[230] S. Diankov, D. Barth, A. Vega-Gonzalez, I. Pentchev, P. Subra-Paternault, J. Supercrit. Fluids 2007, 41(1), 164-172.

[231] M. Banchero, L. Manna, S. Ronchetti, P. Campanelli, A. Ferri, J. Supercrit. Fluids 2009, 49(2), 271-278.

[232] M. Moneghini, I. Kikic, B. Perissutti, E. Franceschinis, A. Cortesi, Eur. J. Pharm. Biopharm. 2004, 58(3), 637-644.

[233] A.R.C. Duarte, J.F. Mano, R.L. Reis, Eur. Polym. J. 2009, 45(1), 141-148.

[234] K. Gong, J.A. Darr, I.U. Rehman, Int. J. Pharm. 2006, 315(1-2), 93-98.

[235] H. Liu, N. Finn, M.Z. Yates, Langmuir 2005, 21(1), 379-385.

[236] K. Gong, I.U. Rehman, J.A. Darr, Int. J. Pharm. 2007, 338(1-2), 191-197.

[237] K. Gong, I.U. Rehman, J.A. Darr, J. Pharm. Biomed. Anal 2008, 48(4), 1112-1119.

[238] L.I. Cabezas, V. Fernández, R. Mazarro, I. Gracia, A. de Lucas, J.F. Rodríguez, J. Supercrit. Fluids 2012, 63, 155-160.

[239] J-P. Yu, Y-X. Guan, S-J. Yao, Z-Q. Zhu, Ind. Eng. Chem. Res. 2011, 50(24), 13813-13818.

[240] A.C.K. Bierhalz, M.A. da Silva, H.C. de Sousa, M.E.M. Braga, T.G. Kieckbusch, J. Supercrit. Fluids 2013, 76, 74-82.

[241] K. Gong, M. Braden, M.P. Patel, I.U. Rehman, Z. Zhang, J.A. Darr, J. Pham. Sci. 2007, 96(8), 2048-2056.

[242] S. Ugaonkar, T.E. Needham, G.D. Bothun, Int. J. Pharm. 2011, 403(1-2), 96-100.

[243] S. Yoda, K. Sato, H.T. Oyama, RSC Adv. 2011, 1, 156-162.

[244] L.I. Cabezas, I. Gracia, M.T. García, A. de Lucas, J.F. Rodríguez, J. Supercrit. Fluids $2013,80,1-8$.

[245] S. Zhan, C. Chen, Q. Zhao, W. Wang. Z. Liu, Ind. Eng. Chem. Res. 2013, 52(8), 2852-2857 .

[246] O. Guney, A. Akgerman, AIChE J. 2002, 48(4), 856-866. 
[247] H.S. Ganapathy, M.H. Woo, S.S. Hong, K.T. Lim, Key Eng. Mater. 2007, 342-343, 501-504.

[248] K. Sugiura, S. Ogawa, I. Tabata, T. Hori, Sen'i Gakkaishi 2005, 61(6), 159-165.

[249] R.J. Ahern, J.P. Hanrahan, J.M. Tobin, K.B. Ryan, A.M. Crean, Eur. J. Pharm. Sci. 2013, 50(3-4), 400-409.

[250] C. Elvira, M.A. Fanovich, M. Fernández, J. Fraile, J. San Román, C. Domingo, J. Control. Release 2004, 99(2), 231-240.

[251] C. Domingo, A. Vega, M.A. Fanovich, C. Elvira, P. Subra, J. Appl. Polym. Sci. 2003, 90(13), 3652-3659.

[252] J.R. Bush, A. Akgerman, K.R. Hall, J. Supercrit. Fluids 2007, 41(2), 311-316.

[253] F. Belhadj-Ahmed, E. Badens, P. Llewellyn., R. Denoyel, G. Charbit, J. Supercrit. Fluids 2009, 51(2), 278-286.

[254] T. Gamse, R. Marr, C. Wolf, K. Lederer, Hemijska Industrija 2007, 61(5), $229-232$.

[255] O. Ayodeji, E. Graham, D. Kniss, J. Lannutti, D. Tomasko, J. Supercrit. Fluids 2007, 41(1), 173-178.

[256] M.T. Nelson, H.R. Munj, D.L. Tomasko, J.J. Lannutti, J. Supercrit. Fluids 2012, 70, 90-99.

[257] J. Zhang, D.J. Martin, E. Taran, K.J. Thurecht, R.F. Minchin, Macromol. Chem. Phys. 2014, 215(1), 64-64.

[258] M.E.M. Braga, M.S. Ribeiro, M.H. Gil, H.S.R. Costa Silva, E.I. Ferreira, H.C. de Sousa, Proceedings of the 2007 AIChE Annual Meeting, Salt Lake City, Utah, USA, November $4-9,2007$.

[259] Z. Shen, G.S. Huvard, C.S. Warriner, M.A. McHugh, J.L. Banyasz, M.K. Mishra, Polymer 2008, 49(6), 1579-1586.

[260] L.C.S. Herek, R.C. Oliveira, A.F. Rubira, N. Pinheiro, Braz. J. Chem. Eng. 2006, 23(2), 227-234.

[261] A.M.A. Dias,M.E.M. Braga, I.J. Seabra, P. Ferreira, M.H. Gil, H.C. de Sousa, Int. J. Pharm. 2011, 408(1-2), 9-19.

[262] A. Torres, J. Romero, A. Macan, A. Guarda, M.J. Galotto, J. Supercrit. Fluids 2014, 85, 41-48.

[263] S. Milovanovic, M. Stamenic, D. Markovic, M. Radetic, I. Zizovic, J. Supercrit. Fluids 2013, 84, 173-181.

[264] N.A. Gañán, A.M.A. Dias, J. Zygadlo, E. Brignole, M.E.M. Braga, H.C. de Sousa, Proceedings of Prosciba 2013 - III Iberoamerican Conference on Supercritical Fluids, Cartagena de Indias, Colombia, April 1-5, 2013.

[265] A.C. de Souza, A.M.A. Dias, H.C. de Sousa, C.C. Tadini, Carbohydr. Polym. 2014, 102, 830-837.

[266] L.M. Comin, F. Temelli, M.D.A. Saldaña, J. Supercrit. Fluids 2012, 61, 221-228.

[267] A.M.A. Dias, A. Rey-Rico, R.A. Oliveira, S. Marceneiro, C. Alvarez-Lorenzo, A. Concheiro, R.N.C. Júnior, M.E.M. Braga, H.C. de Sousa, J. Supercrit. Fluids 2013, 64, 34-45.

[268] M.A. Fanovich, J. Ivanovic, D. Misic, M.V. Alvarez, P. Jaeger, I. Zizovic, R. Eggers, J. Supercrit. Fluids 2013, 78, 42-53.

[269] S. Varona, S. Rodríguez-Rojo, A. Martín, M.J. Cocero, C.M.M. Duarte, J. Supercrit. Fluids 2011, 58(2), 313-319.

[270] E. de Paz, S. Rodríguez, J. Kluge, A. Martín, M. Mazzotti, M.J. Cocero, J. Supercrit. Fluids 2013, 84, 105-112. 
[271] L.M. Comin, F. Temelli, M.D.A. Saldaña, J. Food Eng. 2012, 111(4), 625-631.

[272] C. Tsutsumi, T Hara, N. Fukukawa, K. Oro, K. Hata, Y. Nakayama, T. Shiono, Green Chem 2012, 14, 1211-1219.

[273] C. Tsutsumi, N. Fukukawa, J. Sakafuji, K. Oro, K. Hata, Y. Nakayama, T. Shiono, J. Appl. Polym. Sci. 2011, 121(3), 1431-1441.

[274] C. Tsutsumi, J. Sakafuji, M. Okada, K. Oro, K. Hata, J. Mater. Sci. 2009, 44(13), 3533-3541 .

[275] C. Tsutsumi, A. Tsuzuki, T. Hara, Y. Nakayama, T. Shiono, Kobunshi Ronbunshu 2014, 71(1), 1-10.

[276] A.P. Almeida, S. Rodríguez-Rojo, A.T. Serra, H. Vila-Real, A.L. Simplício, I. Delgadilho, S.B. da Costa, L.B. da Costa, I.D. Nogueira, C.M.M. Duarte, Innov. Food Sci. Emerg. Technol. 2013, 20, 140-145.

[277] M. Díez-Municio, A. Montilla, M. Herrero, A. Olano, E. Ibañez, J. Supercrit. Fluids 2011, 57(1), 73-79.

[278] E.D. Cardona, M.P. Noriega, J.D. Sierra, J. Plast. Film Sheet. 2012, 28(1), 63-78.

[279] A. Kongdee, S. Okubayashi, I. Tabata, T. Hori, J. Appl. Polym. Sci. 2007, 105(4), 2191$-2097$.

[280] K. Vezzù, V. Betto, N. Elvassore, Biochem. Eng. J. 2008, 40(2), 241-248.

[281] M. Temtem, T. Casimiro, J.F. Mano, A. Aguiar-Ricardo, Green Chem. 2007, 9, 75-79.

[282] M. Temtem, T. Barroso, T. Casimiro, J.F. Mano, A. Aguiar-Ricardo, J. Supercrit. Fluids 2012, 66, 398-404.

[283] Q. Peng, Q. Xu, H. Xu, M. Pang, J. Li, D. Sun, J. Appl. Polym. Sci. 2005, 98(2), 864-868.

[284] O. Muth, Th. Hirth, H. Vogel, J. Supercrit. Fluids 2000, 17(1), 65-72.

[285] A. Naylor, S.M. Howdle, J. Mater. Chem. 2005, 15, 5037-5042.

[286] S. Partap, A.K. Hebb, I. ur Rehman, J.A. Darr, Polym. Bull. 2007, 58(5-6), 849-860.

[287] D. Li, B. Han, Ind. Eng. Chem. Res. 2000, 39(12), 4506-4509.

[288] L.N. Nikitin, M.O. Gallyamov, R.A. Vinokur, A.Y. Nikolaec, E.E. Said-Galiyev, R. Khokhlov, H.T. Jespersen, K. Schaumburg, J. Supercrit. Fluids 2003, 26(3), 263-273.

[289] T. Hoshi, T. Sawaguchi, R. Matsuno, T. Konno, M. Takai, K. Ishihara, J. Supercrit. Fluids 2008, 44(3), 391-399.

[290] A. Galia, R. De Gregorio, G. Spadaro, O. Scialdone, G. Filardo, Macromolecules 2004, 37(12), 4580-4589.

[291] L. Su, S. Pei, L. Li, H. Li, Y. Zhang, W. Yu, C. Zhou, Int. J. Hydrogen Energy 2009, 34(16), 6892-6901.

[292] P. López-Aranguren, J. Fraile, L.F. Vega, C. Domingo, J. Supercrit. Fluids 2014, 85, 68-80.

[293] P. López-Aranguren, J. Saurina, L.F. Vega, C. Domingo, Micropor. Mesopor. Mater. 2012, 148(1), 15-24.

[294] D. Sun, Y. Huang, B. Han, G. Yang, Langmuir 2006, 22(10), 4793-4798.

[295] J. Byun, J. Sauk, H. Kim, Int. J. Hydrogen Energy 2009, 34(15), 6437-6442.

[296] M.A. Fanovich, P. Jaeger, Mater. Sci. Eng. C, 2012, 32(4), 961-968.

[297] Z. Bayraktar, E. Kiran, J Supercrit. Fluids 2008, 44(1), 48-61.

[298] R. Zhu, T. Hoshi, Y. Muroga, T. Hagiwara, S. Yano, T. Sawaguchi, J. Appl. Polym. Sci. 2013, $127(5), 3388-3394$. 
[299] F. Furno, K.S. Morley, B. Wong, B.L. Sharp, P.L. Arnold, S.M. Howdle, R. Bayston, P.D. Brown, P.D. Winship, H.J. Reid, J. Antimicrob. Chemother. 2004, 54(6), 1019-1024.

[300] T.T. Ngo, C.L. L. Liotta, C.A. Eckert, S.G. Kazarian, J. Supercrit. Fluids 2003, 27(2), 215-221

[301] T.L. Sproule, J.A. Lee, H. Li, J.J. Lannutti, D.L. Tomasko, J. Supercrit. Fluids 2004, 28(3), 241-248.

[302] S. Uzer, U. Akman, O. Hortaçsu, J. Supercrit. Fluids 2006, 38(1), 119-128.

[303] R. Silva; M.H. Kunita; E.M. Girotto; E. Radovanovic; E.C. Muniz; G.M. Carvalho; A.F. Rubira, Braz. J. Chem. Eng. 2008, 19(6), 1224-1229.

[304] E-B. Kim, J-T. Kim, S-Y. Kim, C-S. Ju, Korean J. Chem. Eng 2011, 28(2), 440-444.

[305] J. Sauk, J. Byun, H. Kim, J. Power Sources 2004, 132(1-2), 59-63.

[306] N.N. Glagolev, A.B. Solovyeva, A.V. Cherkasova, V.P. Melnikov, A.Y. Lyapunov, P.S. Timashev, A.V. Kotova, B.I. Zapadinsky, V.N. Bagratashvili, Russ. J. Phys. Chem. B 2010, 4(7), 1092-1096.

[307] R. Jiang, Y. Zhang, S. Swier, X. Wei, C. Erkey, H.R. Kunz, J.M. Fenton, Electrochem. Solid-State Lett. 2005, 8(11), A611-A615.

[308] Y. Zhang, C. Erkey, Ind. Eng. Chem. Res. 2005, 44(14), 5312-5317.

[309] D. Kim, J. Sauk, J. Byun, K.S. Lee, H. Kim, Solid State Ionics 2007, 178(11-12), 865-870.

[310] J. Wang, Y. Ran, E. Zou, Q. Dong, J. Polym. Res. 2009, 16(6), 739-744.

[311] R. Zhu, T. Hoshi, Y. Chishima, Y. Muroga, T. Hagiwara, S. Yano, T. Sawaguchi, Macromolecules 2011, 44(15), 6103-6112.

[312] Y. Wang, C. Yang, D. Tomasko, Ind. Eng. Chem. Res. 2002, 41(7), 1780-1786.

[313] Z. Hou, Q. Xu, Q. Peng, J. Li, H. Fan, S. Zheng, J. Appl. Polym. Sci. 2006, 100(6), 4280-4285.

[314] S. Tengsuwan, M. Ohshima, J. Supercrit. Fluids 2012, 69, 117-123.

[315] S. Tengsuwan, M. Ohshima, J. Supercrit. Fluids 2014, 85, 123-134.

[316] M.J. Clarke, S.M. Howdle, M. Jobling, M. Poliakoff, Inorg. Chem. 1993, 32(24), 5643-5644 .

[317] S.M. Howdle, J.M. Ramsay, A.I. Cooper, J. Polym. Sci. B: Polym. Phys. 1994, 32(3), 541-549.

[318] X. Ma, D.L. Tomasko, Ind. Eng. Chem. Res. 1997, 36(5), 1586-1597.

[319] J. Zhang, A.J. Busby, C.J. Roberts, X. Chen, M.C. Davies, S.J.B. Tendler, S.M. Howdle, Macromolecules 2002, 35(23), 8869-8877.

[320] A.J. Busby, J. Zhang, A. Naylor, C.J. Roberts, M.C. Davies, S.J.B. Tendler, S.M. Howdle, J. Mater. Chem. 2003, 13, 2838-2844.

[321] K.S. Morley, P.B. Webb, N.V. Tokareva, A.P. Krasnov, V.K. Popov, J. Zhang, C.J. Roberts, S.M. Howdle, Eur. Polym. J. 2007, 43(2), 307-314.

[322] K. Hachiya, T. Kichikawa, T. Takajo, Tribol. T. 2008, 51(5), 636-642.

[323] T. Hoshi, T. Sawaguchi, R. Matsuno, T. Konno, M. Takai, K. Ishihara, J. Mater. Chem. 2010, 20, 4897-4904.

[324] V.N. Bagratashvili, A.B. Solovyeva, N.N. Glagolev, A.V. Cherkasova, I.V. Andreeva, P.S. Timashev, Russ. J. Phys. Chem. B 2011, 5(7), 1144-1154.

[325] K.S. Morley, P.C. Marr, P.B. Webb, A.R. Berry, F.J. Allison, G. Moldovan, P.D. Brown, S.M. Howdle, J. Mater. Chem. 2002, 12, 1898-1905. 
[326] G.A. Baker, M.L. Campbell, M.Z. Yates, T.M. McCleskey, Langmuir 2005, 21(9), 3730-3732 .

[327] W. Yin, Z. Dong, X. Chen, N. Finn, M.Z. Yates, J. Supercrit. Fluids 2007, 41(2), 293-298.

[328] J.L. Ellis, D.L. Tomasko, F. Dehghani, Biomacromolecules 2008, 9(3), 1027-1034.

[329] H.M. Yu, J-H. Yim, K.Y. Choi, J.S. Lim, J. Supercrit. Fluids 2012, 67, 71-75.

[330] M. Tang, T-B. Du, Y-P. Chen, J. Supercrit. Fluids 2004, 28(2-3), 207-218.

[331] M.R. Mauricio, T.S. Silva, M.H. Kunita, E.C. Muniz, G.M. de Carvalho, A.F. Rubira, J. Mater. Sci. 2012, 47(12), 4965-4971.

[332] J.J. Zhao, Y.P. Zhao, B. Yang, J. Appl. Polym. Sci. 2008, 109(3), 1661-1666.

[333] S. Sicardi, L. Manna, M. Banchero, Ind. Eng. Chem. Res. 2000, 39(12), 4707-4713.

[334] O.S. Fleming, F. Stepanek, S.G. Kazarian, Macromol. Chem. Phys. 2005, 206(11), 1077-1083.

[335] W-X. Ma, C. Zhao, S. Okubayashi, I. Tabata, K. Hisada, T. Hori, J. Appl. Polym. Sci. 2010, 117(4), 1897-1907.

[336] R.D. Weinstein, J.J. Gribbin, D. Najjar, Ind. Eng. Chem. Res. 2005, 44(10), 3480-3484.

[337] A. Ohnishi, E. Fujioka, K. Kosuge, N. Ikuta, Compos. Interfaces 2004, 11(3), 263-269.

[338] S.K. Liao, J. Polym. Res. 2005, 11(4), 285-291.

[339] N. Martinez, K. Hisada, I. Tabata, K. Hirogaki, S. Yonezawa, T. Hori, J. Supercrit. Fluids 2011, 56(3), 322-329.

[340] B-H. Woo, M. Sone, A. Shibata, C. Ishiyama, S. Edo, M. Tokita, J. Watanabe, Y. Higo, Surf. Coat. Technol. 2010, 204(11), 1785-1792.

[341] B. Krause, M. Kloth, N.F.A. van der Vegt, M. Wessling, Ind. Eng. Chem. Res. 2002, 41(5), 1195-1204.

[342] S. Yoda, A. Hasegawa, H. Suda, Y. Uchimaru, K. Haraya, T. Tsuji, K. Otake, Chem. Mater. 2004, 16(12), 2363-2368.

[343] Q. Xu, Y. Zhao, J. Appl. Polym. Sci. 2005, 96(6), 2016-2020.

[344] S.L. Shenoy, I. Kaya, C. Erkey, R.A. Weiss, Synth. Met. 2001, 123(3), 509-514.

[345] S. Ito, K. Matsunaga, M. Tajima, Y. Yoshida, J. Appl. Polym. Sci. 2007, 106(6), 3581-3586 .

[346] N. Inoglu, D. Kayrak-Talay, O. Hortaçsu, Proc. Biochem. 2008, 43(3), 271-279.

[347] C. Ji, A. Barrett, L.A. Poole-Warren, N.R. Foster, F. Dehghani, Int. J. Pharm. 2010, 391(1-2), 187-196.

[348] Q. Yu, P. Wu, P. Xu, L. Li, T. Liu, L. Zhao, Green Chem. 2008, 10, 1061-1067

[349] C. Yin, X. Shen, Eur. Polym. J. 2007, 43(5), 2111-2116.

[350] B.H. Hutton, I.H. Parker, Colloid Surface A 2009, 334(1-3), 59-65.

[351] S. Kivotidi, C. Tsioptsias, E. Pavlidou, C. Panayiotou, J. Therm. Anal. Calorim. 2013, 111(1), 475-482.

[352] M. Banchero, S. Ronchetti, L. Manna, J. Chem. 2013, Article ID 583952.

[353] M. Boissière, A. Tourrette, J.M. Devoisselle, F. Di Renzo, F. Quignard, J. Colloid Interface Sci. 2006, 294(1), 109-116.

[354] H-O. Choi, C. Perman, Pharm. Res. 1995, 9 Suppl., S257-S257.

[355] S Yoda, K. Otake, Y. Takebayashi, T. Sugeta, T. Sato, J. Non-Cryst. Solids 2001, 285(1$-3), 8-12$. 
[356] P.L. Dhepe, A. Fukuoka, M. Ichikawa, Chem. Commun. 2003, 590-591.

[357] Shimin Li, Q. Xu, J. Chen, Y. Guo, Ind. Eng. Chem. Res. 2008, 47(21), 8211-8217.

[358] Q-Q. Xu, C-J. Zhang, X-Z. Zhang, J-Z. Yin, Y. Liu, J. Supercrit. Fluids 2012, 62, 184-189.

[359] M.J. Tenorio, C. Pando, J.A.R. Renuncio, J.G. Stevens, R.A. Bourne, M. Poliakoff, A. Cabañas, J. Supercrit. Fluids 2012, 69, 21-28.

[360] J. Morère, M.J. Tenorio, M.J. Torralvo, C. Pando, J.A.R. Renuncio, A. Cabañas, J. Supercrit. Fluids 2011, 56(2), 213-222.

[361] J. Pan, J. Liu, S. Guo, Z. Yang, Catal. Lett. 2009, 131(1-2), 179-183.

[362] A.M. López-Periago, J. Fraile, C.A. García-González, C. Domingo, J. Supercrit. Fluids 2009, 50(3), 305-312.

[363] S. Yoda, Y. Sakurai, A. Endo, T. Miyata, H. Yanagishita, K. Otake, T. Tsuchiya, J. Mater. Chem. 2004, 14, 2763-2767.

[364] Z. Liu, X. Dai, J. Xu, B. Han, J. Zhang, Y. Wang, Y. Huang, G. Yang, Carbon 2004, 42(2), 458-460.

[365] C-Y. Chen, J-K. Chang, W-T. Tsai, C-H. Hung, J. Mater. Chem. 2011, 21, 19063-19068.

[366] S. Xu, P. Zhang, H. Li, H. Wei, L. Li, B. Li, X. Wang, RSC Adv. 2014, 4, 7079-7083.

[367] N. Petkov, B. Platschek, M.A. Morris, J.D. Holmes, T. Bein, Chem. Mater. 2007, 19(6), 1376-1381.

[368] H. Wakayama, Y. Fukushima, Ind. Eng. Chem. Res. 2000, 39(12), 4641-4645.

[369] G. Incera Garrido, F.C. Patcas, G. Upper, M. Türk, S. Yilmaz, B. Kraushaar-Czarnetzk, Appl. Catal. A 2008, 338(1-2), 58-65.

[370] Website: FDA, Guidance for Industry: nonclinical studies for the safety evaluation of pharmaceutical excipients, USA, http://www.fda.gov/downloads/Drugs/GuidanceComplianceRegulatoryInformation/ Guidances/ucm079250.pdf, (accessed April 15, 2014).

[371] Website: IPEC-Americas, International Pharmaceutical Excipients Council of the Americas, http://ipecamericas.org, (accessed April 15, 2014).

[372] Website: IPEC-Americas, Reference Center - Regulatory Reference, http://ipecamericas org/reference-center/regulatory-reference-page, (accessed April 15, 2014).

[373] Website: IPEC-Europe, International Pharmaceutical Excipients Council of Europe, IPEC Guidelines, http://www.ipec-europe.org/page.asp?pid=59, (accessed April 15, 2014).

[374] Website: IPEC Federation, International Pharmaceutical Excipients Council Federation, http://www.ipec.org, (accessed April 15, 2014).

[375] Website: ISO, International Organization for Standardization, Switzerland, http://www. iso.org/iso/home.htm, (accessed April 15, 2014).

[376] Website: FDA, Use of International Standard ISO-10993, "Biological Evaluation of Medical Devices Part 1: Evaluation and Testing - Draft Guidance for Industry and Food and Drug Administration Staff, USA, http://www.fda.gov/downloads/MedicalDevices/DeviceRegulationandGuidance/ GuidanceDocuments/UCM348890.pdf, (accessed April 15, 2014).

[377] Website: USP, United States Pharmacopeial Convention; Reference Standard USP 26 NF1, Chapter 87 and Chapter 88, USA, http://www.usp.org, (accessed April 15, 2014).

[378] Website: European Commission, Medical Devices - Guidance MEDDEVs, EU, http:// ec.europa.eu/health/medical-devices/documents/guidelines, (accessed April 15, 2014).

[379] Website: European Commission, Medical Devices - What process does a Medical Device have to follow to be placed on the market? EU, http://ec.europa.eu/health/medical-devices/faq/market_en.htm, (accessed April 15, 2014). 
[380] Website: IMDRF, International Medical Device Regulators Forum, http://www.imdrf. org, (accessed April 15, 2014).

[381] Website: ASM International, ASM Medical Materials Database, http://products. asminternational.org/meddev/index.aspx, (accessed April 15, 2014).

[382] K.J. Lauritsen, T. Nguyen, Clin. Pharmacol. Ther. 2009, 85(5), 468-470.

[383] S-H. Chang, S-C. Park, J-J. Shim, J. Supercrit. Fluids 1998, 13(1-3), 113-119.

[384] P. Diep, K.D. Jordan, J.K. Johnson, E.J. Beckman, J. Phys. Chem. A 1998, 102(12), 2231-2236.

[385] P. Raveendran, S.L. Wallen, J. Phys. Chem. B 2003, 107(6), 1473-1477.

[386] J. von Schnitzler, R. Eggers, J. Supercrit. Fluids 1999, 16(1), 81-92.

[387] I. Kikic, F. Vecchione, P. Alessi, A. Cortesi, F. Eva, N. Elvassore, Ind. Eng. Chem. Res. 2003, 42(13), 3022-3029.

[388] P. Alessi, A. Cortesi, I. Kikic, F. Vecchione, J. Appl. Polym. Sci. 2003, 88(9), 2189-2183.

[389] A.R.C. Duarte, L.E. Anderson, C.M.M. Duarte, S.G. Kazarian, J. Supercrit. Fluids 2005, 36(2), 160-165.

[390] T. Guadagno, S.G. Kazarian, J. Phys. Chem. B 2004, 108(37), 13995- 13999.

[391] I. Pasquali, J.M. Andanson, S.G. Kazarian, R. Bettini, J. Supercrit. Fluids 2008, 45(3), 384-390.

[392] S.P. Nalawade, F. Picchioni, J.H. Marsman, L.P.B.M. Janssen, J. Supercrit. Fluids 2006, 36 (3), 236-244.

[393] P. Vitoux, T. Tassaing, F. Cansell, S. Marre, C. Aymonier, J. Phys. Chem. B 2009, 113(4), 897-905.

[394] A.R.C. Duarte, C. Martins, P. Coimbra, M.H.M. Gil, H.C. de Sousa, C.M.M. Duarte, J. Supercrit. Fluids 2006, 38(3), 392-398.

[395] C. Cravo, A.R.C. Duarte, C.M.M. Duarte, J. Supercrit. Fluids 2007, 40(2), 194-199.

[396] M. Pantoula, C. Panayiotou, J. Supercrit. Fluids 2006, 37(2), 254-262.

[397] M. Pantoula, J. von Schnitzler, R. Eggers, C. Panayiotou, J. Supercrit. Fluids 2007, 39(3), 426-434.

[398] N. Von Solms, N. Zecchin, A. Rubin, S.I. Andersen, E.H. Stenby, Eur. Polym. J. 2005, 41(2), 341-348.

[399] Z. Lei, H. Ohyabu, Y. Sato, H. Inomata, R.L. Smith Jr., J. Supercrit. Fluids 2007, 40(3), 452-461.

[400] J.H. Aubert, J. Supercrit. Fluids 1998, 11(3), 163-172.

[401] D. Liu, D.L. Tomasko, J. Supercrit. Fluids 2007, 39(3), 416-425.

[402] L.A. Madsen, Macromolecules 2006, 39(4), 1483-1487.

[403] M. Temtem, T. Casimiro, A.G. Santos, A.L. Macedo, E.J. Cabrita, A. Aguiar-Ricardo, J. Phys. Chem. B 2007, 111(6), pp. 1318-1326.

[404] E. Aionicesei, M. Skerget,Z. Knez, J. Supercrit. Fluids 2008, 47(2), 296-301.

[405] S. Inoue, N. Yamazaki, Organic and Bioorganic Chemistry of Carbon Dioxide, John Wiley \& Sons, 1982.

[406] C.A. Eckert, C.L. Liotta, D. Bush, J.S. Brown, J.P. Hallett, J. Phys. Chem. B 2004, 108(47), 18108-18118.

[407] K.N. West, C. Wheeler, J.P. McCarney, K.N. Griffith, D. Bush, C.L. Liotta, C.A. Eckert, J. Phys. Chem. A 2001, 105(16) 3947-3948. 
[408] M. Saharay, S. Balasubramanian, J. Phys. Chem. B 2006, 110(8), 3782-3790.

[409] W. Xu, J. Yang, Y. Hu, J. Phys. Chem. B, 2009, 113(14), 4781-4789.

[410] J. Zagrobelny, F.V. Bright, J. Am. Chem. Soc. 1993, 115(2), 701-707.

[411] Y. Iwai, D. Tanabe, M. Yamamoto, T. Nakajima, M. Uno, Y. Arai, Fluid Phase Equilib. 2002, 193(1-2), 203-216.

[412] J.R. Fried, W. Li, J. Appl. Polym. Sci. 1990, 41(5-6), 1123-1131.

[413] M. Kanakubo, T. Aizawa, T. Kawakami, O. Sato, Y. Ikushima, K. Hatakeda, N. Saito, J. Phys. Chem. B 2000, 104(12), 2749-2758.

[414] K.E. Anderson, J.I. Siepmann, J. Phys. Chem. B 2008, 112(36), 11374-11380

[415] B. Tomberli, S. Goldman, C.G. Gray, Fluid Phase Equilib. 2001, 187-188, 111-130.

[416] B. Tomberli, S. Goldman, C.G. Gray, M.D.A. Saldaña, F. Temelli, J. Supercrit. Fluids 2006, 37(3), 333-341.

[417] B.E. Poling, J.M. Prausnitz, J.P. O'Connell, The properties of gases and liquids, $5^{\text {th }}$ Ed., McGraw-Hill, 2001.

[418] J.M. Prausnitz, R.N. Lichtenthaler, E. Gomes de Azevedo, Molecular thermodynamics of fluid-phase equilibria, $3^{\text {rd }}$ Ed., Prentice Hall, 1998.

[419] J.V. Sengers, R.F. Kayser, C.J. Peters, H.J. White, (Eds.), Equations of state for fluids and fluid mixtures, Elsevier, 2000.

[420] S.I Sandler, (Ed.), Models for thermodynamic and phase equilibria calculations, CRC Press, 1993.

[421] J. Chrastil, J. Phys. Chem. 1982, 86(15), 3016-3021.

[422] K.D. Bartle, A.A. Clifford, S.A. Jafar, G.F. Shilstone, J. Chem. Phys. Ref. Data 1991, 20(4) 713-756.

[423] J. Méndez-Santiago, A.S. Teja, Fluid Phase Equilib. 1999, 158-160, 501-510.

[424] A. Jouyban, H-K. Cha, N.R. Foster, J. Supercrit. Fluids 2002, 24(1), 19-35.

[425] D.B. Robinson, D.Y. Peng, Ind. Eng. Chem. Fundamen. 1976, 15(1), 59-64.

[426] G. Soave, Chem. Eng. Sci. 1972, 27(6), 1197-1203.

[427] G. Soave, Fluid Phase Equilib. 1993, 84(1), 339-342.

[428] J.O. Valderrama, J. Chem. Eng. Jpn. 1990, 23(1), 87-90.

[429] J.O. Valderrama, Ind. Eng. Chem. Res. 2003, 42(8), 1603-1618.

[430] A.Z. Panagiotopoulos, R.C. Reid, in: K.C. Chao, R.L. Robinson (Eds.), Equations of State: Theories and Applications, ACS Symposium Series, Vol. 300, American Chemical Society, 571-582, 1986.

[431] M. Mukhopadhyay, G.V. Rao, Ind. Eng. Chem. Res. 1993, 32(5), 922-930.

[432] P. Coimbra, C.M.M. Duarte, H.C. de Sousa, Fluid Phase Equilib. 2006, 239(2), 188-196.

[433] P. Gosh, Chem. Eng. Technol. 1999, 22(5), 379-399.

[434] T. Adrian, M. Wendland, H. Hasse, G. Maurer, J. Supercrit. Fluids 1998, 12(3), 185-221.

[435] F.P. Lucien, N.R. Foster, J. Supercrit. Fluids 2000, 17(2), 111-134.

[436] M. Skerget, Zeljko Knez, M. Knez-Hrncic, J. Chem. Eng. Data 2011, 56(4), 694-719.

[437] D.E. Knox, Pure Appl. Chem. 2005, 77(3), 513-530.

[438] R. Dohrn, G. Brunner, Fluid Phase Equilib. 1995, 106(1-2), 213-282.

[439] M. Christov, R. Dohrn, Fluid Phase Equilib. 2002, 202(1), 153-218. 
[440] R. Dohrn, S. Peper, J.M.S. Fonseca, Fluid Phase Equilib. 2010, 288(1-2), 1-54.

[441] J.M.S. Fonseca, R. Dohrn, S. Peper, Fluid Phase Equilib. 2011, 300(1-2), 1-69.

[442] U.K. Deiters, G.M. Schneider, Fluid Phase Equilib. 1986, 29, 145-160.

[443] R. Dohrn, J.M.S. Fonseca, S. Peper, Annu. Rev. Chem. Biomol. Eng. 2012, 3, 343-367.

[444] Z-H Chen, K. Cao, Z. Yao, Z-M. Huang, J. Supercrit. Fluids 2009, 49(2), 143-153.

[445] H. Higashi, Y. Iwai, Y. Arai, Chem. Eng. Sci. 2001, 56(10), 3027-3044.

[446] J. Crank, The mathematics of diffusion, $2^{\text {nd }}$ Ed., Oxford University press, 1980.

[447] O.J. Catchpole, M.B. King, Ind. Eng. Chem. Res. 1994, 33(7), 1828-1837.

[448] J.J. Suárez, I. Medina, J.L. Bueno, Fluid Phase Equilib. 1998, 153(1), 167-212.

[449] I. Medina, J. Chromatogr. A 2012, 1250, 124-140.

[450] V. Carlà, Supercritical fluid polymer processing: anomalous sorption and dilation behaviour. PhD Thesis, Università di Bologna, Italy, 2007.

[451] P. Arce, M. Aznar, Fluid Phase Equilib. 2005, 238(2), 242-253.

[452] H-S. Byun, M.A. McHugh, J. Supercrit. Fluids 2007, 41(3), 482-491.

[453] I.C. Sanchez, R.H. Lacombe, J. Phys. Chem. 1976, 80(21), 2352-2362.

[454] I.C. Sanchez, R.H. Lacombe, Macromolecules 1978, 11(6) 1145-1156.

[455] E. Kiran, Y. Xiong, W. Zhuang, J. Supercrit. Fluids 1993, 6(4) 193-203.

[456] E. Neau, Fluid Phase Equilib. 2002, 203(1-2), 133-140.

[457] C. Panayiotou, Fluid Phase Equilib. 2005, 237(1-2) 130-139.

[458] C. Panayiotou, J. Chem. Thermodyn. 2003, 35(2), 349-381.

[459] C. Panayiotou, M. Pantoula, E. Stefanis, I. Tsivintzelis, Ind. Eng. Chem. Res. 2004, 43(20), 6592-6606.

[460] W.G. Chapman, K.E. Gubbins, G. Jackson, M. Radosz, Ind. Eng. Chem. Res. 1990, 29(8), 1709-1721.

[461] S.H. Huang, M. Radosz, Ind. Eng. Chem. Res. 1990, 29(11), 2284-2294.

[462] J. Gross, G. Sadowski, Ind. Eng. Chem. Res. 2001, 40(4), 1244-1260.

[463] J.H. Gibbs, E.A. Dimarzio, J. Chem. Phys. 1958, 28(3), 373-383.

[464] E.A. DiMarzio, J.H. Gibbs, J. Polym. Sci. Part A: Gen. Papers 1963, 1(4), 1417-1428.

[465] J. Prinos, C. Panayiotou, Polymer 1995, 36(6), 1223-1227.

[466] V. Carla, K. Wang, Y. Hussain, K. Efimenko, J. Genzer, C. Grant, G.C. Sarti, R.G. Carbonell, F. Doghieri, Macromolecules 2005, 38(24), 10299-10313.

[467] P.D. Condo, I.C. Sanchez, C. Panayiotou, K.P. Johnston, Macromolecules 1992, 25(23), 6119-6127.

[468] D. Boudouris, L. Constantinou, C. Panayiotou, Ind. Eng. Chem. Res. 1997, 36(9), 3968$-3973$.

[469] D.W. Van Krevelen, K. Te Nijenhuis, Properties of polymers, their correlation with chemical structure, their numerical estimation and prediction from additive group contributions, $4^{\text {th }}$ Ed., Elsevier, 2009. 